\title{
Characterization of Waste Density Via Microgravity and Settlement Analysis
}

by

Kyle Harris

A thesis submitted to the Faculty of Graduate and Postdoctoral Affairs in partial fulfillment of the requirements for the degree of

Master of Science

In

Earth Sciences

Carleton University

Ottawa, Ontario

(C)2012

Kyle Harris 


\section{Acknowledgements}

I express my deepest thanks to my supervisor, Dr. Claire Samson, as well as Dr. Paul Van Geel; each of whom made this project possible, and assisted and supported me on every level of this work. Also my deepest thanks go to Jacques Liard of the Geodetic Survey Division of NRCan, who generously arranged the use of the gravimeter, and provided his expertise in the field of microgravity.

Thank you to the staff and administration at Waste Management, including Simon Mercier and Benoit Marsolais at Sainte-Sophie, who always remained helpful and supportive of our project.

I acknowledge our industry support from WESA, Genivar, Golder Associates, and AECOM. Also the support of the Ontario Centres of Excellence.

For all the hard work on the surveys, I thank Michelle Roberge, Michael Cunningham, Chris Fry, Alex Boivin, Jamie Bonany, and Emily Vingerhoeds.

Finally, I thank all my family and friends for their continuous care and support throughout this project. 


\section{Abstract}

Optimizing the utilization of landfill airspace and production of biogas for use as an energy source relies on an understanding of the compaction, settlement, and stabilization of waste over time. A higher degree of compaction reduces the landfill footprint; however, this may not provide the optimal conditions for bacteria development and waste stabilization. This thesis reports on a research project that pilots the use of repeated microgravity surveys to map the density of waste over time in a bioreactor landfill.

Over the duration of 3 years, five microgravity surveys were conducted on a new cell at a bioreactor landfill in Sainte-Sophie, Quebec, Canada, as it was gradually filled with waste up to a height of $25 \mathrm{~m}$. After each survey, waste density values were extracted by comparing with previous data from lower elevations. For an accurate density computation, a settlement model was applied in order to estimate the degree to which waste had been compacted over time.

This model was derived from settlement data recorded by sensors buried at various elevations throughout the waste column.

The density values obtained from the microgravity surveys were $1.35 \pm 0.31 \mathrm{~g} / \mathrm{cm}^{3}$ in the first waste slab, $1.44 \pm 0.22 \mathrm{~g} / \mathrm{cm}^{3}$ and $1.20 \pm 0.25 \mathrm{~g} / \mathrm{cm}^{3}$ in the second waste slab in the northeast and southwest ends of the cell respectively, and $1.15 \pm 0.28 \mathrm{~g} / \mathrm{cm}^{3}$ and $1.12 \pm 0.15 \mathrm{~g} / \mathrm{cm}^{3}$ in the third waste slab in the northeast and southwest ends of the cell respectively. These results agreed best with the densities computed from the landfill operation data in the first slab (within 3\%), and deviated later in the study (within 22\% in the third slab, in the northeast end). 


\section{Table of Contents}

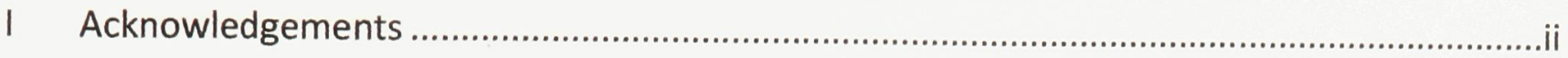

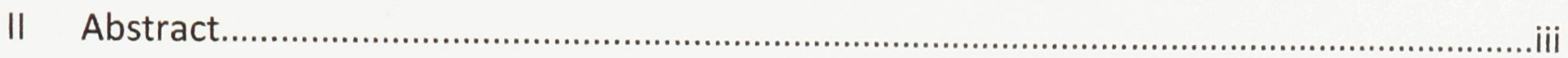

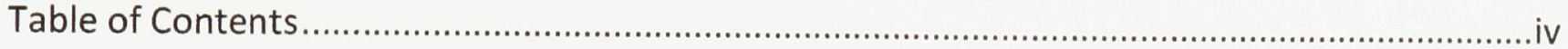

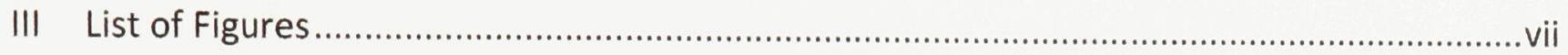

IV List of Tables .................................................................................................................

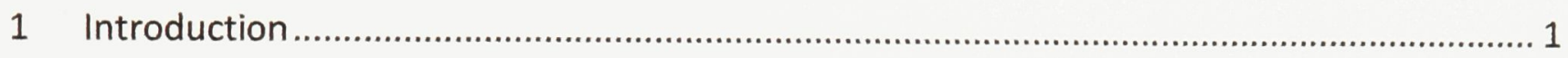

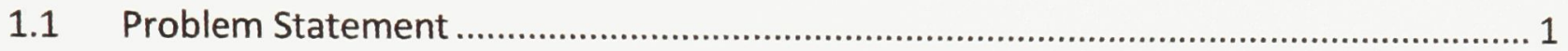

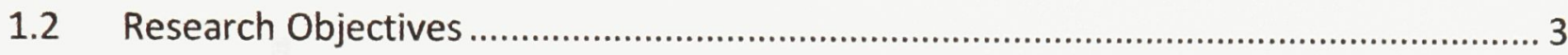

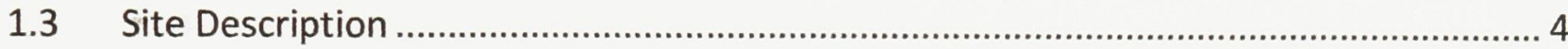

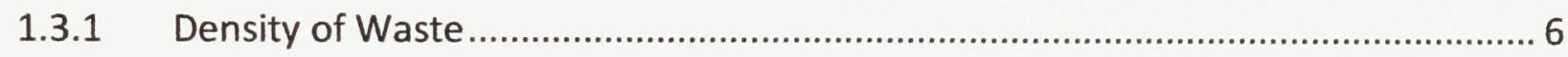

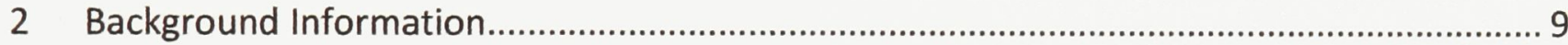

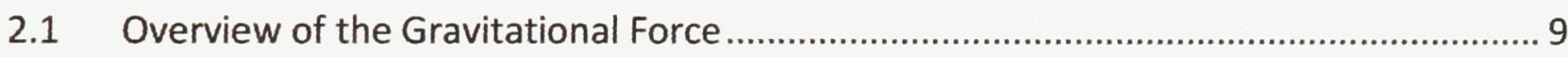

2.1.1 Bouguer Slab Approximation ............................................................................ 10

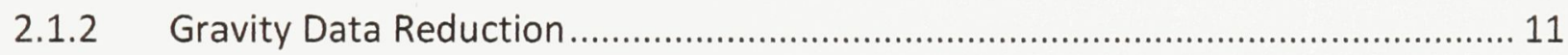

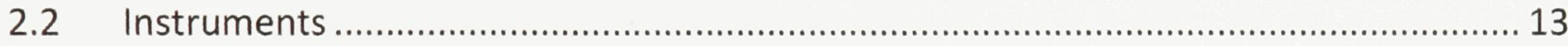

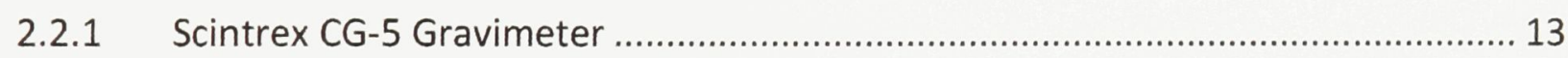

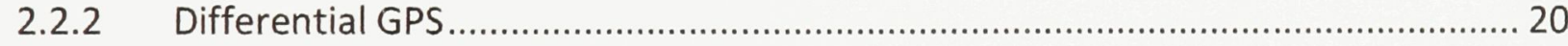

2.2.3 Instrument Bundles............................................................................................. 21

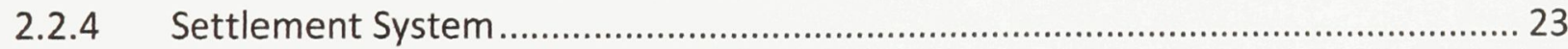

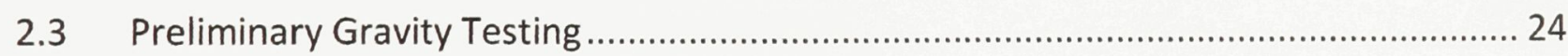

2.3.1 Estimating Duration of "Morning Sickness" ......................................................... 24

2.3.2 Estimating Measurement Errors ......................................................................... 27

2.3.3 Estimating Tidal Contributions........................................................................... 30

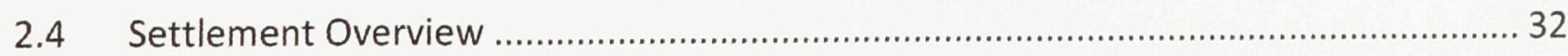

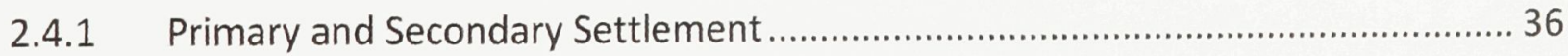

2.4.2 Settlement Due to Biodegradation ................................................................. 37

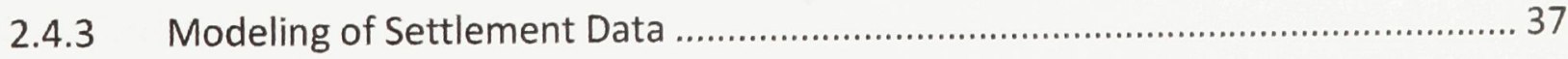


3 Survey Overviews

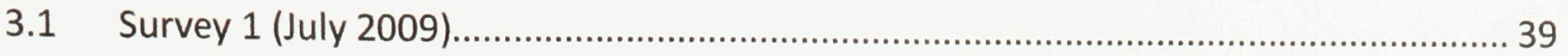

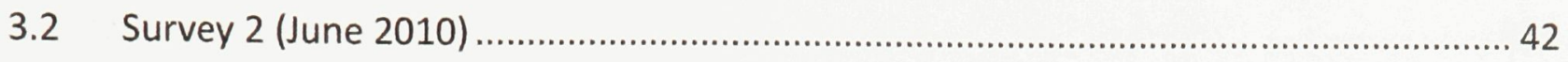

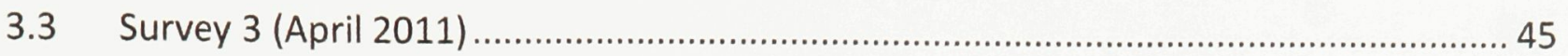

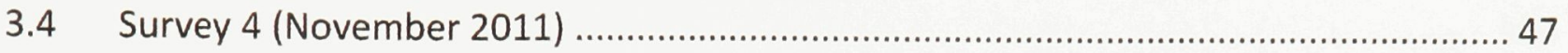

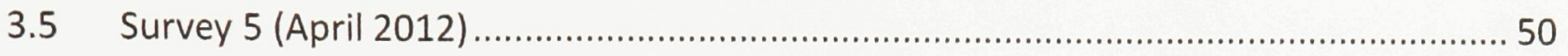

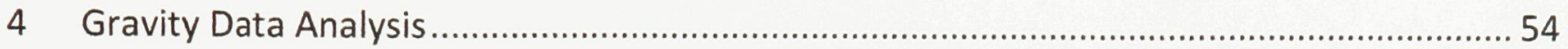

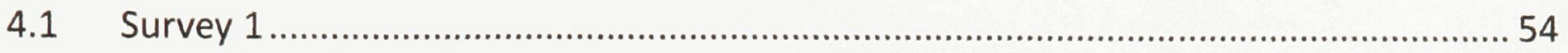

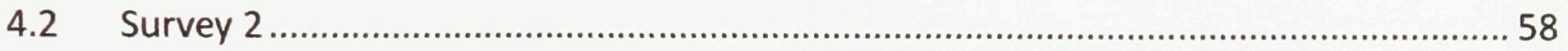

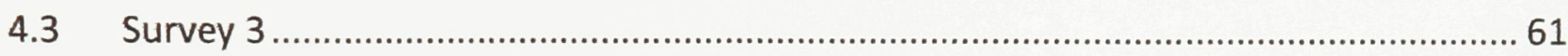

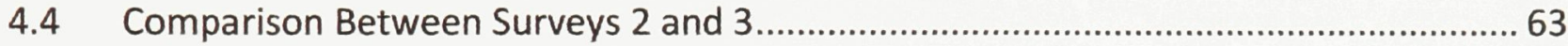

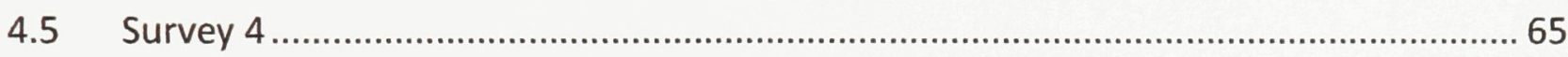

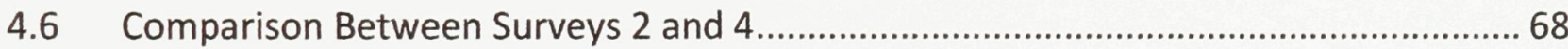

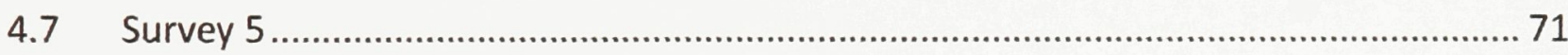

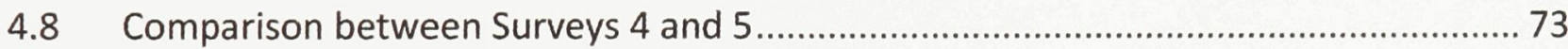

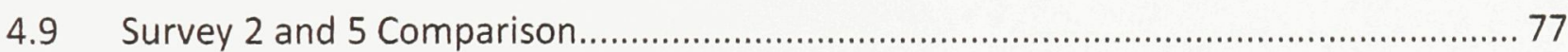

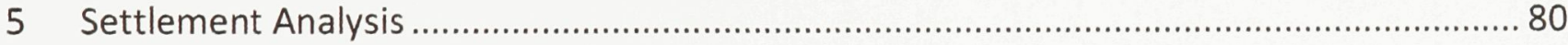

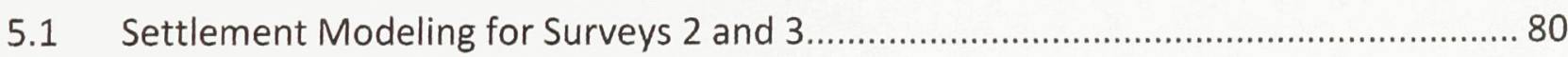

5.1.1 Primary and Secondary Settlement ...................................................... 82

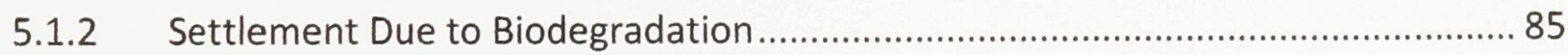

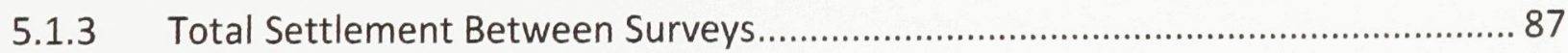

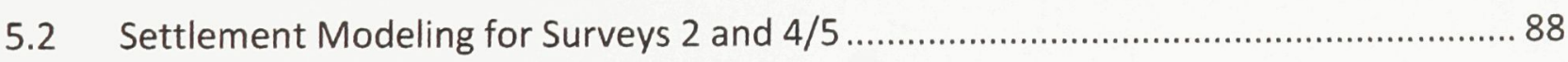

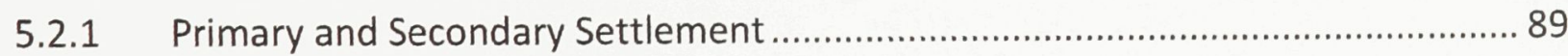

5.2.2 Settlement Due to Biodegradation ......................................................... 91

5.2.3 Total Settlement Between Surveys......................................................... 92

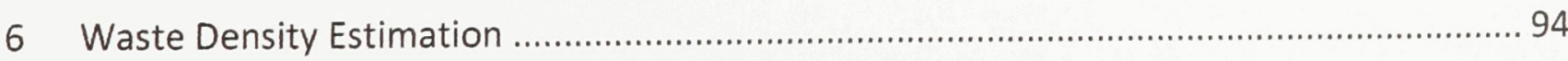

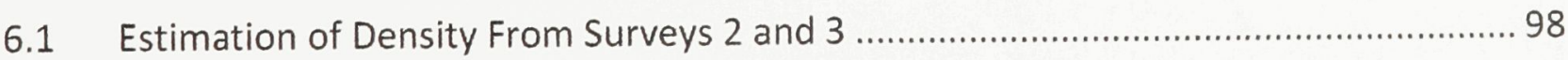

6.1.1 Comparison With Quarterly Survey Results (AUF) ...................................... 99

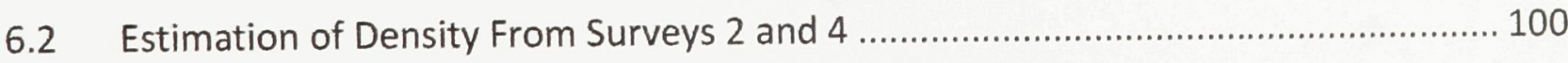


6.2.1 Comparison With Quarterly Survey Results (AUF) ....................................... 101

6.3 Estimation of Density From Surveys 2 and 5 ............................................... 102

6.3.1 Comparison With Expected Values.................................................................. 103

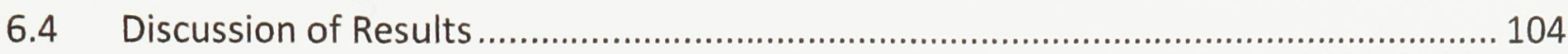

7 Conclusions and Recommendations ................................................................ 108

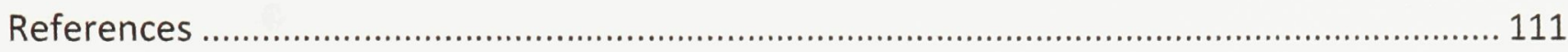

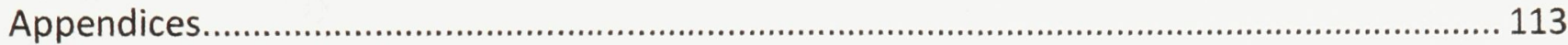




\section{List of Figures}

Figure 1-1: Dimensions of Zone 4 of the Sainte-Sophie Bioreactor Landfill (Modified from Genivar 2008) 5

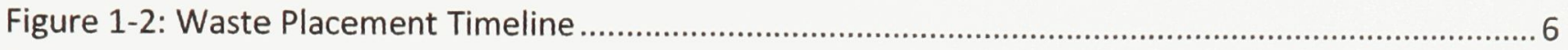

Figure 2-1: Linear Nature of Internal Drift [CG-5 Manual] ................................................................. 12

Figure 2-2: Scintrex CG-5 Gravimeter (With Sensor Visible) [CG-5 Manual] ............................................ 15

Figure 2-3: Surveying in the Landfill Using the CG-5 Gravimeter ....................................................... 16

Figure 2-4: Layout of Instrument Bundles (adapted from Vinderhoeds (2011)) ..................................... 22

Figure 2-5: Schematic Cross-Section Showing the Instrument Bundles in Landfill Cell.............................22

Figure 2-6: "Morning Sickness" Trials ....................................................................................................26

Figure 2-7: Measurement Error When Gravimeter is Kept Fixed Between Readings (Red Squares Omitted

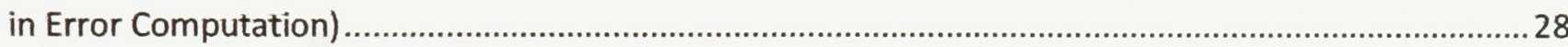

Figure 2-8: Measurement Error For Gravimeter When Releveled Between Readings (Red Squares

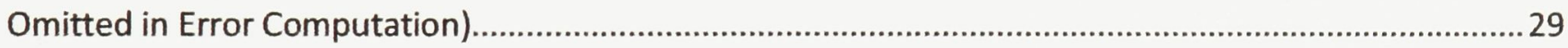

Figure 2-9: Measurement Error For Survey Conditions ...........................................................................2 29

Figure 2-10: Uncorrected Gravity Data For Tidal Trial (Sampling Frequency Too High to Show Discrete

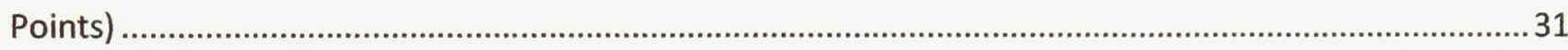

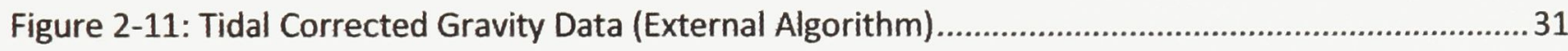

Figure 2-12: Tidal Corrected Gravity Data (Internal Algorithm) ........................................................... 32

Figure 2-13: Evaluating the Thickness of Waste After Settlement ........................................................ 33

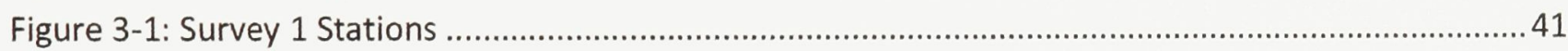

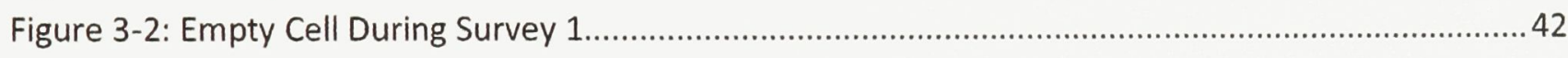

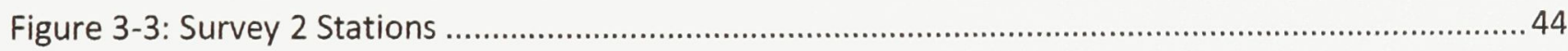

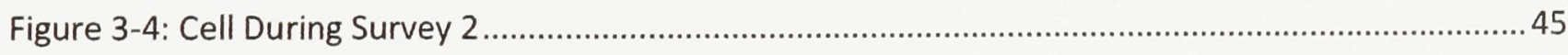

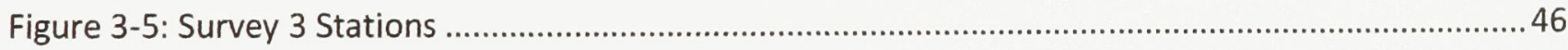

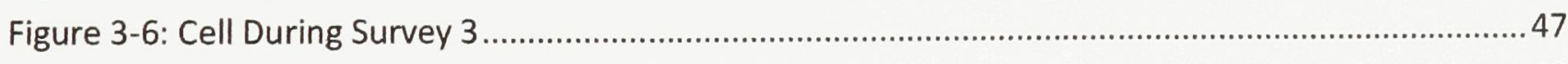

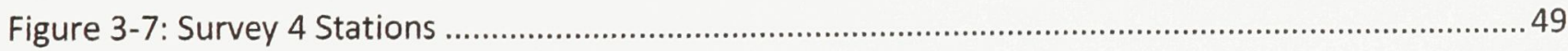

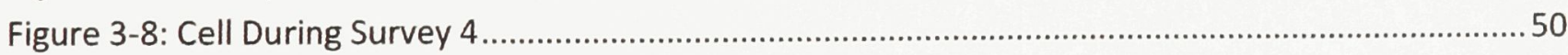

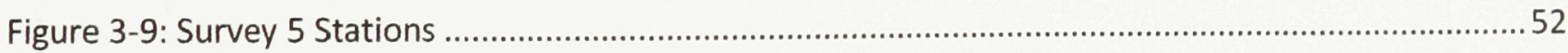

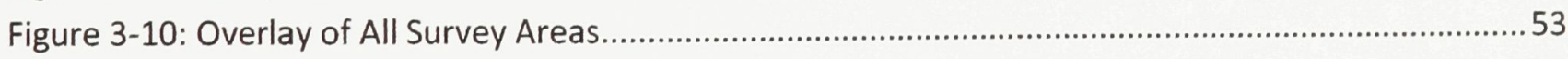

Figure 4-1: Elevation Map of the Entire Cell ...................................................................................... 55

Figure 4-2: Gravity Map of the Entire Cell of Survey 1 (Before Elevation Corrections).............................56

Figure 4-3: Corrected Gravity Map of the Entire Cell in Survey 1.........................................................5

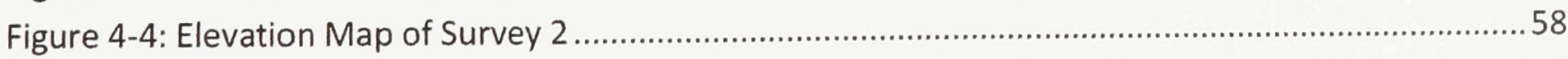

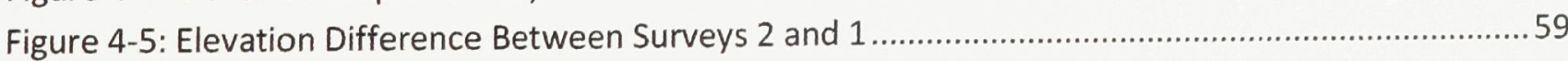

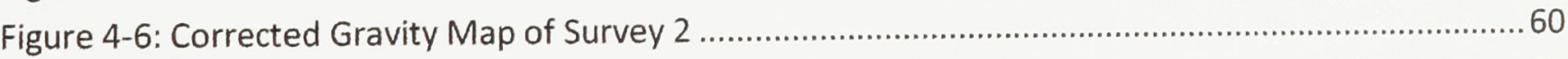

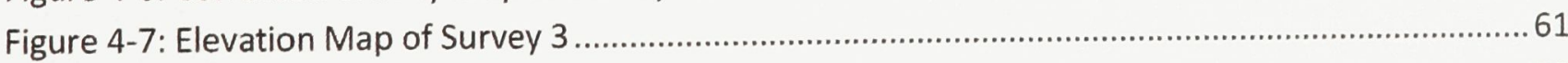

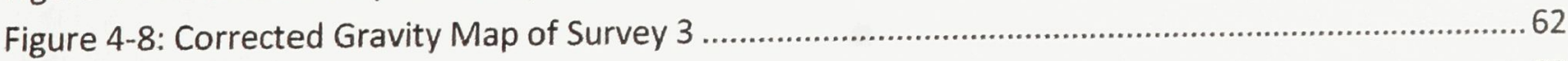

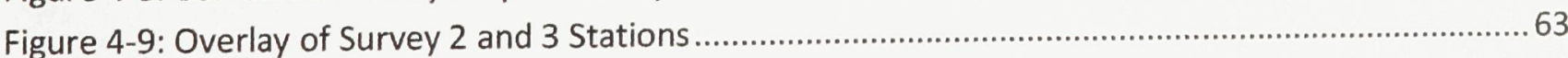

Figure 4-10: Gravity Contrast Between Surveys 3 and 2 (Outliers in Survey 3 Removed) ........................64 


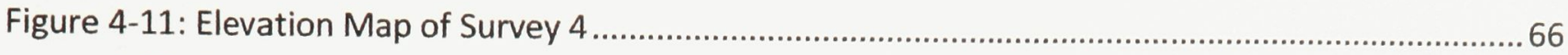

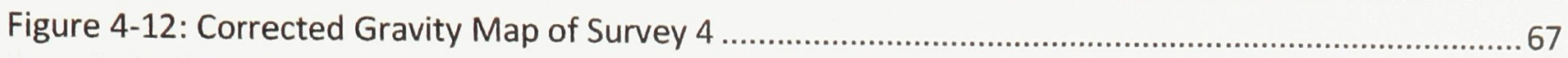

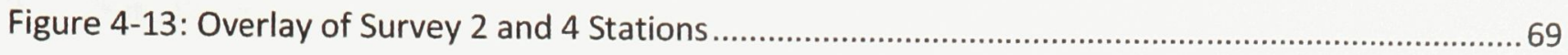

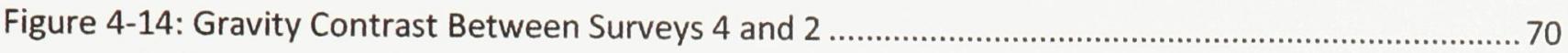

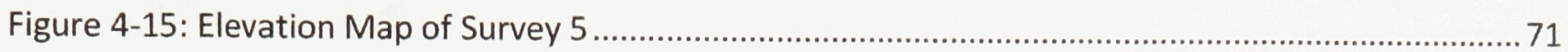

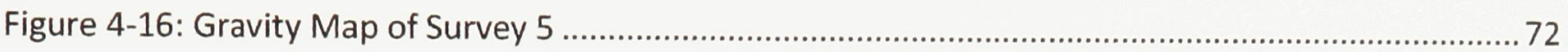

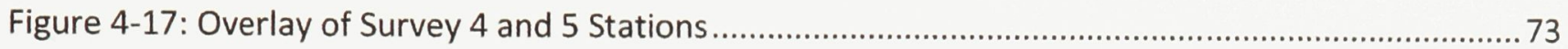

Figure 4-18: Elevation Difference Between Surveys 5 and 4 (Negative Values Correspond to Settlement)

Figure 4-19: Gravity Contrast Between Surveys 5 and 4 ..umumus

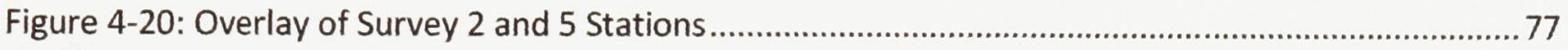

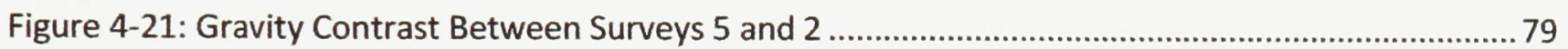

Figure 5-1: Settlement Data For All Instrument Bundles..................................................................... 81

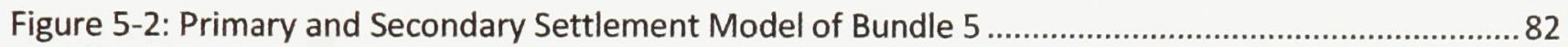

Figure 5-3: Primary and Secondary Settlement Model of Bundle 6 ......................................................8 84

Figure 5-4: Biodegradation-Induced Settlement Model of Bundle 5 ...................................................... 85

Figure 5-5: Biodegradation-Induced Settlement Model of Bundle 6 .................................................... 86

Figure 5-6: Biodegradation-Induced Settlement Model of Bundle 6 With Additional Linear Term...........87

Figure 5-7: Primary and Secondary Settlement Model of Bundle 5 ...................................................89

Figure 5-8: Primary and Secondary Settlement Model of Bundle 6 ......................................................90

Figure 5-9: Biodegradation Model of Bundle 5 (with linear term) .........................................................91

Figure 5-10: Biodegradation Model of Bundle 6 (with linear term) ..................................................... 92

Figure 6-1: Summary of AUF Density Computations in NE and SW Ends of the Cell...............................96

Figure 6-2: Summary of Density Values Computed Via Microgravity Surveys ........................................97

Figure 6-3: Density Distribution Between Surveys 2 and 3............................................................... 99

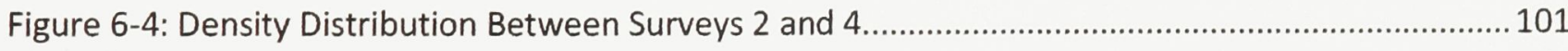

Figure 6-5: Density Distribution Between Surveys 2 and 5............................................................. 103

Figure 6-6: Temperature Data From Instrument Bundles ................................................................. 107

\section{List of Tables}

Table 1-1: Typical Waste Values Quoted From Timmons et al. (2011) .................................................. 7

Table 2-1: Scintrex CG-5 Gravimeter Specifications ........................................................................... 17

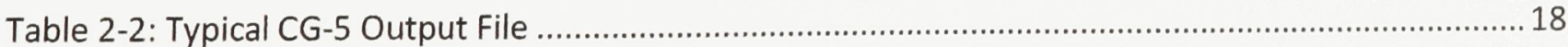

Table 2-3: RTK-DGPS Readings at a Fixed Location at Various Times....................................................2 21

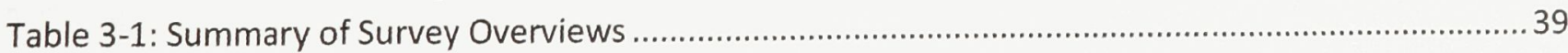

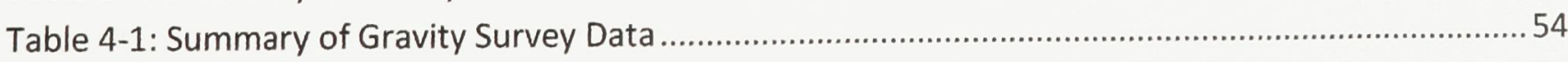

Table 5-1: Settlement Summary of Instrument Bundles ................................................................... 93

Table 6-1: Summary of AUF and Microgravity Results ..................................................................... 104 


\section{Introduction}

\subsection{Problem Statement}

Due to the abundance of municipal and industrial solid waste, and the increasing need for new energy sources, the production and harvesting of biogas in anaerobic bioreactor landfills is becoming a viable method for power generation. An anaerobic bioreactor landfill is one where conditions are suited for bacteria to develop and to digest waste in the absence of oxygen, resulting in accelerated waste decomposition and the generation of biogas. While the production and consumption of this biogas results in methane and carbon dioxide being released into the atmosphere, the process has the advantage of reducing environmental harm that results from the extraction and refining of fossil fuels.

Many economical and environmental advantages result from the increased rate of biodegradation in an anaerobic bioreactor landfill. The airspace above a landfill cell may be reclaimed sooner, and then may be refilled. This minimizes the dimensional footprint of the landfill, thus reducing environmental impact and land cost. This also minimizes the cost of maintenance of the landfill after its closure. After degradation, inert objects such as metals and plastics may be removed from the cell and recycled [Warith, 2002]. Bioreactors have been found to stabilize waste in less than ten years as opposed to conventional landfills which can take more than one hundred years [Reinhart and Townsend, 1998].

Anaerobic bacteria, by definition, survive and grow in environments void of oxygen. These bacteria digest waste and release methane and carbon dioxide in nearly equal proportions. The moisture content at which anaerobic biodegradation is optimal is between $40-70 \%$ [Reinhart and Townsend, 1998]. Typical bioreactor landfills, however, tend to have significantly lower moisture content, and operators strive to increase it. Moisture can be supplied simply through the infiltration of rain water or added through a leachate recirculation system. Not only does leachate recirculation aid to accelerate waste settlement through biodegradation, but it also provides a means to treat leachate on-site, thus saving costs [Warith, 2005]. The recirculation 
enhances biodegradation in a number of ways: the leachate distributes the bacteria throughout the waste, brings nutrients to the bacteria, dilutes toxins, and serves to more rapidly transfer heat [Warith et al., 2005]. Also, by recirculating and confining the leachate, contamination of the local ground and surface water is minimized [Warith, 2002].

Several parameters must be monitored and optimized in order to attain a maximum rate of degradation in an anaerobic bioreactor landfill. Generally, a neutral pH $(\approx 7)$ is favorable to the survival of anaerobic bacteria, thus low levels of sulphates and alkalis are desirable. Moisture, as mentioned before is optimal between $40-70 \%$, and temperature is optimal at approximately $40^{\circ} \mathrm{C}$ [Yuen, 1994; Rees, 1980]. An inherent difficulty in designing and operating a bioreactor landfill in a northern climate involves maintaining waste at an adequately high temperature. When buried, frozen waste absorbs heat very slowly and can take more than a year to thaw and reach the temperature necessary for the survival and development of fuel-producing bacteria [Vingerhoeds, 2011]. It is also important to monitor the density of the waste. Maximum compaction directly minimizes the landfill footprint; however, it might not provide the optimal environmental conditions for bacteria development and waste stabilization. An increase in waste density corresponds to a decrease in hydraulic conductivity. This is detrimental to the survival of fuel-producing bacteria resulting from a decrease in moisture throughout the waste, and consequently a decrease in nutrients delivered uniformly to the bacteria [Warith, 2005]. Waste is typically deposited in stages known as "lifts", with each lift having a thickness of between 3 and $4 \mathrm{~m}$, and each lift comprising of a series of layers of approximately $40 \mathrm{~cm}$. It has even been suggested that the bottom layer should not be compacted at all, in order to ensure a minimum percentage of porosity and permeability and to allow the waste to decompose and stabilize before any successive waste is deposited [Stegmann, 1983]. 


\subsection{Research Objectives}

The primary research objective of this research project is to evaluate the feasibility of microgravity surveying as a means to characterize variations in waste density in space and time in an anaerobic bioreactor landfill. This thesis presents the results from five microgravity surveys performed over three years, as well as settlement data taken over the same duration. The surveys were done in July 2009, June 2010, April 2011, November 2011, and April 2012 at a bioreactor landfill in Sainte-Sophie, Quebec.

Each survey comprised of collecting gravity data through the use of a relative gravimeter. Each gravity measurement must be corrected for internal and external effects before it can be interpreted. Each measurement must also be georeferenced with northings, eastings, and elevation values, and this is accomplished by using a differential global positioning system (DGPS) to record the position of each gravity station. The data from a specific survey can be compared with data from the same area from another survey, and the density of the waste between the two surveys may be extracted mathematically. The elevations of each survey must be extrapolated in order to determine the thickness of the waste between the two layers; this is accomplished by installing and monitoring settlement gauges placed throughout the waste during the filling process, and then modeling the settlement trends.

This work was done as a component of a broader environmental engineering project; the aim of which is to pursue an understanding of how environmental and operational parameters affect the rate of waste stabilization at an anaerobic bioreactor landfill in a northern climate. A better understanding of such parameters will be used to develop methods to optimize waste stabilization, and subsequently, the production of biogas via anaerobic biodegradation. The characterization of waste density is relevant to this project as it impacts the hydraulic conductivity of the waste and the dimensional footprint of the landfill.

The results and analysis of each microgravity survey are presented in this thesis, as well as the waste settlement models applied to obtain those results. 


\subsection{Site Description}

The Sainte-Sophie Waste Management facility is located at a latitude of $45.785 \mathrm{~N}$ and a longitude of $-73.907 \mathrm{~W}$, and is approximately $40 \mathrm{~km}$ northwest of downtown Montreal. The work in this project was done entirely in zone 4 of the facility. At the Sainte-Sophie facility, one previous landfill cell was designed and built as an anaerobic bioreactor landfill, and was the first of its kind in Canada. Zone 4 is the second cell at the facility that was designed and built as such, and is approximately $650 \mathrm{~m}$ by $475 \mathrm{~m}$ in area, and is projected to have a height of $25 \mathrm{~m}$ by the time the cell is closed [Vingerhoeds, 2011]. The cell receives between 700,000 to $1,000,000$ tonnes of waste annually, collected from municipal, commercial, and industrial sources [AUF Ste Sophie]. Waste is deposited onto the cell throughout the entire year. Since the landfill is located in a northern climate, this leads to a heterogeneous density distribution as frozen and unfrozen waste coexist in the cell [Vingerhoeds, 2011].

Zone 4 is divided into three filling phases, and all gravity surveying was done exclusively in phase 3. Phase 3 was chosen for this study due to the fact that it was completely empty when the study began in July 2009 and would be gradually filled during the duration of the study. Phases 1 and 2 were already full, and therefore were not useful for this project. Figure 1-1 depicts the dimensions of zone 4 in the landfill, and phase 3 is located in the eastern area of the map. The blue squares represent locations of instrument bundles installed in vertical columns within the waste (see section 2.3.3), and the red rectangle represents the instrument/data shed that was constructed for use in this project. 


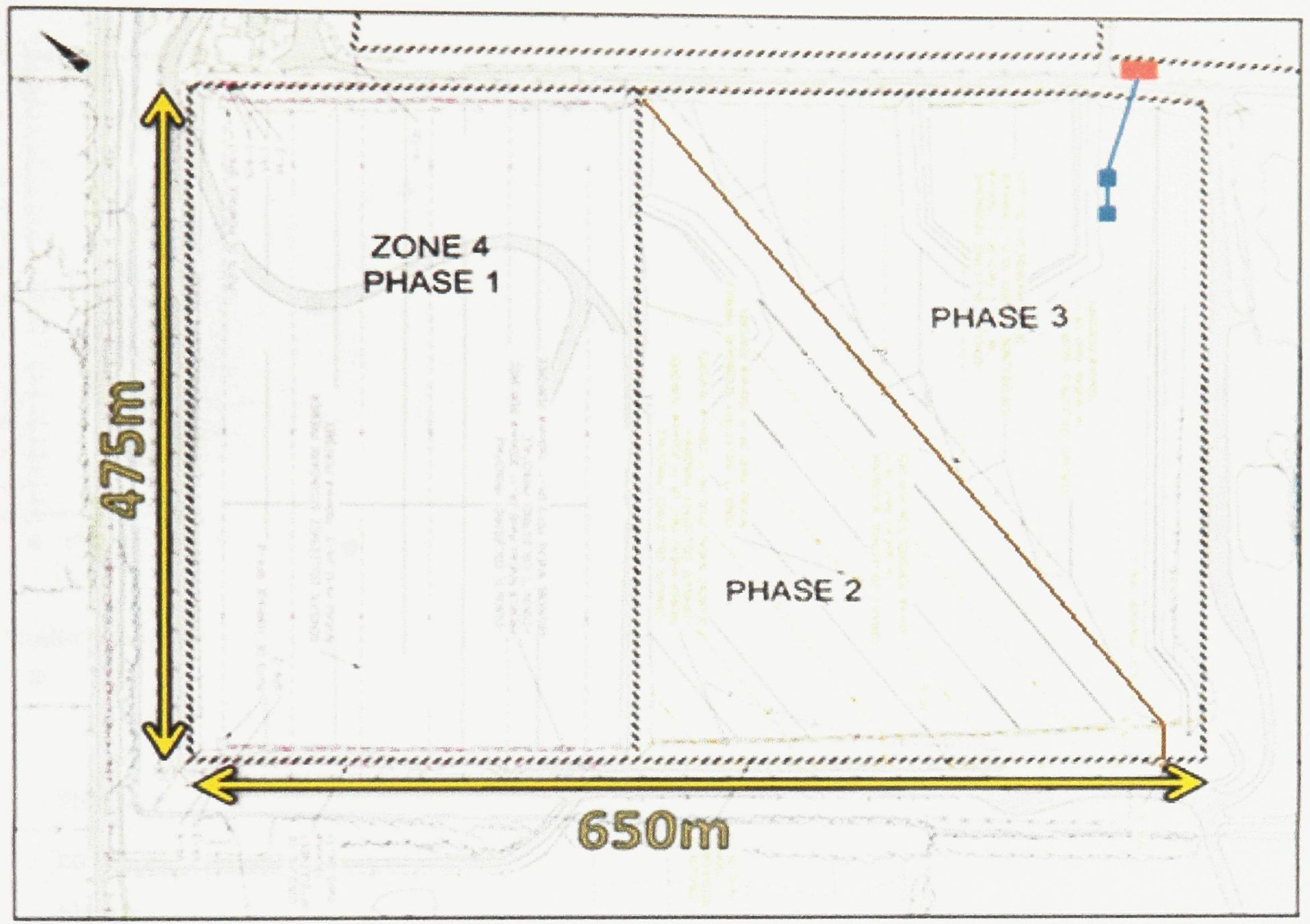

- location of instrument bundles = location of instrument/data shed

Figure 1-1: Dimensions of Zone 4 of the Sainte-Sophie Bioreactor Landfill

(Modified from Genivar 2008)

The filling of phase 3 began in October 2009 over a layer of gravel which lines the bottom of the cell, and is underlain by a composite low permeable barrier. Most of the northeast area of phase 3 was deposited during winter months, and the southwest area of phase 3 was deposited mostly during warmer months. This resulted in the northeast part of phase 3 consisting largely of frozen waste, while the southwest part was unfrozen. Figure 1-2 shows the approximate waste placement timeline of Phase 3, where it is clear that this trend was not broken until August 2011. 


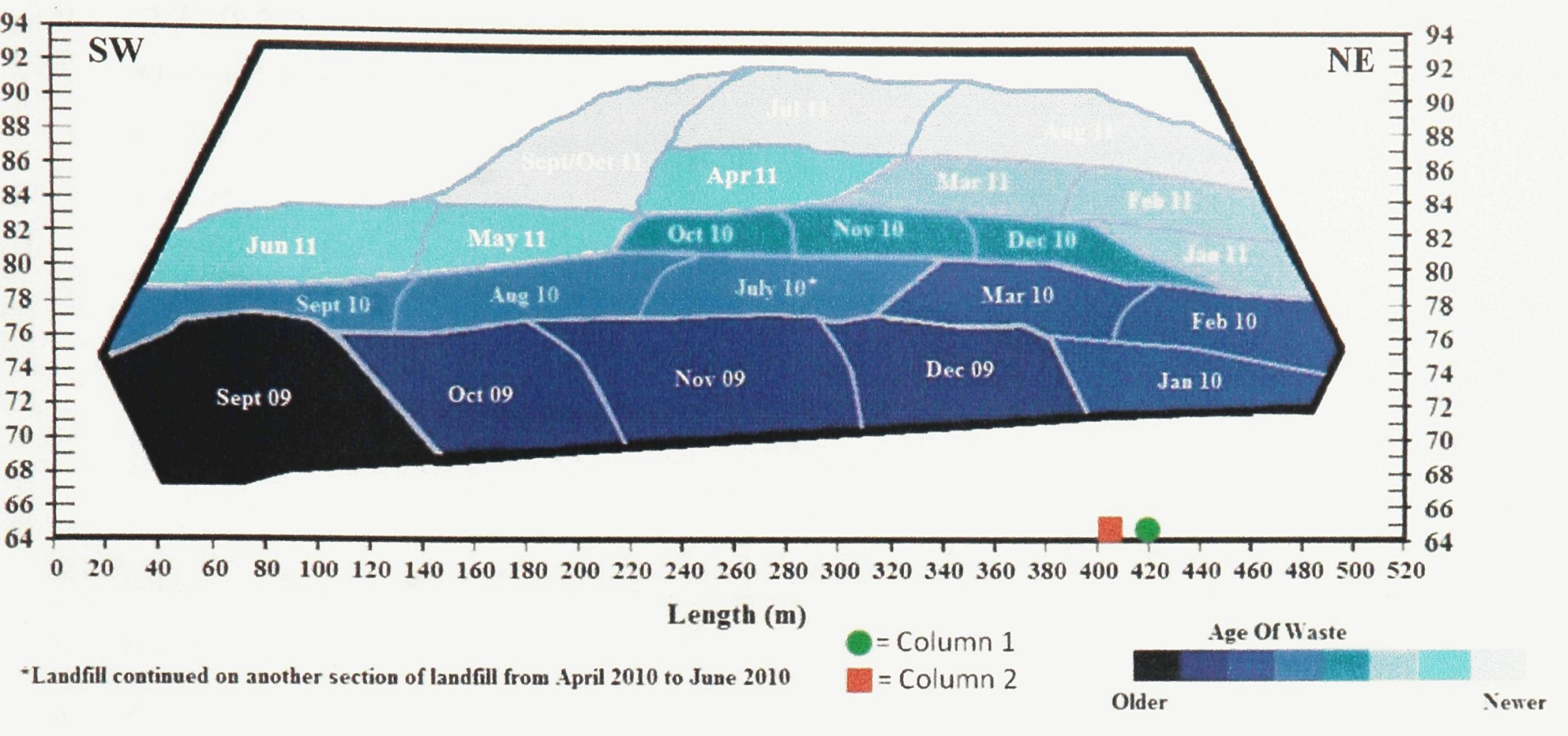

Figure 1-2: Waste Placement Timeline

Throughout the cell, four levels of piping were installed during waste deposition in order to collect and transport biogas. Currently, the Sainte-Sophie facility produces over 70 million $\mathrm{m}^{3}$ of biogas each year, much of which is sold to a local industrial plant, Cascades paper mill, in SaintJérôme. The plant uses the biogas mainly to operate equipment, and receives the gas via a 13 $\mathrm{km}$ pipeline between the plant and landfill [Catley, 2006].

\subsubsection{Density of Waste}

Waste is classified into six different classes at the landfill facility. In zone 4, there exists residential, commercial, industrial, special, sludge, and construction/demolition waste. Approximately $90 \%$ of the total waste in zone 4 is residential, while commercial and construction/demolition waste each make up approximately $4 \%$ each. Also deposited on the cell are soils used for daily cover and slope correction along the edges. These soils comprise approximately $20 \%$ of the total solid mass deposited on the landfill. In order to reach optimal 
moisture content for anaerobic biodegradation, liquid leachate is added intermittently to the waste and makes up only $0.2 \%$ of the total mass on the cell. Due to the increased water content of the waste, the density increases subsequently; however, the slope stability of the waste is reduced [AUF Ste Sophie].

Waste Management calculates an Airspace Utilization Factor (AUF), which is essentially a density value of all deposited solid material on the cell. It is calculated simply by dividing all of the deposited mass by the volume of the landfill cell (as determined by quarterly GPS surveys). The AUF is calculated quarterly, and ranges from 0.8 tonnes $/ \mathrm{m}^{3}$ to 1.8 tonnes $/ \mathrm{m}^{3}\left(0.8 \mathrm{~g} / \mathrm{cm}^{3}-\right.$ $\left.1.8 \mathrm{~g} / \mathrm{cm}^{3}\right)$, and thus it is clear that the density of material is quite heterogeneous in the landfill. These figures account for the total waste and soil deposited, however it is possible to calculate the density strictly of the deposited waste (crude AUF). This figure ranges from 0.7 tonnes $/ \mathrm{m}^{3}$ to 1.2 tonnes $/ \mathrm{m}^{3}\left(0.7 \mathrm{~g} / \mathrm{cm}^{3}-1.2 \mathrm{~g} / \mathrm{cm}^{3}\right)$ when computed quarterly [AUF Ste Sophie]. It should be noted that these figures represent the waste at the time of placement and the AUF values do not account for changes in density over time. In addition, the AUF values tend to overestimate the density of the waste since they do not account for settlement from preceding elevation surveys. This results in underestimating the volume, thus overestimating the density. Upon reviewing other sources (Table 1-1), it is clear that though waste density can vary greatly, the AUF at this Sainte-Sophie cell is typical of those in landfills across North America.

Table 1-1 shows typical landfill density values in North America determined by Zornberg et al. (1999), Qian et al. (2002), Zekkos et al. (2006), and Timmons et al. (2011).

Table 1-1: Typical Waste Values Quoted From Timmons et al. (2011)

\begin{tabular}{|c|c|}
\hline Study & Landfill Density $\left(\mathrm{g} / \mathrm{cm}^{3}\right)$ \\
\hline Zornberg et al. (1999) & $1.10-1.49$ \\
\hline Qian et al. (2002) & $0.86-1.10$ \\
\hline Zekkos et al. (2006) & $1.1-1.8$ \\
\hline Timmons et al. (2011) & $0.99-1.17$ \\
\hline AUF Sainte-Sophie (2012) & $0.8-1.8$ \\
\hline
\end{tabular}


Compared with the Sainte-Sophie cell, $0.8-1.8 \mathrm{~g} / \mathrm{cm}^{3}$, these values align with the lowest Qian et al. (2002) estimate and the highest Zekkos et al. (2006) estimate. 


\section{Background Information}

\subsection{Overview of the Gravitational Force}

Gravity is strictly an attractive force, and the strength of its field is proportional to the mass and the distance from the location of the mass via Newton's equation:

$$
g=\frac{G M}{R^{2}}
$$

Where $G$ is the universal gravitational constant, $6.674 \times 10^{-11} \mathrm{Nm}^{2} \mathrm{~kg}^{-2}, M$ is the mass of the source body, and $R$ is the distance between the source body and bodies it attracts. Hence, the more massive the source body, the stronger the surrounding gravitational field, and the further from the source body, the weaker the gravitational field. If mass is substituted for an expression in terms of density $(M=$ Volume $\times$ Density $=V \rho)$, then the gravitational field strength may be written as:

$$
g=\frac{G V \rho}{R^{2}}
$$

Thus, if the gravitational field strength is measured over an area with heterogeneous underlying density, then the field strength will vary proportionally. Such is the concept of gravity surveying. The strength of a gravitational field is a quantity of acceleration and is typically measured in $\mathrm{m} / \mathrm{s}^{2}$. However in the context of geophysical gravity surveys, fluctuations are too small to be conveniently expressed in these units. The preferred unit is milligal (mGal), which is equal to $10^{-5} \mathrm{~m} / \mathrm{s}^{2}$. 


\subsubsection{Bouguer Slab Approximation}

The goal is to extract a density value from a gravity reading. In order to do this, the geometry of the survey area must be described. Gauss' Law for gravity is expressed as follows:

$$
\oint \vec{g} \cdot d \vec{A}=-4 \pi G M
$$

Where $A$ is the area of the Gaussian surface, and $M$ is the mass enclosed by the Gaussian surface. The simplest way to represent the geometry of the waste is to approximate it as a cylinder with height, $h$, and an infinite radius, $r$. Approximating the radius as infinite when the landfill has finite dimensions is done to simplify the calculations, as will become evident in the derivation below. Such an approximation is allowed because at a large distance, the gravity from the faraway mass is negligible compared to the gravity of the underlying waste. This cylinder is known as a Bouguer Slab. To apply the Bouguer Slab approximation to Gauss' Law, we can assume that $g \cdot d A$ along the sides of the cylinder at infinity is equal to zero due to the gravitational field and area vectors being orthogonal. Therefore, only the top and bottom contribute:

$$
\oint \vec{g} \cdot d \vec{A}=g 2 \pi r^{2}=-4 \pi G M
$$

Since the area of the top and bottom of the cylinder are each $\pi r^{2}$. Now the enclosed mass can be expressed in terms of the density of the waste and the volume of the cylinder $\left(\pi h r^{2}\right.$, where $h$ is the thickness of the slab) as follows:

$$
g 2 \pi r^{2}=-4 \pi G\left(\rho \pi h r^{2}\right)
$$

which simplifies to:

$$
\rho=-\frac{g}{2 \pi G h}
$$

Now we have an equation that allows the computation of density from the gravity measurements as long as the thickness of the waste layer, $h$, is known. 
In this study, the gravity value of the slab is obtained by subtracting the gravity at the bottom of the slab from the value at the top of the slab, which is necessary to remove the signal from all Earth mass below. From this point on, the gravity will therefore be represented by $\Delta g$.

\subsubsection{Gravity Data Reduction}

In order to obtain a dataset that reflects the density distribution in the bioreactor cell, corrections must be applied to remove undesired effects. The corrections that were not applied automatically by the instrument had to be done in post-processing. They include internal drift, free-air, and tidal corrections.

The internal drift correction is necessary due to internal effects in the instrument that cause the measurements to gradually stray as a function of time. The physical cause of this drift involves the relaxation of the spring (approximately $0.5 \mathrm{ppm} /$ day depending on the temperature and latitude) used to hold the proof mass in the sensor (refer to section 2.2.1 for information on the functioning of the sensor). According to Hooke's Law, the amount of force required to extend a spring a distance of $x$ is proportional to a spring constant, $k$,

$$
F=-k x
$$

However, over time, the spring constant gradually decreases and thus the force required to extend the spring is reduced. After the spring system has stabilized, the long-term drift tends to follow a linear relationship with time.

Figure 2-1 shows the linear nature of internal drift over a period of ten days (the periodic oscillations are due to tidal effects). Readings for this trial were taken every ten minutes and a drift rate of $0.01067 \mathrm{mGal} / \mathrm{day}$ was found. During surveys in the landfill, base station readings were taken approximately every two hours for the duration of each survey. For each day, a linear fit was conducted of each base station readings, with the first reading taken to be the $y$ intercept of the gravity versus time curve. Each reading during the day was corrected by simply subtracting the drift rate (in $\mathrm{mGal} /$ hour) multiplied by the time since the survey was started (in hours) from the gravity value. 


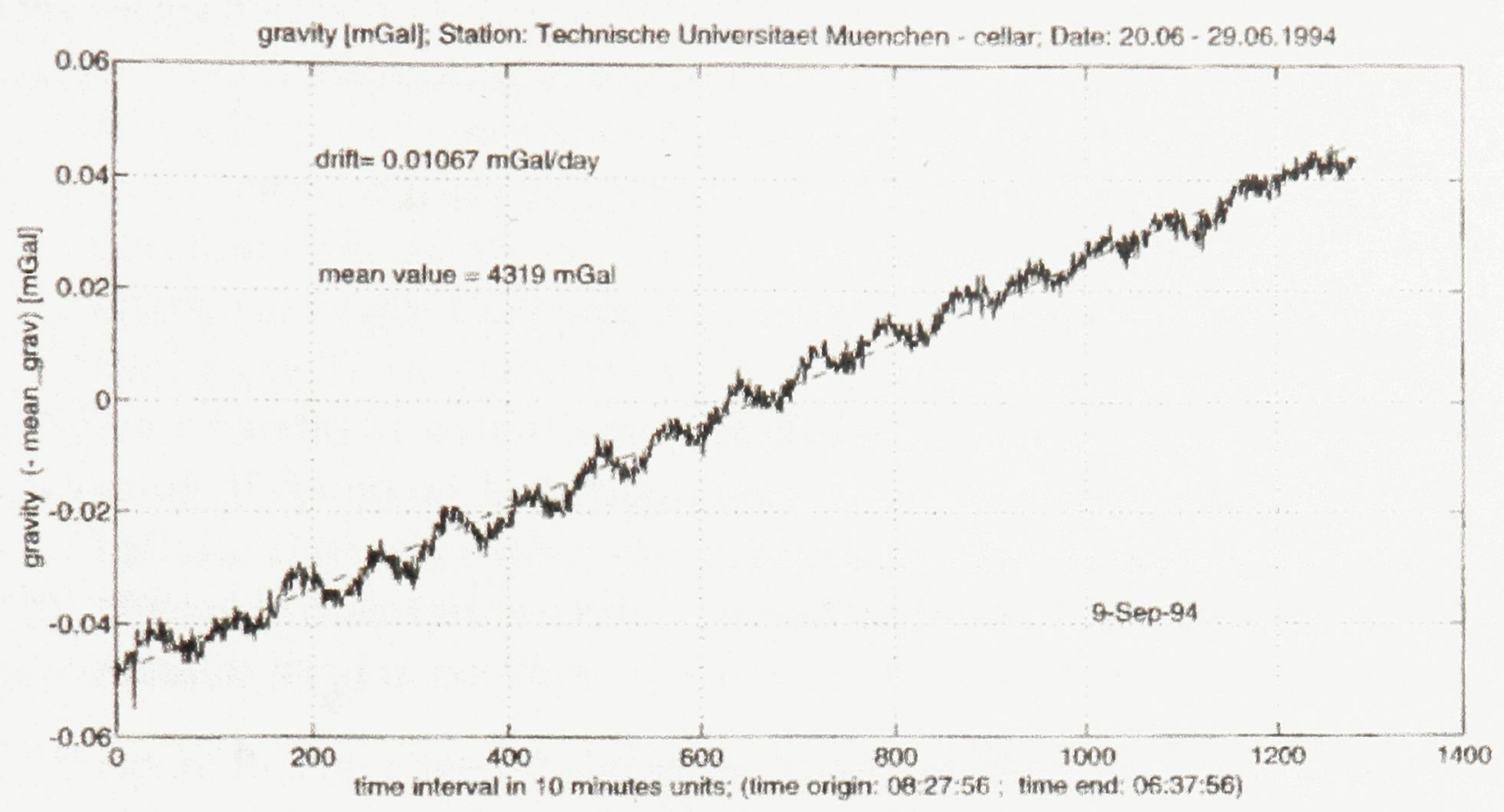

Figure 2-1: Linear Nature of Internal Drift [CG-5 Manual]

The free-air correction is necessary in order to represent the gravity distribution as if it were only affected by the underlying mass and not the elevation of the waste. The free-air correction negates the dependency on the distance from the mass. To quantify this correction, let us first find the rate at which the strength of the gravitational field changes with distance by taking the derivative of $g$ with respect to $r$ in equation 2.1:

$$
\begin{gathered}
g=\frac{G m}{r^{2}} \\
\frac{d g}{d r}=-\frac{2 G m}{r^{3}}=-\frac{2 g}{r}
\end{gathered}
$$

The latitude of the survey area is approximately $45.8^{\circ} \mathrm{N}$. The average gravity at this latitude can be calculated:

$$
\begin{gathered}
g_{\varphi}=978031.85\left(1+0.005278895 \sin ^{2} \varphi+0.000023462 \sin ^{4} \varphi\right) \\
g_{45.8}=982906.662 \mathrm{mGal}
\end{gathered}
$$


And the average distance to the center of the earth from the surface at this latitude is 6358.04 $\mathrm{km}$. Thus:

$$
\frac{d g}{d r}=2 \cdot 982906.662 \mathrm{mGal} / 6358040 \mathrm{~m}=0.3092 \mathrm{mGal} / \mathrm{m}
$$

So to apply the free-air correction, $0.3092 \mathrm{mGal} / \mathrm{m}$ was multiplied by the height above the datum, and then added to the measured value. During the surveys, the datum was taken to be the lowest elevation on the surveyed area.

The final correction that needs to be applied to the gravity data is the tidal correction. This correction is necessary to account for the gravitational force caused by nearby celestial bodies. The gravitational force of any mass is nonzero at any finite distance; however due to the inverse squared relationship between force and distance, masses that are far from earth or objects with low masses can be considered to have negligible effect on the data. In order to remove the effects of nearby celestial bodies, their locations and gravitational forces must be known at the time of each measurement. This is best accomplished through the use of a computer program that models the locations of each significant body. Most tidal programs account for only the sun and moon; however, 1200 tidal parameters were accounted for in this survey. The program employed is from the International Center for Earth Tides (ICET), and also accounts for the effects of Jupiter and Venus on the orbits of other planets.

\subsection{Instruments}

\subsubsection{Scintrex CG-5 Gravimeter}

During this project, the instrument used to measure the gravitational field strength was the Scintrex CG-5 gravimeter. The CG-5 measures relative gravitational field strength as opposed to absolute.

The sensing mechanism in the instrument measures gravity through a method based on equilibrating a proof mass on a quartz spring. Gravitational force causes the proof mass to 
accelerate downward. This downward motion is counteracted by an electrostatic force acting on the proof mass that is generated by a DC voltage applied to capacitor plates. Voltage is increased until the proof mass is returned to its original position, as measured by a capacitive displacement transducer. The applied DC voltage is proportional to the gravitational force that it is counteracting, and the strength of the signal is digitized and sent to the data acquisition system to be converted to a gravity value [CG-5 Manual].

The gravimeter has a range of more than $8000 \mathrm{mGal}$ and a resolution of $0.001 \mathrm{mGal}$, which is adequate for this project as the measurement error during survey conditions was found to be $0.044 \mathrm{mGal}$ (refer to section 2.3.2), and the range rarely exceeded $1 \mathrm{mGal}$ during a survey. Each reading consists of a preset amount of samples (in this case, 120; one measurement per second) that are averaged [CG-5 Manual]. To minimize measurement error, it is crucial to ensure the instrument is leveled in order for the spring to align with the downward gravitational force. This is accomplished by placing the instrument on a tripod with adjustable legs, and varying the height of each leg until the gravimeter indicates that there is no tilt.

The instrument can detect tilt with a precision of 1 arc second and make corrections in realtime for up to 400 arc seconds. Also, since the sensor is encased in a vacuum chamber, it is adequately isolated from changes in atmospheric pressure. This allows for a very accurate prediction of long-term instrumental drift, which is corrected internally such that it is less than $0.02 \mathrm{mGal}$ per day. An internal seismic filter is also employed to remove the effects of seismic activity from the readings. This is done by increasing the rejection threshold of each sample, and by applying unequal weighting to each sample to remove edge effects. However, most seismic activity in our area of study is caused by microseisms in the Atlantic Ocean, whose effects on the gravity measurements rarely exceed $0.1 \mathrm{mGal}$. Another internally applied correction is to compensate for tidal forces. The instrument uses the Longman formula to compute the gravitational effects of the sun and moon at a specified time, and applies them to the readings [CG-5 Manual]. However, since the ICET program provides a more robust correction, the internal tidal correction was turned off. 
Table 2-1: Scintrex CG-5 Gravimeter Specifications

\begin{tabular}{|c|c|}
\hline Physical Characteristics & \\
\hline Dimensions (Instrument) & $336 \times 215 \times 201 \mathrm{~mm}$ \\
\hline Mass & $6.4 \mathrm{~kg}$ \\
\hline Hardware Specifications & \\
\hline Graphic Display & VGA $320 \times 240$ LCD \\
\hline Memory & $12 \mathrm{Mb}$ \\
\hline Batteries & $2 \times$ Lithium $5 \mathrm{Ah}$ \\
\hline Ports & $2 \times$ COM (RS-232) \\
\hline & $1 \times$ USB \\
\hline & $1 \mathrm{x}$ analog strip chart recorder output \\
\hline Software Specifications & \\
\hline Operating System & Scintrex Proprietary Embedded OS \\
\hline Automated Data Corrections & Tide \\
\hline & Instrument tilt \\
\hline & Temperature \\
\hline & Advanced Noisy Reading Rejection \\
\hline & Noise Filter / FIR filter \\
\hline & Near Terrain Corrections \\
\hline General Specifications & \\
\hline Reading Resolution & $0.001 \mathrm{mGal}$ \\
\hline Minimum Operating Range & $8000 \mathrm{mGal}$ \\
\hline Residual Long-term Drift & Less than $0.02 \mathrm{mGal}$ per day \\
\hline Typical Repeatability in Field & Less than $0.01 \mathrm{mGal}$ standard deviation \\
\hline
\end{tabular}


Table 2-2: Typical CG-5 Output File

\begin{tabular}{|c|c|c|c|c|c|c|c|c|c|}
\hline$\stackrel{3}{0}$ & 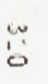 & $\begin{array}{l}w \\
0 \\
c\end{array}$ & $\stackrel{\%}{0}$ & $\frac{a}{c}$ & so & $\because$ & s. & $\ddot{0}$ & 高 \\
\hline In & g & $\ddot{d}$ & s̊ & 8 & 它 & $\stackrel{5}{\circ}$ & 灾 & 空 & $\frac{n}{2}$ \\
\hline 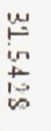 & 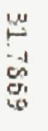 & 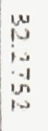 & 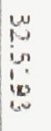 & 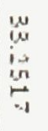 & $\begin{array}{l}w \\
w \\
4 \\
w \\
w \\
w \\
w\end{array}$ & $\begin{array}{l}w \\
0 \\
\vdots \\
+1 \\
+\end{array}$ & $\begin{array}{l}\omega \\
\vdots \\
\vdots \\
\omega \\
w\end{array}$ & 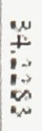 & $\frac{5}{5}$ \\
\hline $\begin{array}{l}\text { in } \\
\text { in } \\
\text { sin } \\
\text { is } \\
0 \\
0 \\
\text { os }\end{array}$ & 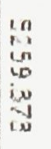 & 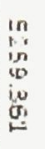 & $\begin{array}{l}1 n \\
0 \\
i n \\
0 \\
0 \\
i 0 \\
10 \\
1\end{array}$ & 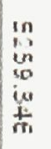 & 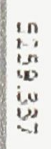 & 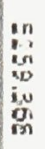 & $\begin{array}{l}\text { in } \\
\text { is } \\
\text { in } \\
\text { is } \\
\text { in } \\
\text { s }\end{array}$ & 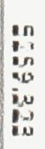 & $\begin{array}{l}y \\
y \\
y\end{array}$ \\
\hline $\begin{array}{l}0 \\
0 \\
0 \\
0\end{array}$ & $\begin{array}{l}\text { 品 } \\
\text { 品 }\end{array}$ & 芯 & $\begin{array}{l}0 \\
0 \\
0 \\
i-1\end{array}$ & $\begin{array}{c}0 \\
0 \\
0 \\
-1\end{array}$ & $\begin{array}{l}0 \\
0 \\
0 \\
0\end{array}$ & $\begin{array}{l}0 \\
0 \\
0 \\
+\end{array}$ & $\begin{array}{l}\text { 足 } \\
\text { 点 }\end{array}$ & $\begin{array}{l}0 \\
0 \\
0 \\
4\end{array}$ & is \\
\hline 点 & $\begin{array}{l}\dot{c} \\
\dot{c} \\
\sigma .\end{array}$ & $\underset{\substack{\dot{j} \\
\text { in } \\
\text { in }}}{ }$ & 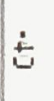 & 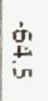 & ${ }_{\dot{\omega}}^{\dot{B}}$ & $\begin{array}{r}-1 \\
-1\end{array}$ & $\underset{\text { is }}{\text { in }}$ & $\frac{\therefore}{2}$ & $\frac{1}{5}$ \\
\hline$\because 1$ & $\stackrel{亡}{ \pm}$ & i & $\dot{\grave{w}}_{-1}$ & $\begin{array}{l}w \\
\text { on } \\
\text { on }\end{array}$ & is & $\frac{\dot{y}}{+\infty}$ & is & $\stackrel{\div}{\div}$ & $\frac{1}{\frac{1}{3}}$ \\
\hline$\dot{w}$ & $\cos _{\text {in }}$ & $\begin{array}{l}\text { w } \\
\stackrel{5}{\infty}\end{array}$ & $i_{i=1}$ & $\begin{array}{l}\text { is } \\
\text { is }\end{array}$ & $\sum_{i}$ & $\begin{array}{l}\text { in } \\
i-1\end{array}$ & $\dot{i m}_{\sigma ;}$ & 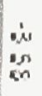 & $\frac{\pi}{\mathrm{T}}$ \\
\hline 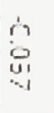 & $\begin{array}{l}\text { r. } \\
\text { ci } \\
\text { ul } \\
\text { ul }\end{array}$ & 乌े & $\begin{array}{l}\dot{3} \\
\stackrel{0}{ \pm}\end{array}$ & 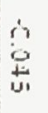 & $\begin{array}{l}0 \\
\dot{0} \\
\stackrel{1}{+}\end{array}$ & $\dot{0}$ & On & @ي & $\frac{1}{\underline{\omega}}$ \\
\hline 点 & 点 & $\stackrel{\stackrel{s}{r}}{\stackrel{s}{n}}$ & 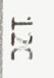 & 点 & 宫 & 点 & $\stackrel{5}{r}$ & 点 & 产 \\
\hline$\stackrel{\leftrightarrow}{s}$ & in & $\omega$ & $\leftarrow$ & 0 & $\stackrel{\leftrightarrow}{\circ}$ & $\mapsto$ & 0 & on & 召 \\
\hline 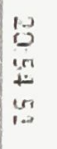 & $\begin{array}{l}\mathrm{J} \\
\mathrm{O} \\
+ \\
\mathrm{w} \\
\text { is }\end{array}$ & $\begin{array}{l}1 J \\
0 \\
\pm \\
\text { in }\end{array}$ & 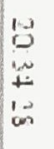 & 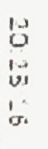 & $\begin{array}{l}1.0 \\
0 \\
0 \\
0\end{array}$ & 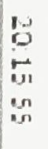 & $\begin{array}{l}3 \\
0 \\
0 \\
0 \\
0\end{array}$ & $\begin{array}{l}0 \\
0 \\
0 \\
0 \\
10\end{array}$ & $\frac{\frac{1}{\frac{7}{11}}}{11}$ \\
\hline 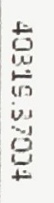 & 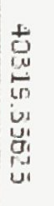 & 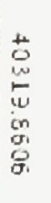 & 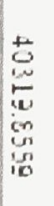 & 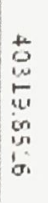 & 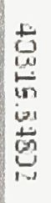 & 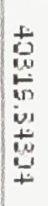 & 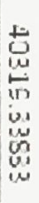 & 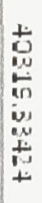 & 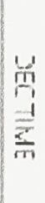 \\
\hline 0 & $c$ & 0 & 0 & 0 & 0 & 0 & 0 & 0 & 勃 \\
\hline $\begin{array}{l}m \\
03 \\
0 \\
0 \\
\frac{5}{2}\end{array}$ & 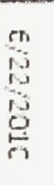 & 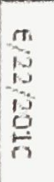 & $\begin{array}{l}m \\
13 \\
-3 \\
0 \\
0 \\
13\end{array}$ & $\begin{array}{l}n \\
1 \\
0 \\
0 \\
0 \\
0 \\
n\end{array}$ & $\begin{array}{l}n \\
13 \\
10 \\
13 \\
0 \\
0 \\
n\end{array}$ & $\begin{array}{l}n \\
1 \\
0 \\
0 \\
0\end{array}$ & $\begin{array}{l}n \\
0 \\
9 \\
0 \\
0\end{array}$ & $\stackrel{8}{1}$ & $\frac{9}{1}$ \\
\hline
\end{tabular}


Table 2-2 shows an example of a typical output file. The LINE and STN (station) are simply inputted by the user, and represent the location of the surveyed point. The ALT (altitude in meters) is simply a relative elevation that can be set to any value up to $50000 \mathrm{~m}$. GRAV (gravity) is the relative gravity value in $\mathrm{mGal}$ and SD is its corresponding standard deviation. This value is calculated by computing the standard deviation of 120 measurements that make up the GRAV reading. TILTX and TILTY show the angles of the instrument in the $X$ and $Y$ axes in $\operatorname{arc}$ seconds. TEMP (temperature) is the correction for temperature, in milligals, that is applied internally to each reading, TIDE does the same for tidal corrections, and TER (terrain) does the same for near terrain corrections. DUR (duration) is the duration of the reading in seconds and REJ (rejected) is the number of rejected measurements during the reading. TIME is displayed in Greenwich Mean Time (GMT), and DEC TIME is a decimal representation of the time. 


\subsubsection{Differential GPS}

All georeferencing and elevation measurements were done using a Real-Time Kinematic with Differential Global Positioning System (RTK-DGPS). GPS technology delivers spatial accuracy on the scale of several meters when DGPS and RTK are not employed. DGPS technology improves the accuracy through the addition of a fixed base station receiver. The base station receiver is installed near the survey site, and its position is known with sub-centimeter accuracy. The base station receiver is used to calibrate the satellite's locating system. This is done by comparing the apparent position of the base station as measured by the satellite with the true location of the base station. DGPS then adjusts its coordinate system accordingly so that any other receivers in the area are referenced to the base station.

All measurements were taken by a mobile receiver, known as a rover. The receiver is mounted atop a two meter high pole in order to allow for a better line-of-sight with the base station receiver, therefore a two meter elevation correction is automatically applied to each reading. Each measurement made by the rover must be taken when the receiver is leveled to ensure that the receiver is exactly two meters above the ground.

RTK is employed with the DGPS technology to allow for the correction of the coordinates to be applied in real-time. During surveying, a clear line-of-sight is necessary to maintain connection between the rover and the base station receiver. When there are obstacles in the line-of-sight, there might be difficulties maintaining connection with this system, but this problem may be rectified through the use of a repeater. A repeater is an additional receiver that acts to relay the signal between the rover and the base station. This allows for the rover to be out of of sight with the base station as long as it maintains line-of-sight with the repeater. At the Ste-Sophie site, a repeater has been installed at a height of $\approx 4 \mathrm{~m}$ on an electrical pole near the data acquisition shed, at a distance of $\approx 700 \mathrm{~m}$ from the base station receiver, to allow our team to do RTK-DGPS surveying in Phase 3 of Zone 4.

Table 2-3 shows RTK-DGPS readings taken at a fixed location, known as "monument 7", at three different times to evaluate the precision of the system. 
Table 2-3: RTK-DGPS Readings at a Fixed Location at Various Times

\begin{tabular}{|r|c|c|c|}
\hline & Northing & Easting & Elevation (m) \\
\hline Jul-09 & 5071559.359 & 273092.019 & 79.081 \\
\hline Jun-10 & 5071559.417 & 273092.096 & 79.060 \\
\hline Apr-11 & 5071559.362 & 273091.965 & 79.068 \\
\hline Standard Deviation & 0.033 & 0.065 & 0.011 \\
\hline
\end{tabular}

The standard deviation of these readings provides a means of quantifying the measurement error of the DGPS system. In the X-Y plane, the measurement error is,

$$
\sigma_{X-Y}=\sqrt{\sigma_{X}^{2}+\sigma_{Y}^{2}}=\sqrt{0.033^{2}+0.065^{2}}=0.073 m
$$

Thus, the measurement error in the $X-Y$ plane is $7.3 \mathrm{~cm}$, and the error in the elevation is $1.1 \mathrm{~cm}$.

\subsubsection{Instrument Bundles}

Instrument bundles, each containing a settlement system, a total earth pressure cell, a piezometer, an oxygen sensor, a moisture and conductivity sensor, and temperature thermistors, were installed in the waste column. Figure 2-4 shows the layout of the instruments in a bundle. Data obtained from these instruments is being analyzed by our collaborators in the Department of Civil and Environmental Engineering at Carleton University, whose goal is to find means of optimizing operational practices to enhance methane production in bioreactor landfills.

In total, twelve bundles have been installation, with the final two placed in May 2012. The bundles were installed in two columns at various heights in the waste column (Figure 2-5). Each instrument bundle had to be buried to avoid possible damage from the working vehicles on the 
cell. Cables from the instruments were run through the waste, under the road, and into the data acquisition system located in the instrument/data shed.

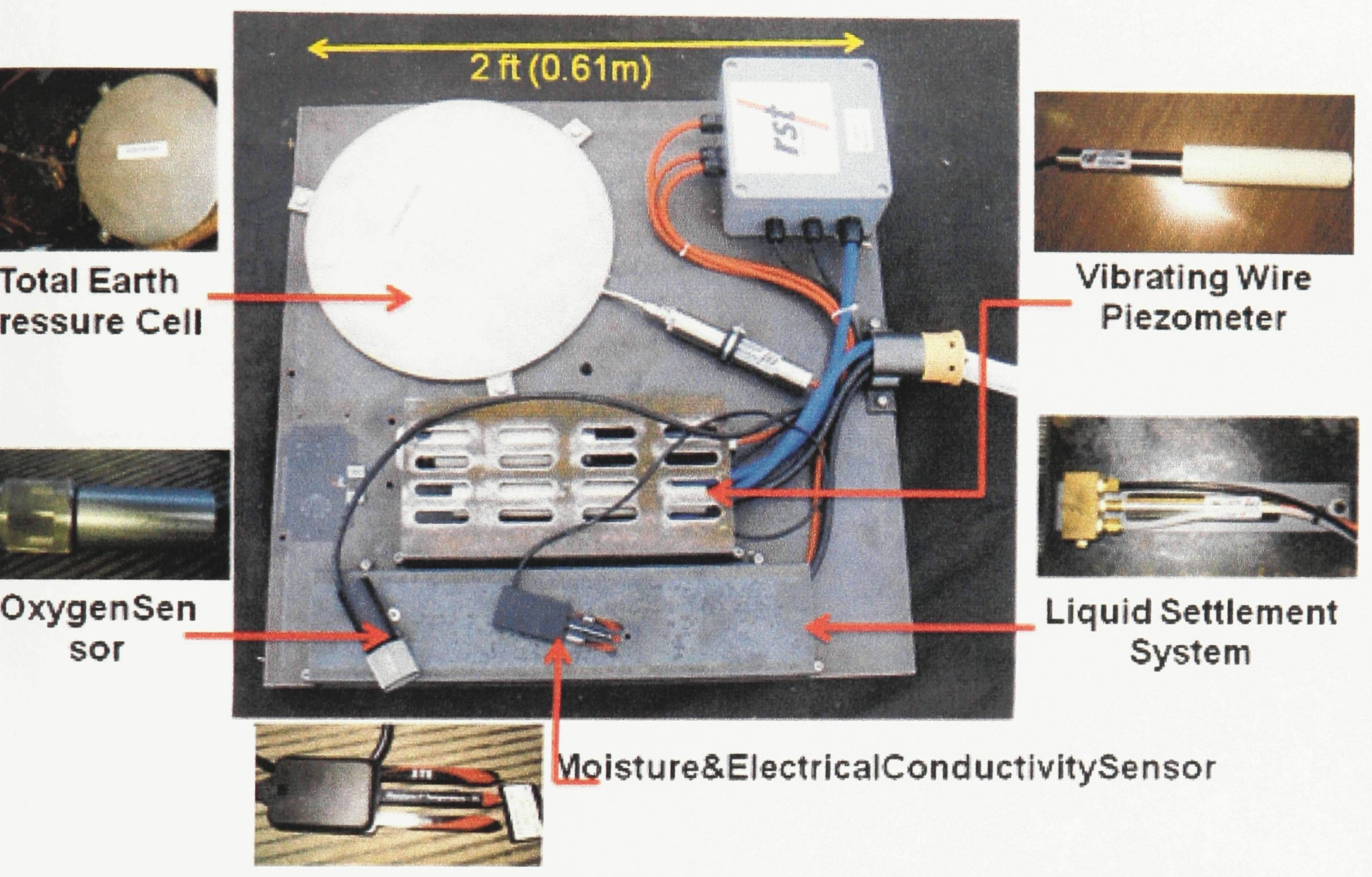

Figure 2-4: Layout of Instrument Bundles (adapted from Vinderhoeds (2011)) 


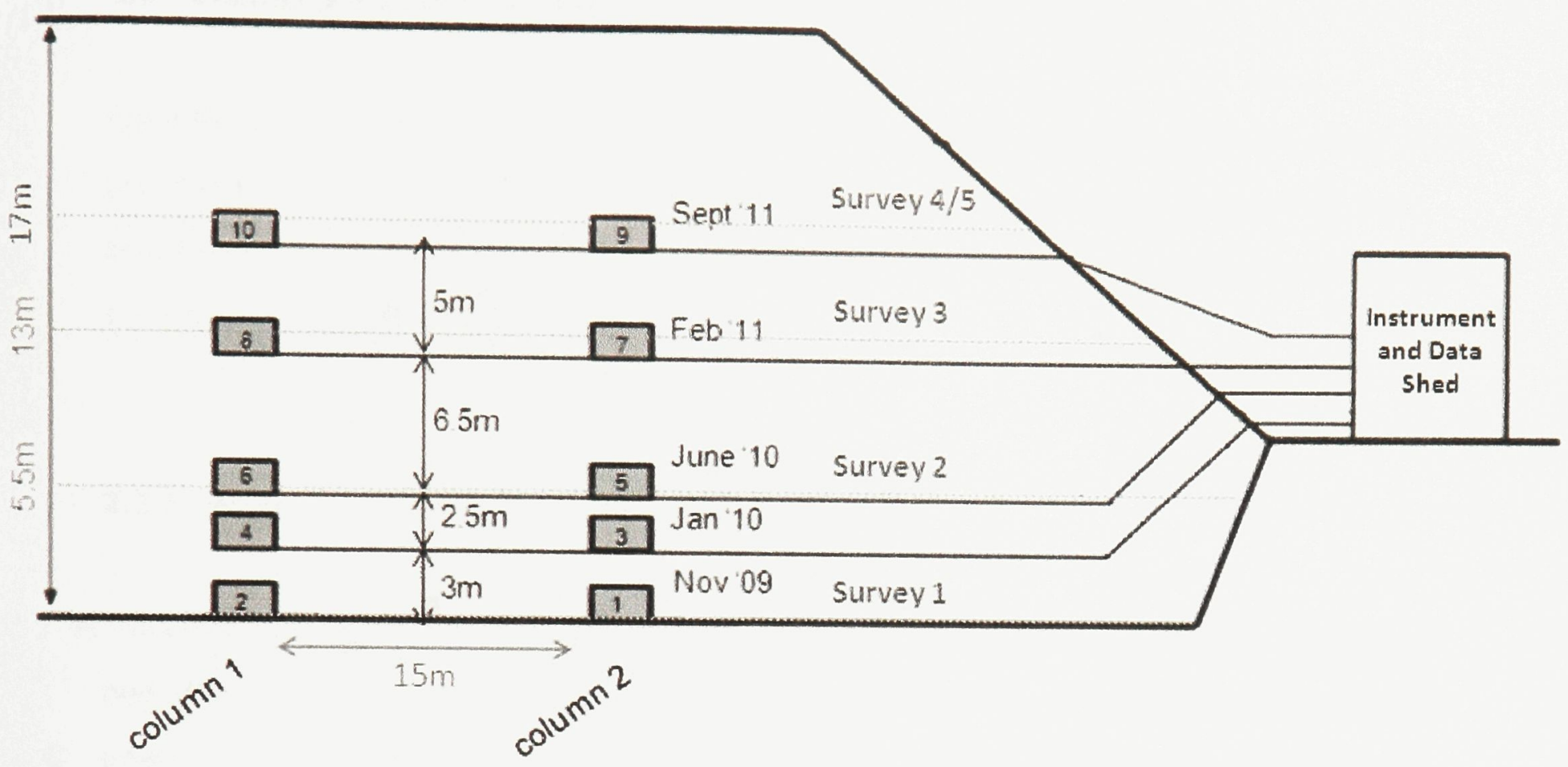

Figure 2-5: Schematic Cross-Section Showing the Instrument Bundles in Landfill Cell

\subsubsection{Settlement System}

The data obtained from the liquid settlement systems included in each instrument bundle was used in this project. The settlement system, the RST Instruments' Vibrating Wire Liquid Settlement System (Figure 2-4), consists primarily of liquid settlement gauges and a vibrating wire. Two tubes connect the settlement system in an instrument bundle to a reservoir in the instrument shed. These tubes are filled with a 50/50 water/glycol mixture. The alcohol is added to protect the liquid from freezing in sub-zero ambient temperatures. As the elevation of the instrument bundle changes, so does the pressure differential between the instrument bundle and the reservoir in the shed. This pressure differential is measured by a pressure sensor at the reservoir and is converted to a change in elevation, so long as the density of the liquid is known. To make sure that the pressure differential is always positive, the reservoir in the instrument shed was pressurized to $70 \mathrm{kPa}$. The net settlement of the instrument bundle is simply calculated by subtracting the final elevation value from the initial elevation value. 


\subsection{Preliminary Gravity Testing}

From November 24 to November 28, 2010, preliminary testing was done with the Scintrex CG-5 gravimeter. The objective of these tests was to investigate various sources of error and their effects on measurements prior to performing surveys at the landfill. All preliminary testing was performed at Carleton University campus.

\subsubsection{Estimating Duration of "Morning Sickness"}

"Morning sickness" refers to an effect on readings due to internal processes in the instrument and often results in a period of unpredictable data after the instrument is removed from an $A C$ power source. This process is due mainly to a transient drift that results when the instrument switches from an AC source to its internal batteries. During this switch, the instrument changes to operate on a new internal drift regime. The magnitude of this effect is greatest when the temperature contrast between the survey conditions and the storage conditions is large.

In order to quantify the effect of morning sickness on the gravity readings, three trials were undergone of repeated gravity readings until the readings leveled off. All readings were taken in a fixed location in order to minimize the effects of moving and releveling the instrument. Each trial was performed on different days in order to assure the effect was completely renewed.

Figure 2-6 shows trial 1 (Nov 24, 2010), in blue, for the estimation of the duration of the "morning sickness". At 64 min the instrument froze and was restarted. This resulted in the disturbance of the horizontality of the instrument. It was estimated that the measurements were leveling off at $\sim 53 \mathrm{~min}$ and the data from after the freeze was ignored. Trial 2 (Nov 25), in red, shows measurements leveling off at $61 \mathrm{~min}$. Trial 3 (Nov 28), in green, shows measurements leveling off at $\sim 44 \mathrm{~min}$.

The average duration of "morning sickness" of the instrument was found to be $52 \pm 8 \mathrm{~min}$, when measured from the time the gravimeter was taken off of the AC power supply. 
It should also be noted that approximately $100 \mathrm{~m}$ away from the site of the trials, there was active construction. Equipment from the construction is believed to have been a source of random error on the measurements. 


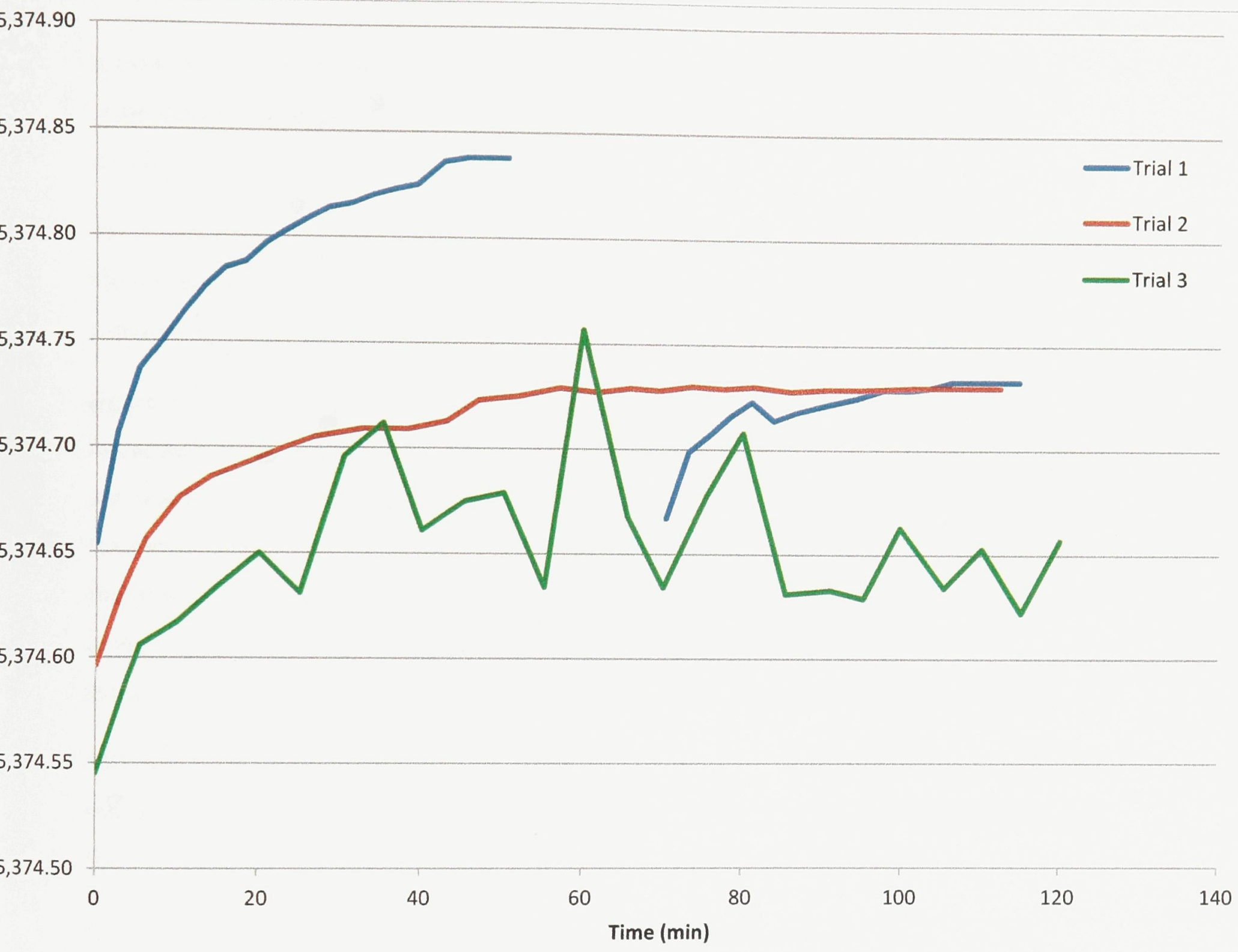

Figure 2-6: "Morning Sickness" Trials 


\subsubsection{Estimating Measurement Errors}

In order to quantify the measurement error of the Scintrex CG-5 gravimeter, three trials were undergone to investigate the precision of the measurements under increasing degrees of disturbance in the environment.

The first trial (Nov 23, 2010) was done to determine the minimum measurement error possible. Measurements were taken indoors on flat ground, and the gravimeter was not moved nor releveled between each reading.

Figure 2-7 shows the gravity data for the first trial. The first seven readings (in red) were discarded on the basis that they were still in the regime of "morning sickness". The final reading was discarded due to the fact that only two measurements were taken instead of 120 . The standard deviation was computed and was taken to be the measurement error. It was found that the minimum measurement error was $0.0009 \mathrm{mGal}$, which is slightly below the resolution of the instrument quoted by the manufacturer, which is 0.001 . Thus the minimum measurement error was then concluded to be the resolution of the instrument, $0.001 \mathrm{mGal}$.

For the second trial (Nov 23, 2010), the same station was used to take the readings. In this trial, however, the instrument was releveled after each reading. This method was used to investigate the measurement error on an ideal surface but in more realistic conditions.

Figure 2-8 shows the gravity data for the second trial. The first seven readings (in red) were discarded on the basis that they were still in the regime of "morning sickness". The standard deviation was computed and was taken to be the measurement error. The measurement error was found to be equal to $0.003 \mathrm{mGal}$. In the conditions used during trial 2, the measurement error is therefore estimated to be three times larger than the resolution of the instrument.

The third trial (Nov 23, 2010) attempted to closely emulate field survey conditions. Three stations were marked in the snow outside, and readings were taken repeatedly at each one. Outside weather, uneven terrain, construction in the background, and the need to move and relevel between each reading replicated conditions at the landfill. 
Figure 2-9 shows the gravity data for the third trial. In this trial, readings were not taken until the morning sickness regime was finished. The measurement stations were close enough together (approximately $2 \mathrm{~m}$ ) so that gravity was assumed to be constant and variations between measurements could be solely attributed to measurement error. The standard deviation was computed, and was taken to be the measurement error. The measurement error was found to be $0.044 \mathrm{mGal} ; 44$ times the resolution of the instrument. Note how surveying outside and moving the gravimeter between stations increased measurement error by an order of magnitude The conclusion of the third trial is that a value of $0.044 \mathrm{mgal}$ is a reliable estimate of the measurement error in the landfill surveys.

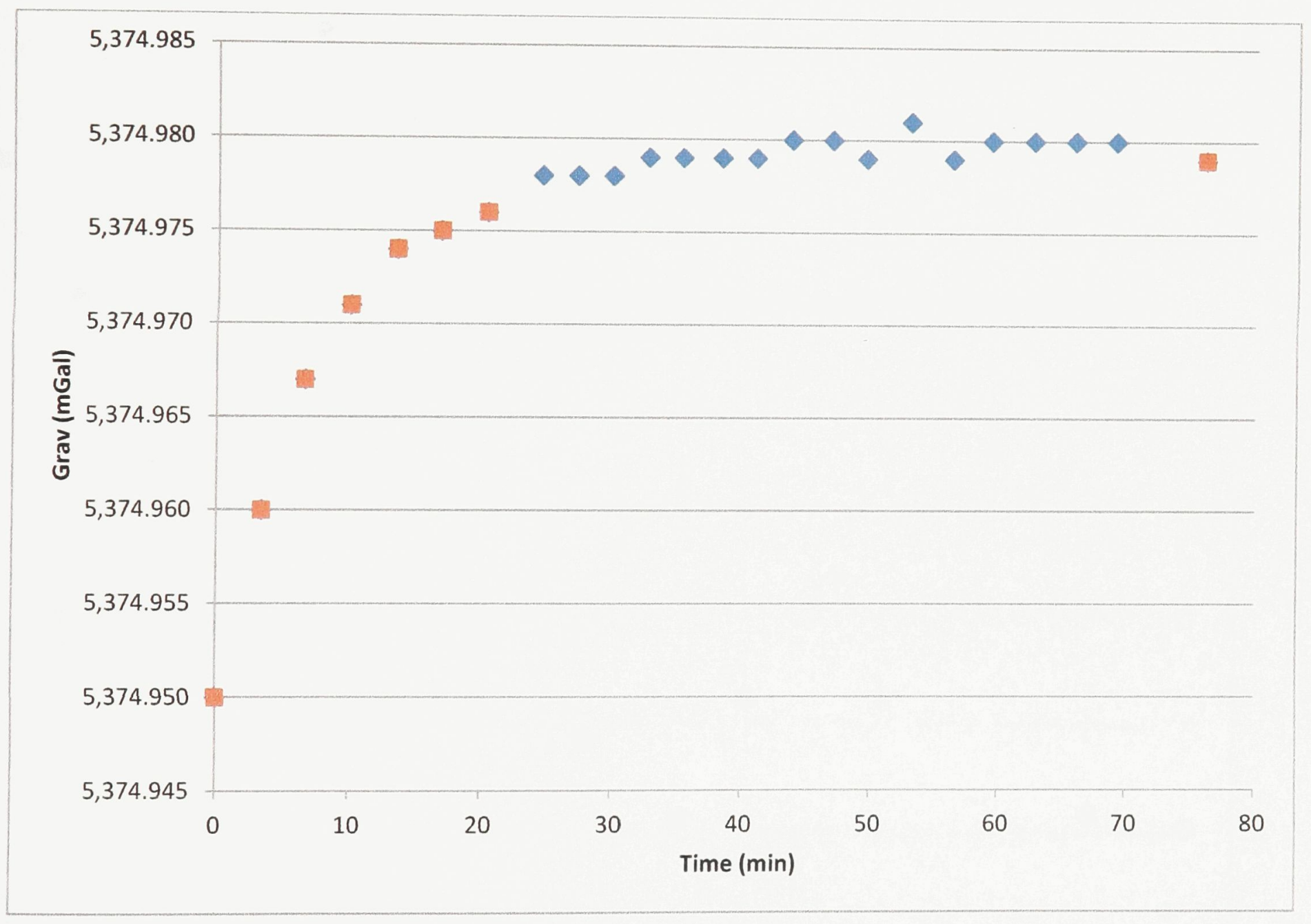

Figure 2-7: Measurement Error When Gravimeter is Kept Fixed Between Readings (Red Squares Omitted in Error Computation) 


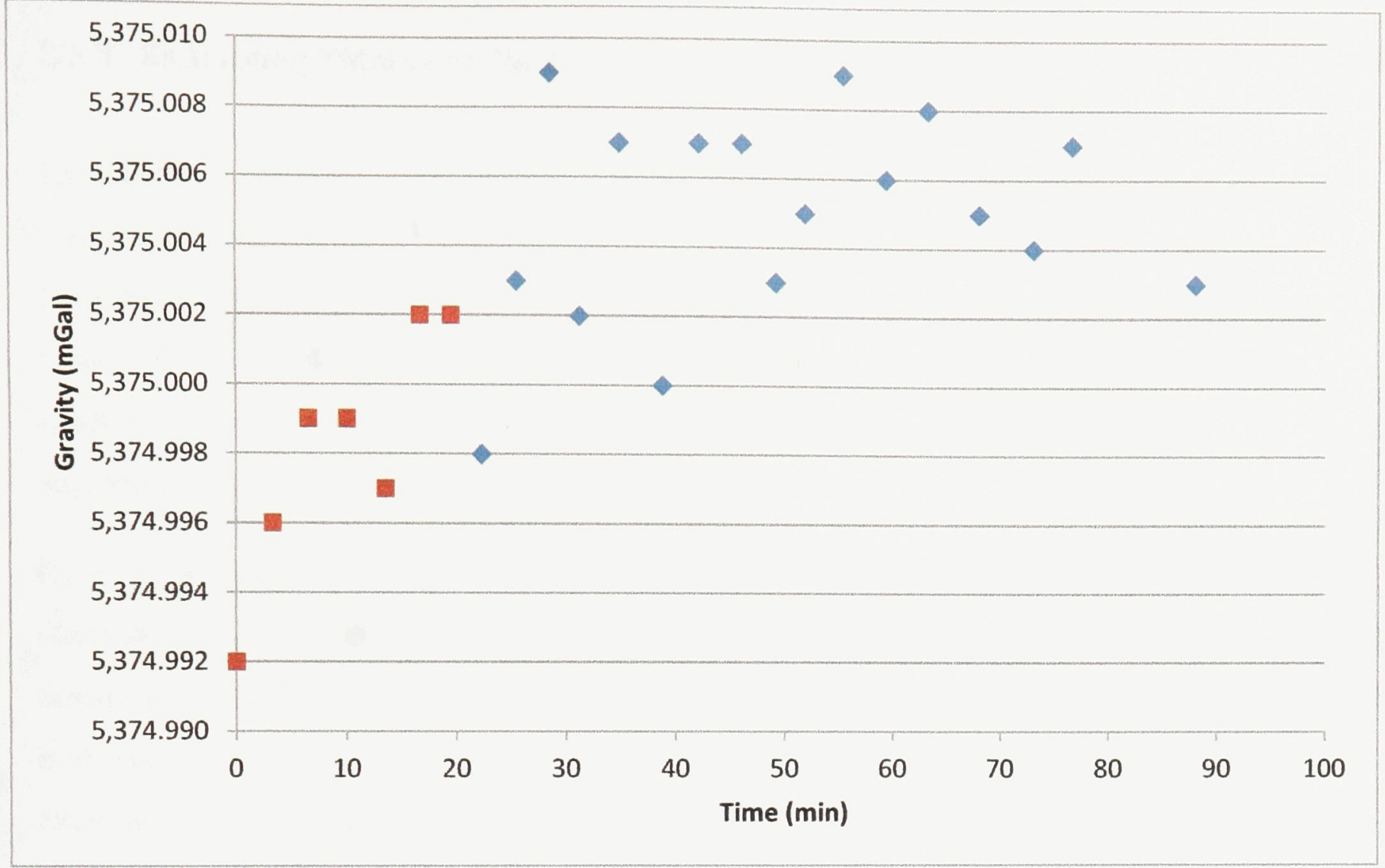

Figure 2-8: Measurement Error For Gravimeter When Releveled Between Readings (Red Squares Omitted in Error Computation)

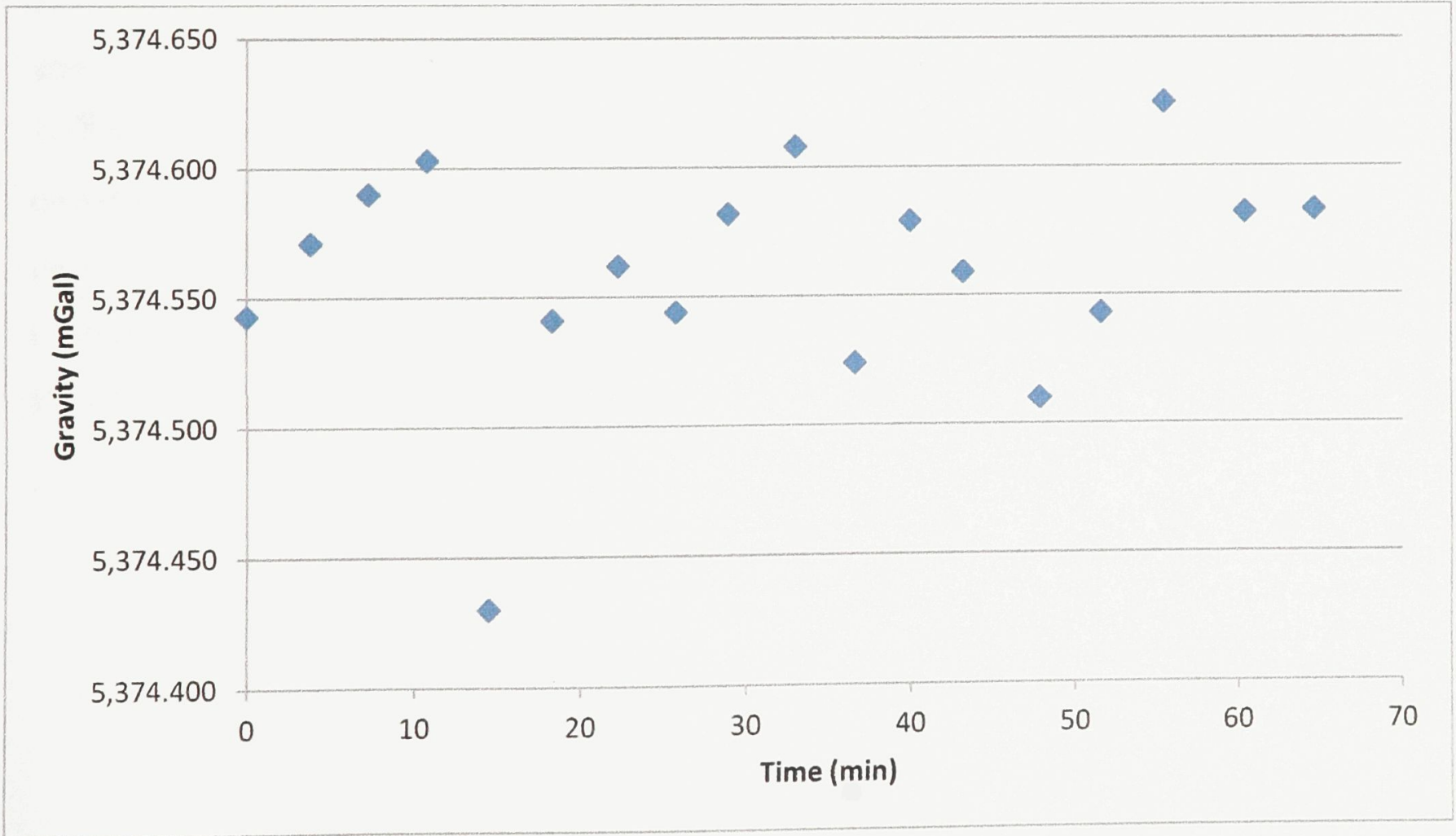

Figure 2-9: Measurement Error For Survey Conditions 


\subsubsection{Estimating Tidal Contributions}

To investigate the effects of the gravity pull of celestial bodies on the instrument, readings were taken approximately every fifteen minutes for twelve hours. A duration of twelve hours was used because it is roughly a half period for the effects of the sun and moon. The readings were taken indoors on a flat floor, and the instrument was not moved nor releveled between each reading. Random error was introduced to the readings due to construction occurring approximately $100 \mathrm{~m}$ from the instrument.

Figure 2-10 shows uncorrected data from the twelve hour trial. From section 2.3.2, the standard deviation of gravity readings in this setting should be on the same scale as the resolution of the instrument, $0.001 \mathrm{mGal}$. However, the standard deviation of these readings is $0.03 \mathrm{mGal}$ with a maximum deviation of $0.07 \mathrm{mGal}$. These tidal effects are removed via the external algorithm described in section 2.1.2. Figure 2-11 shows the gravity after the external algorithm described in 2.1.2 was applied to each reading to remove tidal effects. Note the scale of the fluctuations in this figure is smaller than those in the uncorrected plot. The standard deviation is now $0.004 \mathrm{mGal}$ with a maximum deviation of $0.02 \mathrm{mGal}$. This correction now places any fluctuations on the same scale as the measurement error of the instrument. Figure 2-12 shows the gravity after the internal algorithm was applied to each reading. The standard deviation of these readings is $0.005 \mathrm{mGal}$ with a range of $0.02 \mathrm{mGal}$. This algorithm does not perform as well as the external one, yet it still places any fluctuations on the same scale as the measurement of the instrument. Based on the results of this trial, the external algorithm was chosen to correct for tidal forces. 


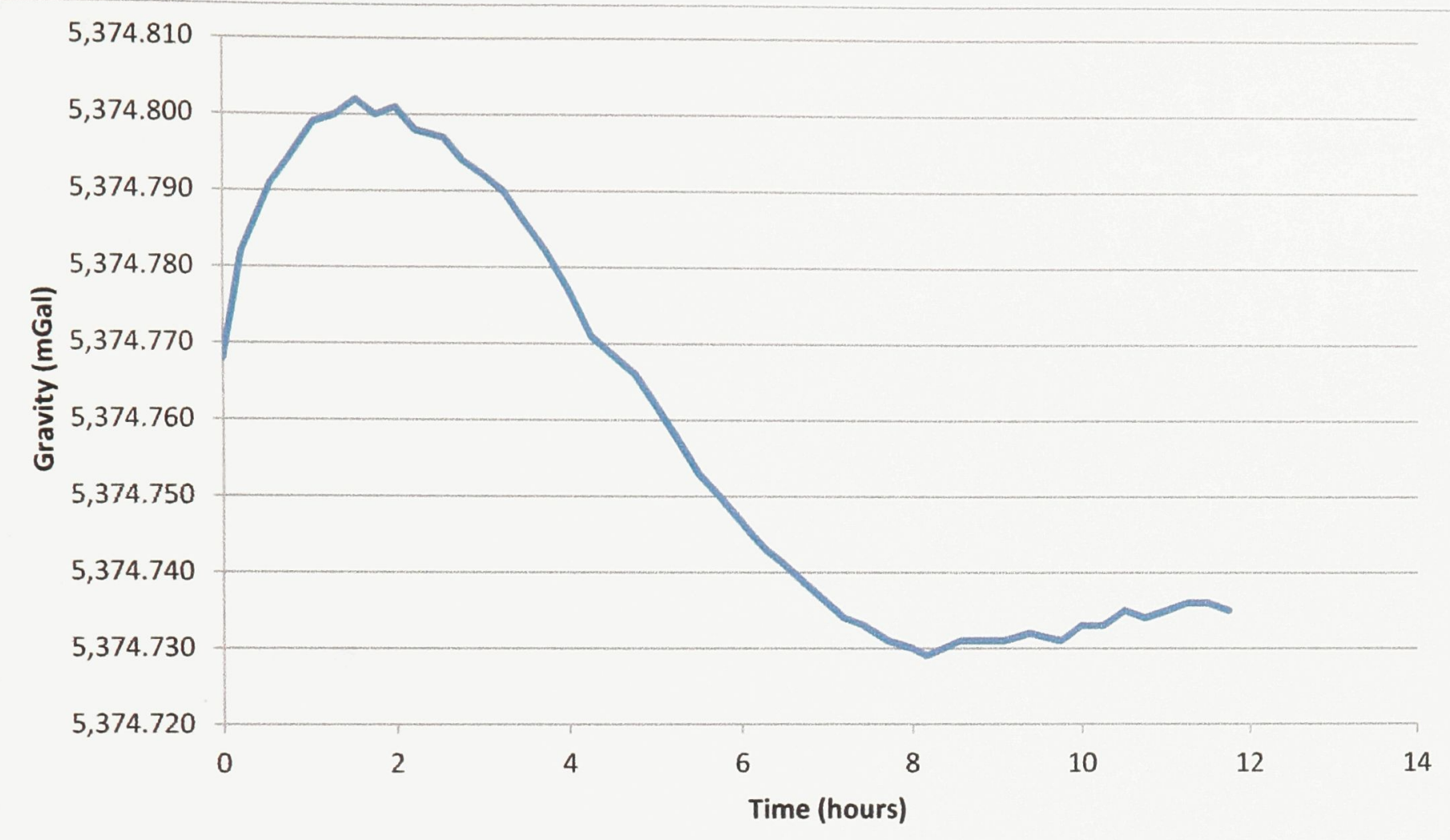

Figure 2-10: Uncorrected Gravity Data For Tidal Trial (Sampling Frequency Too High to Show Discrete Points)

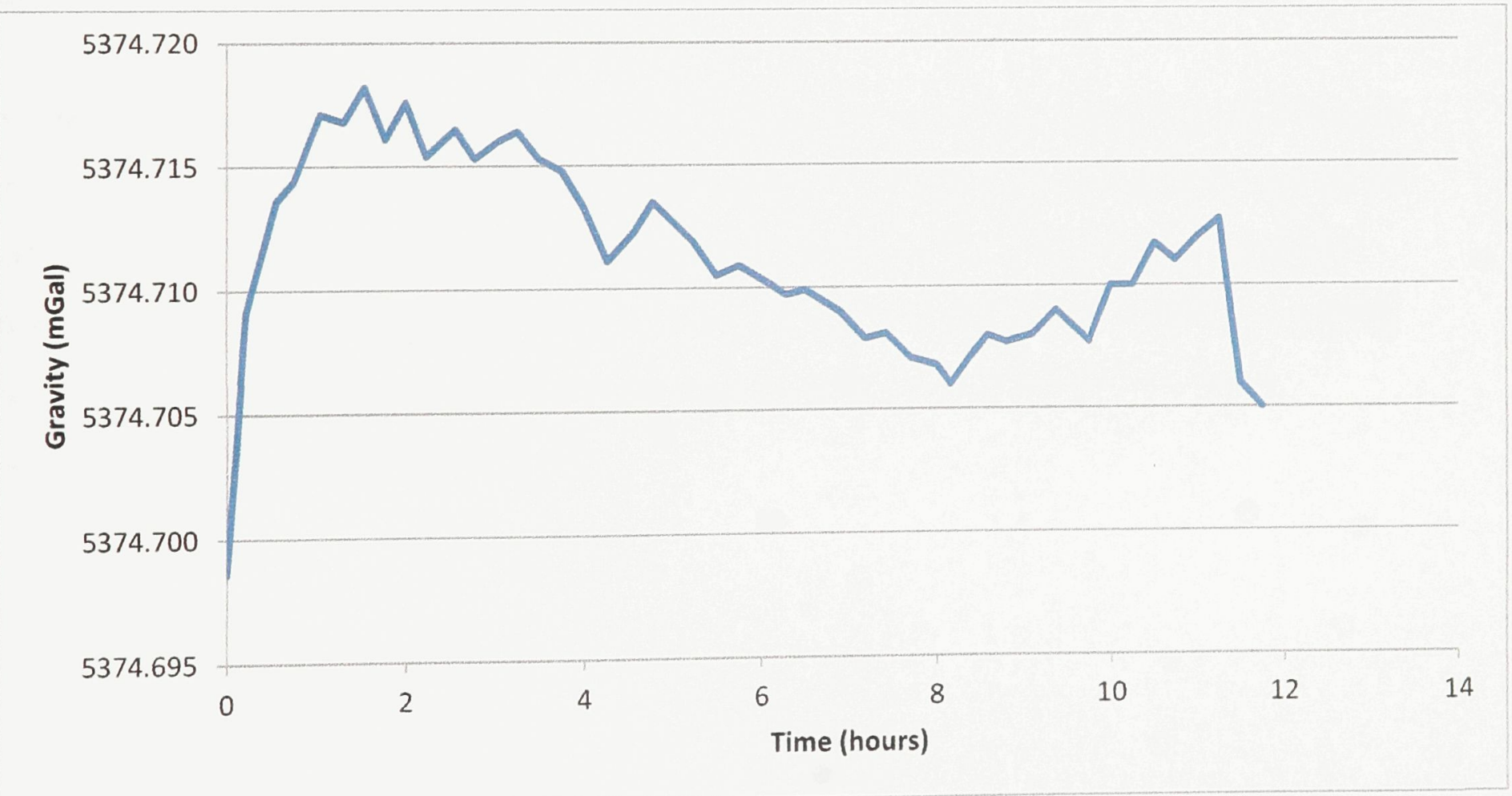

Figure 2-11: Tidal Corrected Gravity Data (External Algorithm) 


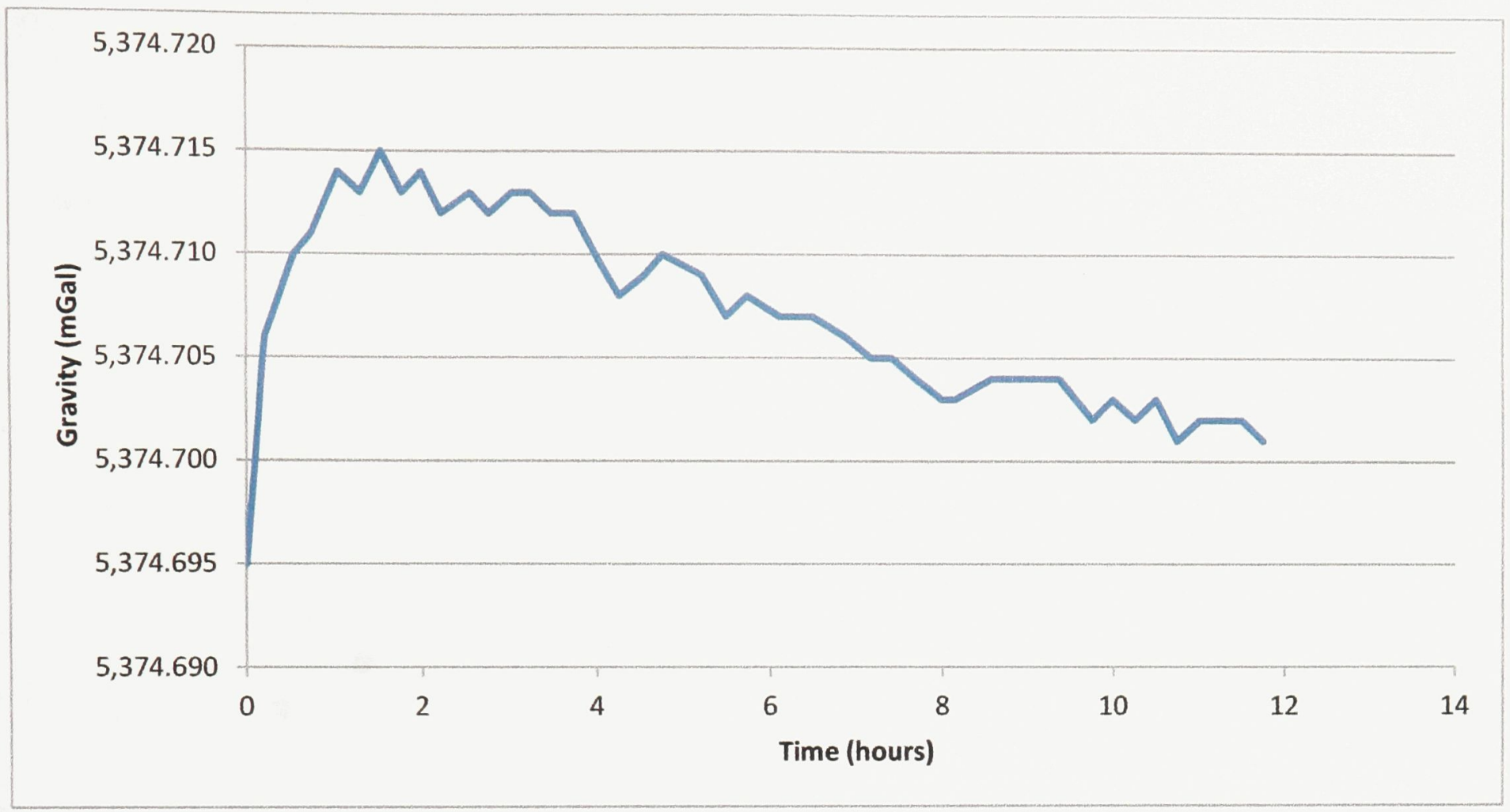

Figure 2-12: Tidal Corrected Gravity Data (Internal Algorithm)

\subsection{Settlement Overview}

In order to estimate the density of the waste, the thickness of the waste slab must be known, as is outlined in section 2.1.1. Due to settlement of the waste, the thickness of the slab may not be taken simply as the elevation differential between successive surveys. By the time a survey is done, the plane along which data from the previous survey has been acquired will have settled to a lower elevation (Figure 2-13). It is necessary to quantify this settlement in order to calculate the thickness of the waste slab. 


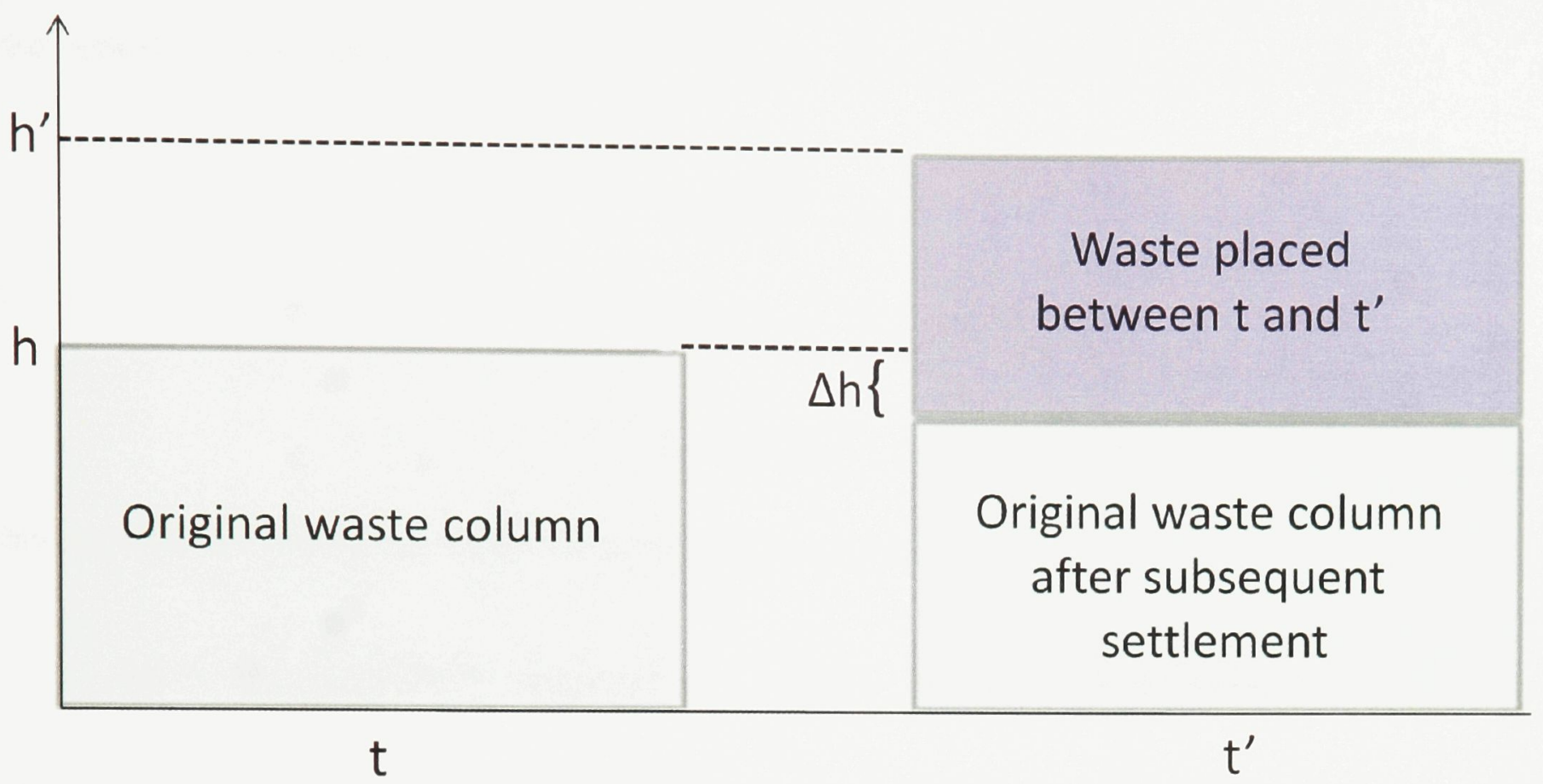

Figure 2-13: Evaluating the Thickness of Waste After Settlement

The settlement is characterized by analyzing the settlement records at discrete locations in the waste as measured by settlement gauges in instrument bundles. Refer to sections 2.2 .3 and 2.2.4 for information regarding these instruments. These settlement records are given context by fitting them to models developed for settlement in a bioreactor landfill.

Also, the effect of decreasing volume on the gravity as a result of settlement should be investigated. As the volume, $V$, of the underlying waste decreases, the density, $\rho$, increases. If this affects the gravity, then a correction must be applied to the gravity values acquired during the original survey. To investigate the magnitude of this effect, the density equation 2.6 must be analyzed:

$$
\begin{gathered}
\rho=-\frac{g}{2 \pi G h} \\
g=-\rho 2 \pi G h \\
\Delta g=-\left(\rho 2 \pi G h-\rho^{\prime} 2 \pi G h^{\prime}\right)
\end{gathered}
$$


where the density and waste thickness after settlement are $\rho^{\prime}$ (or $\rho-\Delta \rho$ )and $h^{\prime}$ (or $h-\Delta h$ ), respectively. The density after settlement will be (assuming infinite radius of Bouguer slab):

$$
\rho^{\prime}=\frac{m^{\prime}}{V^{\prime}}=\frac{m^{\prime}}{\pi r^{2}(h-\Delta h)}
$$

Assuming the mass of the waste does not change due to settlement $\left(m^{\prime}=m\right)$ :

$$
\rho^{\prime}=\frac{m}{\pi r^{2}(h-\Delta h)}
$$

Now, putting this density expression back into the $\Delta g$ expression:

$$
\Delta g=-\left(\left(\frac{m}{\pi r^{2} h}\right) 2 \pi G h-\left(\frac{m}{\pi r^{2}(h-\Delta h)}\right) 2 \pi G(h-\Delta h)\right)=\frac{2 G m}{r^{2}}-\frac{2 G m}{r^{2}}=0
$$

No change in gravity should be observed due to settlement alone; therefore, no correction is needed.

When empty pore space in the waste is filled in by leachate or precipitation fluid, the total mass will increase but the volume will remain the same, and the gravity will be affected accordingly:

$$
\begin{gathered}
\Delta g=\rho_{2} 2 \pi G h-\rho_{1} 2 \pi G h \\
\Delta g=\left(\rho_{2}-\rho_{1}\right) 2 \pi G h=\Delta \rho 2 \pi G h
\end{gathered}
$$

Note that in the case of the fluids vacating the pores space, this equation will simply yield a negative value.

For a given gravity resolution, the minimum density contrast that can be measured is:

$$
\Delta \rho=\frac{\Delta g}{2 \pi G h}
$$

The estimated measurement error found in section 2.3.2 was approximately $0.04 \mathrm{mGal}$, and a typical thickness of waste between surveys is $6 \mathrm{~m}$. Thus the minimum density contrast that could be measured with one reading would be: 


$$
\Delta \rho=\frac{0.04 \mathrm{mGal}}{2 \pi G \cdot 6 \mathrm{~m}}=0.16 \mathrm{~g} / \mathrm{cm}^{3}
$$

However, if instead of computing the density with each gravity reading, an average for a section or the entirety of the cell is computed, then a smaller density contrast may be observed. For example, a typical standard deviation of $0.15 \mathrm{mGal}$ would be observed over 90 gravity stations. Thus the standard deviation of the mean gravity in this section would be:

$$
\sigma_{\mu}=\frac{\sigma_{g}}{\sqrt{N}}=\frac{0.15 \mathrm{mGal}}{\sqrt{90}}=0.02 \mathrm{mGal}
$$

Where $\sigma_{\mu}$ is the standard deviation of the mean, $\sigma_{g}$ is the standard deviation of the gravity data, and $N$ is the number of gravity stations used to calculate the average gravity. This yields an error of half the measurement error, and thus the minimum density contrast that could typically be measured under the above circumstances would be $0.08 \mathrm{~g} / \mathrm{cm}^{3}$. This value is approximately $8 \%$ of the density of waste.

It has previously been shown that under the Bouguer slab approximation, a change in waste thickness does not affect the gravitational field strength measured directly above it. Therefore any change measured in the gravity of the waste must be due to a flux of mass in the landfill. So if the mass in the landfill increases or decreases while settlement occurs, only the density change caused by the mass flux will result in a gravity change.

Therefore the minimum density change that can be measured with this method depends on the number of survey stations in the section used for density computation, the standard deviation of those measurements, and the thickness of the waste slab. 


\subsubsection{Primary and Secondary Settlement}

The first model considered for modeling the settlement at the survey site was one resulting strictly from primary and secondary settlement due to the load of overlying mass.

Primary settlement is a time-dependent regime of settlement wherein the pore volume is filled in and the contained water is expelled. The skeleton is deformed from the motion and compression of the grains. After a theoretically infinite time, the amount of skeleton deformation will reach zero. Secondary settlement (creep) occurs when the grains are packed tightly enough together that they deform, resulting in further volumetric change [Verruijt, 2006].

Primary and secondary settlement models were adapted from soil mechanics principles by ElFadel and Al-Rashed (1998) and applied to settlement in a landfill as follows:

$$
\begin{gathered}
S_{s 1}=H_{0} C_{a 1} \log \left(\frac{t}{t_{i}}\right) ; t_{i}>t>t_{2} \\
S_{s 2}=H_{0} C_{a 2} \log \left(\frac{t}{t_{2}}\right) ; t>t_{2}
\end{gathered}
$$

where $S_{s 1}$ and $S_{s 2}$ are primary and secondary settlement, $H_{0}$ is the initial thickness of the waste, $C_{a 1}$ and $C_{a 2}$ are modified primary compression index and rate of secondary compression, respectively. Time $t_{i}$ is the end of the initial settlement period and $t_{2}$ is the time at which the slope of the stress-strain curve changes.

A drawback of this approach to modeling settlement at a bioreactor landfill is inherent in its logarithmic behaviour. A logarithmic function predicts a large strain at the end of the landfill's lifetime. In practice, the settlement should level-off at the end of the landfill's lifetime due to the end of biodegradation. Also, the use of the two equations (2.12a, 2.12b) by El-Fadel and AlRashed (1998) is simply an approximation since it assumes the two different models are active at different times rather than any overlap between the two, i.e. one regime starts after the other one stops. There is also difficulty in applying their model during periods of waste deposition [Hettiarachchi, 2007]. 


\subsubsection{Settlement Due to Biodegradation}

Hettiarachchi (2007) developed a model for settlement in a bioreactor landfill that incorporates terms for mechanic compression and biodegradation-induced strain. The model is as follows:

$$
\varepsilon(t)=\varepsilon_{m}+\varepsilon_{b, \max }[1-\exp (-\lambda t)](2.13)
$$

Where $\varepsilon(t)$ is the time-dependent total settlement, $\varepsilon_{m}$ is the mechanic settlement, and $\varepsilon_{b, \text { max }}$ is the maximum biodegradation-induced strain and is an amalgamation of several properties of the degradable solids. Variable $\lambda$ is the first-order kinetic constant.

Mechanical settlement is due to the filling of void space and compression of solid waste from the application of stress from the overlying mass. Compared to the lifetime of the landfill, the mechanical settlement is instantaneous upon the application of overlying stress.

Biodegradation-induced strain is due simply to the reduction of waste volume resulting from decomposition of biodegradable material.

Hettiarachchi (2007) applied this model to three data sets taken from bioreactor landfill cells, and each fit yielded coefficient of determination $\left(R^{2}\right)$ values ranging from 0.95 to 1.00 .

\subsubsection{Modeling of Settlement Data}

Using both models described by equations 2.12 and 2.13, the settlement data was fitted and equations were extracted to describe the settlement. Though settlement data was recorded by each instrument bundle, only data from instrument bundles nearest to the elevations of the gravity surveys (bundles 5 and 6 ) were analyzed, in order to best represent the settlement of the survey stations (Figure 2-5).

Difficulty in modeling the settlement data was encountered due to the fact that the cell was being filled as the preexisting waste was settling. Thus, the overlying load was not constant during the settlement, and the densities of the overlying waste varied depending on when it 
was deposited. Due to these difficulties, the settlement was fitted by the models mentioned above only during times following periods of deposition, when the mass of the overlying load remained approximately static. When necessary, the total settlement experienced during periods of deposition was simply added as a constant to the models.

All fitting was done via a $\mathrm{C}++$ compiler using methods available from ROOT [ROOT]. ROOT is a system of object-oriented frameworks intended for use in data analysis made available by The European Organization for Nuclear Research (CERN). The settlement data was fitted using a method that employs chi-squared minimization to find the best possible fit. In order to perform this fit, the program calculates the chi-squared test statistic as follows:

$$
X^{2}=\sum_{i=1}^{n} \frac{\left(O_{i}-E_{i}\right)^{2}}{E_{i}}
$$

where the $O$ values are the observed settlement values and the $E$ values are the theoretical settlement values calculated from the models. The program varies the parameters in the model equations until it finds a minimum value for the chi-squared test statistic [ROOT]. 


\section{Survey Overviews}

Overviews of each of the five surveys are presented in the sections below, and are summarized in Table 3-1.

Table 3-1: Summary of Survey Overviews

\begin{tabular}{|c|c|c|c|c|c|c|c|}
\hline Survey & Date & $\begin{array}{l}\text { Base } \\
\text { Station }\end{array}$ & $\begin{array}{c}\text { Instrument } \\
\text { ID }\end{array}$ & $\begin{array}{c}\text { Number } \\
\text { of } \\
\text { Stations }\end{array}$ & $\begin{array}{l}\text { Surface } \\
\text { Conditions }\end{array}$ & $\begin{array}{l}\text { Weather } \\
\text { Conditions }\end{array}$ & $\begin{array}{l}\text { Avg. Standard } \\
\text { Dev. of } \\
\text { Measurements } \\
\text { (mGal) }\end{array}$ \\
\hline 1 & $\begin{array}{c}\text { July } 20-23 \\
2009\end{array}$ & A & 40004 & 195 & $\begin{array}{l}\text { Dry, flat } \\
\text { gravel }\end{array}$ & Dry, warm & 0.04 \\
\hline 2 & $\begin{array}{c}\text { June } 22-24 \\
2010 \\
\end{array}$ & B & 40490 & 109 & $\begin{array}{l}\text { Dry, firm, } \\
\text { flat waste }\end{array}$ & Dry, warm & 0.09 \\
\hline 3 & $\begin{array}{c}\text { April 15, 16, } \\
22,2011\end{array}$ & B & 40498 & 135 & $\begin{array}{l}\text { Moist, very } \\
\text { soft, } \\
\text { uneven } \\
\text { waste }\end{array}$ & $\begin{array}{l}\text { Brief rain, } \\
\text { cool, windy }\end{array}$ & 0.07 \\
\hline 4 & $\begin{array}{c}\text { Nov } 11-13 \\
2011\end{array}$ & B & 40498 & 88 & $\begin{array}{l}\text { Fairly dry, } \\
\text { firm, } \\
\text { uneven } \\
\text { waste }\end{array}$ & $\begin{array}{l}\text { Brief rain, } \\
\text { cool, windy }\end{array}$ & 0.09 \\
\hline 5 & $\begin{array}{c}\text { April 14, 15 } \\
2012\end{array}$ & B & 40498 & 95 & $\begin{array}{c}\text { Very dry, } \\
\text { flat waste, } \\
\text { heavy } \\
\text { machinery } \\
\text { nearby }\end{array}$ & $\begin{array}{l}\text { Dry, cool, very } \\
\text { windy }\end{array}$ & 0.18 \\
\hline
\end{tabular}

\subsection{Survey 1 (July 2009)}

Survey 1 was performed between July 20 and July 22, 2009. The survey was done primarily in the northeasternmost section of phase 3 , in zone 4 of the facility, and comprised of the stations (blue) illustrated in Figure 3-1. Also included in this survey were a few lines that spanned into the southwest section in order to obtain an understanding of any larger trends in the cell. Station spacing was, for the most part $5 \mathrm{~m}$ by $5 \mathrm{~m}$, but increased to $10 \mathrm{~m}$ in some of the southwest locations. Stations on the far north edge in Figure 3-1 were located on top of a gravel berm approximately $2 \mathrm{~m}$ higher than the rest of the cell and, for this reason, the spacing of these stations is not consistent with the spacing of the other stations. 
During survey 1 and similarly for all the subsequent surveys, a break is taken approximately every two hours to return to a base station and take 2-5 measurements in order to characterize the internal drift effects. Initially, data from survey 1 was going to be used with data from subsequent surveys to extract density values for the waste between them; however, this idea became unfeasible after the base station used for survey 1 was lost. The survey 1 base station (termed "base station A"), located at 5070859.0, 237204.5 alongside the northeast edge of the cell, became unusable after it became buried under soil when the landfill management reconfigured the access roads in the area. Without readings at a common reference station at fixed coordinates and elevations, gravity data from different surveys cannot be tied together and directly compared.

Survey 1 was performed before any waste was placed in the cell. At that time, the cell was lined with a layer of gravel and was fairly flat, as can be seen in Figure 3-2. Such conditions allowed for a relatively low measurement error as the gravimeter could remain easily leveled on the gravel; also, water and soil mounds were not present, and thus need not be avoided. The average standard deviation of the measurements in this survey was $0.04 \mathrm{mGal}$, which is comparable to the minimum expected measurement error of $0.04 \mathrm{mGal}$ mentioned in section 2.4.2. 


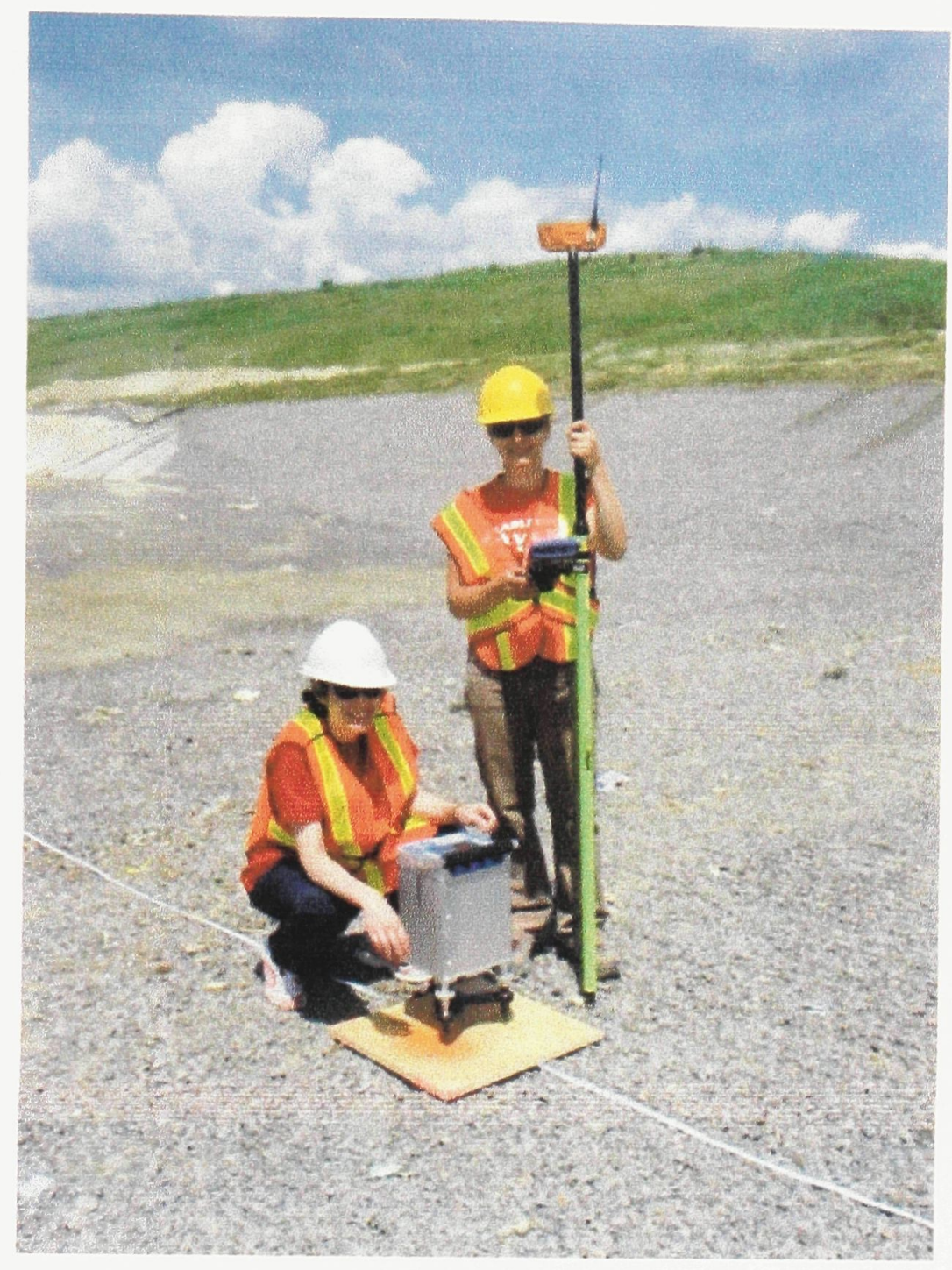

Figure 3-2: Empty Cell During Survey 1

\subsection{Survey 2 (June 2010)}

Survey 2 was performed between June 22 and June 24, 2010. A survey map is shown in Figure 3-3, with the same surrounding box as in Figure 3-1 for spatial reference. Station spacing was 5 $\mathrm{m}$ by $5 \mathrm{~m}$. It should be noted that since the berm present in survey 1 was only $2 \mathrm{~m}$ in height, it was buried approximately $3 \mathrm{~m}$ below the surface when survey 2 took place, so it was not an issue.

Base station B was used during this survey, which is located in the parking lot of the main facility building; a better location in the sense that it is less likely to be modified by the landfill 
management. Base station B was also used for survey 3 (and all subsequent surveys), and the data from surveys 2 and 3 was compared in order to extract a density value for the waste between them.

Approximately $5 \mathrm{~m}$ of waste was contained in the cell at the time of survey 2 . As opposed to the conditions in survey 1 , the waste is neither as level nor as firm as the gravel as can be seen in Figure 3-4; thus measurement error was greater due to both the difficulty in leveling the gravimeter before each measurement, and the gravimeter settling slightly during the measurement. The instrument takes 120 readings for each measurement and computes an average value. As one side of the instrument settles more than the other sides during that time period, the average will be skewed as the gravimeter becomes progressively less leveled. The conditions were still fairly dry, and no water accumulations had to be avoided. The average standard deviation of the measurements during survey 2 was $0.09 \mathrm{mGal}$, which is more than twice the minimum expected measurement error computed in section 2.4.2. 


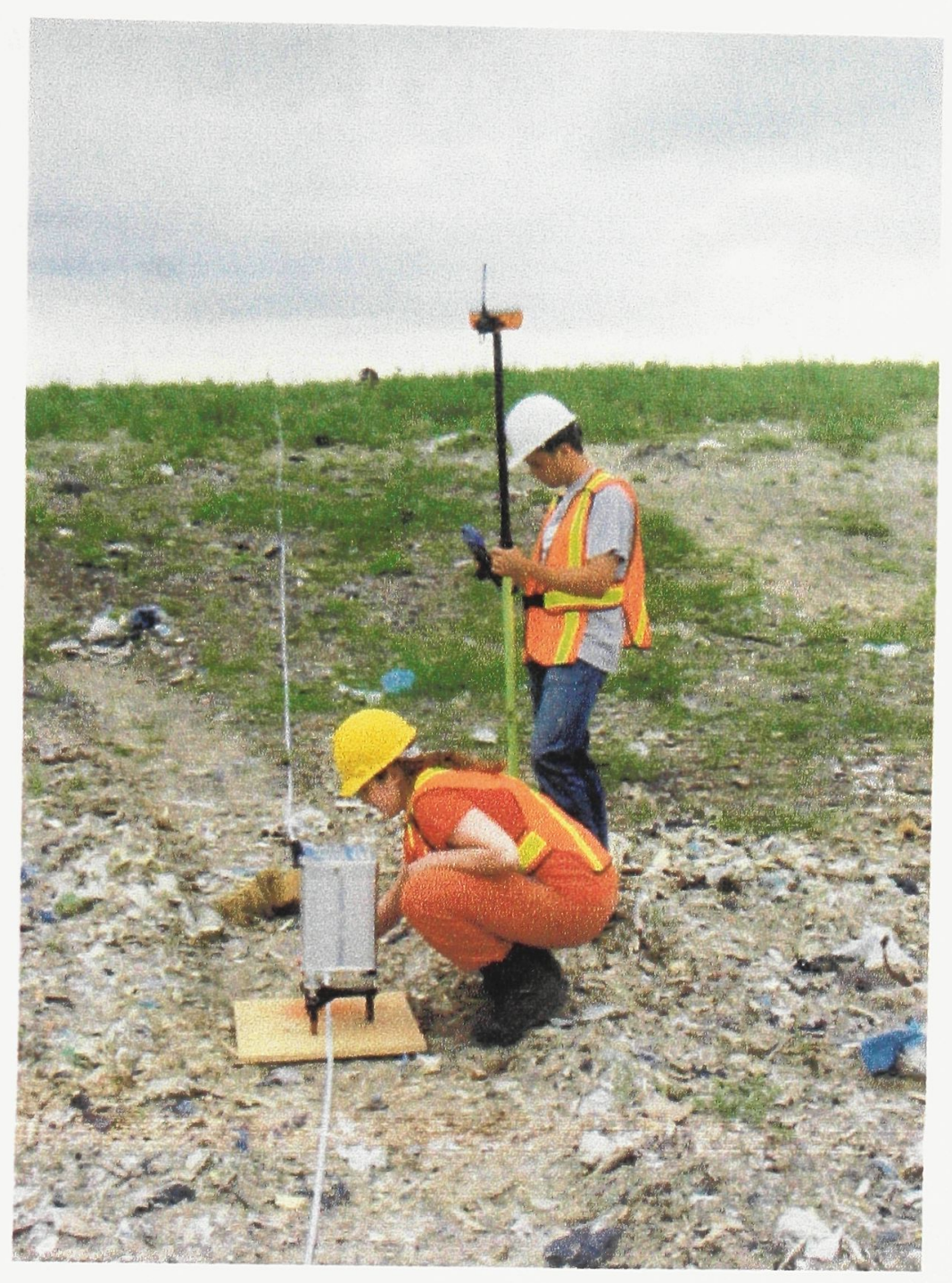

Figure 3-4: Cell During Survey 2

\subsection{Survey 3 (April 2011)}

Survey 3 was performed on April 15, 16, and 22, 2011. It was necessary to split the survey into two separate trips. During the first trip, the gravimeter batteries malfunctioned and could not maintain a charge; therefore the survey had to be abandoned on the morning of April 16 (only base station data was obtained on that day) and completed the following weekend. Fortunately for continuity purposes, the environmental conditions remained similar to those in the first trip. The survey was done in the northeasternmost section of phase 3 , in zone 4 of the facility, and comprised of the purple squares illustrated in Figure $3-5$. In this figure, the surrounding box is in 
the same location as for surveys 1 and 2 for spatial reference. Station spacing was $5 \mathrm{~m}$ by $5 \mathrm{~m}$. Base station B was again used.

Survey 3 was done over approximately $13 \mathrm{~m}$ of waste (plus or minus $0.5 \mathrm{~m}$ in some places). Surface conditions, however, were quite different than during the survey 2 (Figure 3-6). The waste and overlying clay were quite moist and soft, resulting in localized accumulations of water. This resulted in the loss of several survey stations, and added difficulty in accessing most other stations. The average standard deviation of the measurements during survey 3 was 0.07 mGal. Heavy machinery and large mounds of cover soil were stored on the cell, and had to be avoided during surveying in order to minimize their gravitational effects.

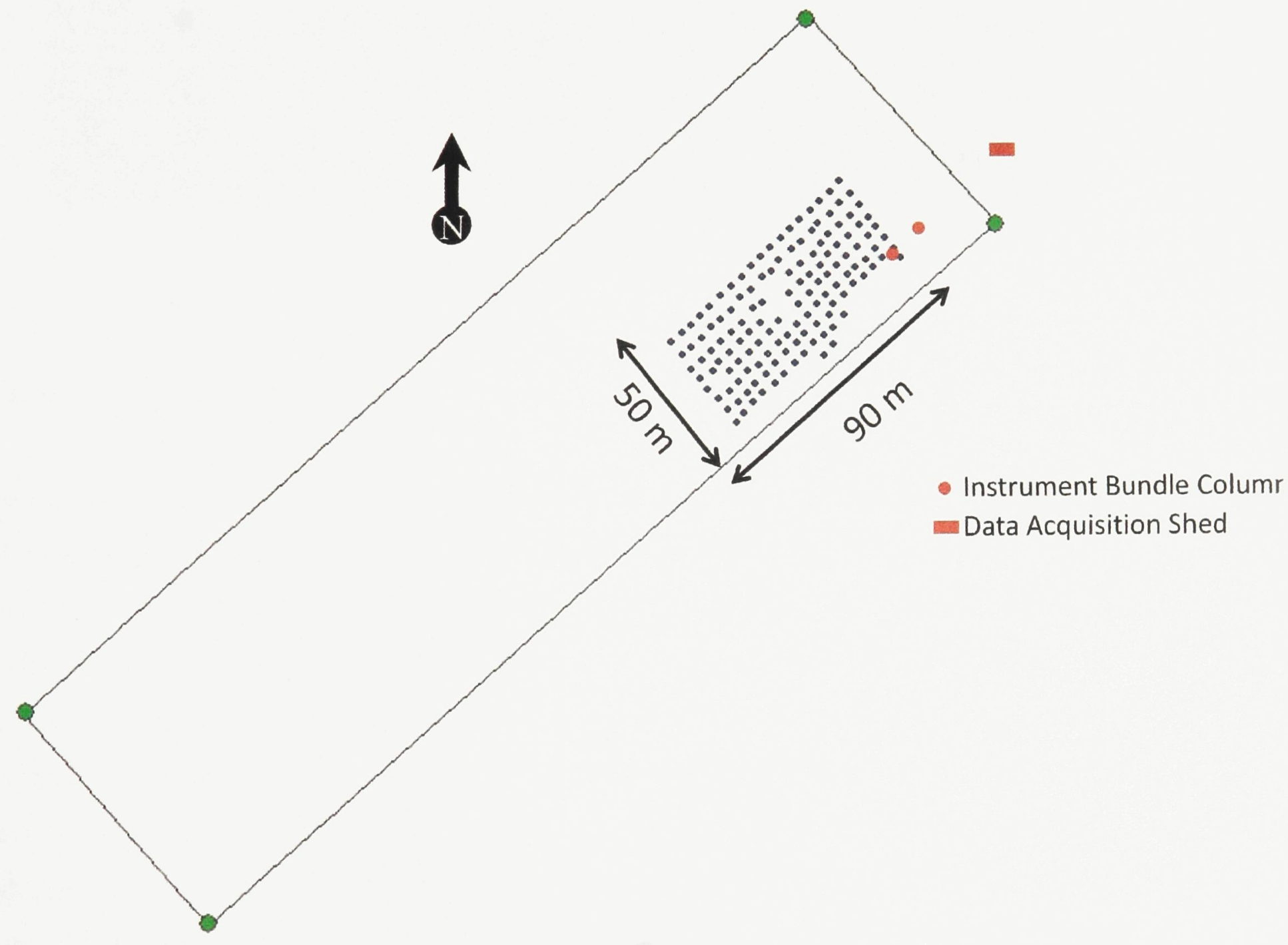

Figure 3-5: Survey 3 Stations 


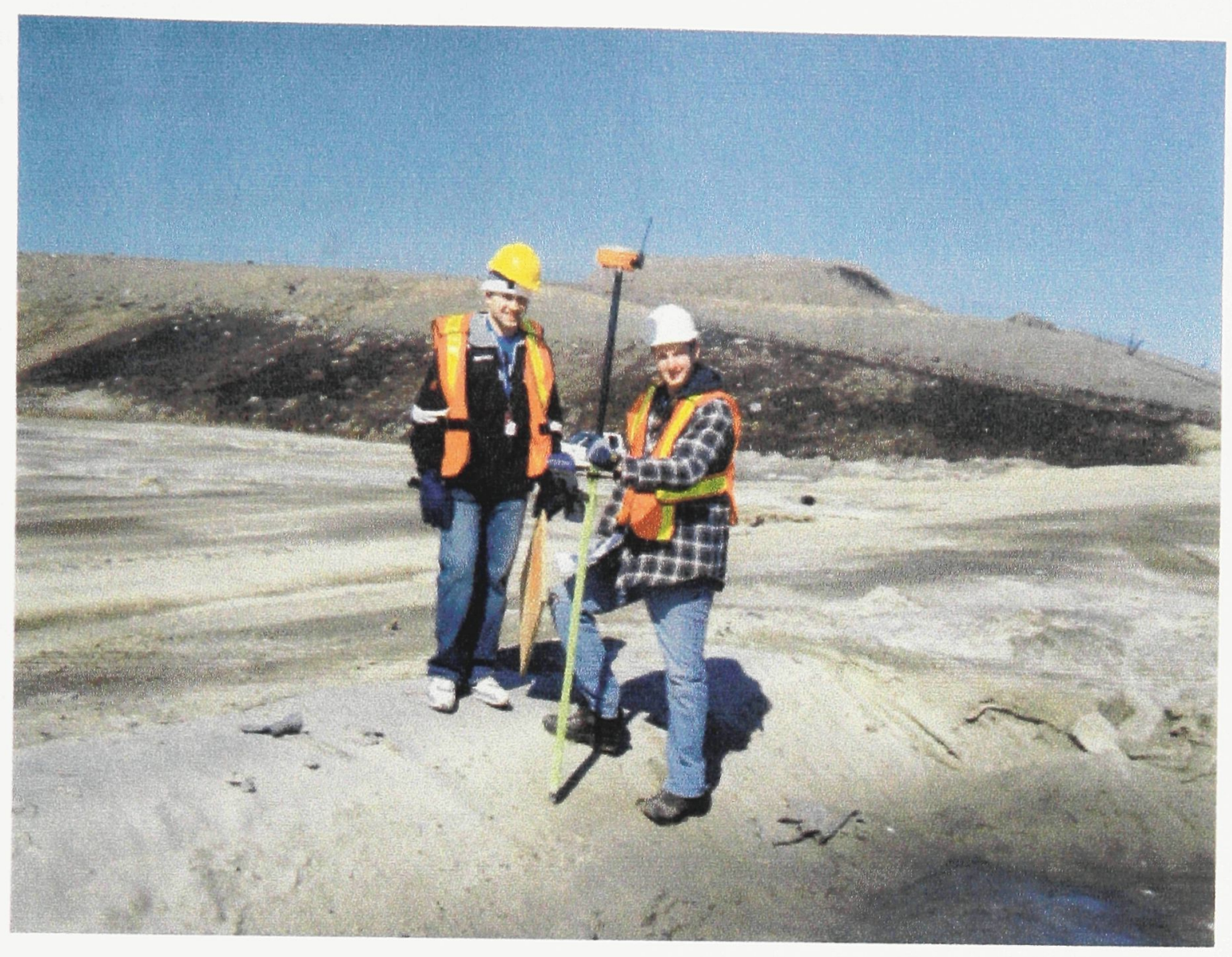

Figure 3-6: Cell During Survey 3

\subsection{Survey 4 (November 2011)}

Survey 4 was performed between November 11 and 13, 2011. The survey was done over most of the surface area of phase 3 , in zone 4 of the facility, and comprised of the green squares illustrated in Figure 3-7. Station spacing was $10 \mathrm{~m}$ by $10 \mathrm{~m}$ in order to cover a larger area than in previous surveys. Visible in Figure 3-7, the lengths of the lines were reduced to only two stations in the middle of the cell as a result of heavy machinery stored near that location, and in the northern portion of the diagram the stations have shifted to the left to avoid a large mound of soil. It should be noted that all of the data was collected on November 12 and 13 due to a small amount of persistent rain throughout the day on November 11. Only base station measurements were taken on November 11. On November 12, a small amount of rain occurred for a few hours, limiting the amount of data that could be recorded. As the rain was only light 
during those two days, the conditions of the waste and soil remained quite dry and ideal for surveying (Figure 3-8).

Base station B was used again. The purpose of survey 4 was to obtain gravity data in order to develop an understanding of density and settlement trends over a larger area than that covered in surveys 2 and 3.

The height of the waste during survey 4 was approximately $17 \mathrm{~m}$, as can be seen in Figure 3-8, but near the southwest portion of the cell, the waste column is as much as $2 \mathrm{~m}$ lower due to a slight slope downward. Heavy machinery and large mounds of cover soil were stored on the cell, and once again had to be avoided; however, the waste and soil were quite dry compared to survey 3 . The average standard deviation of the measurements was $0.09 \mathrm{mGal}$. 


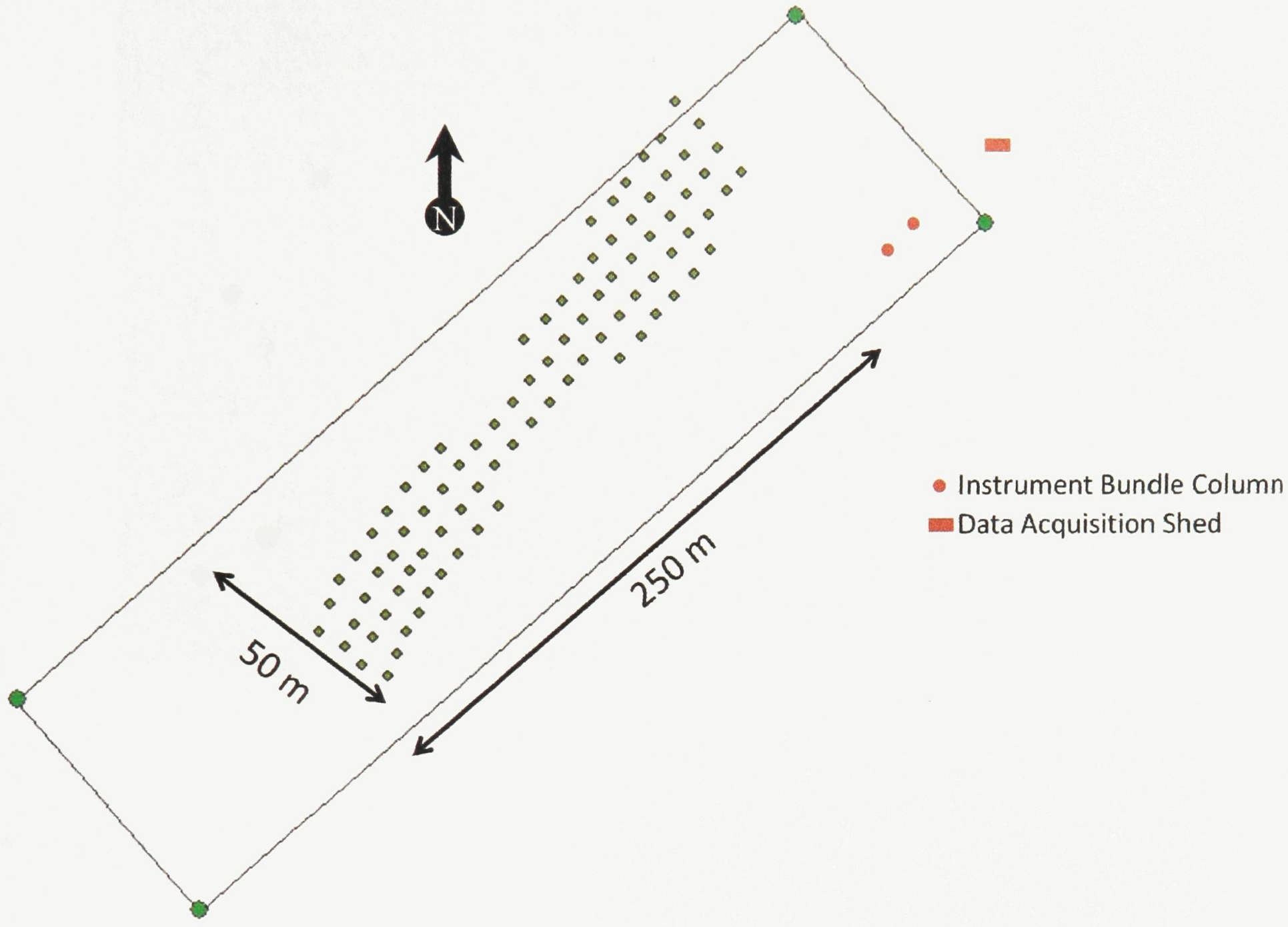

Figure 3-7: Survey 4 Stations 


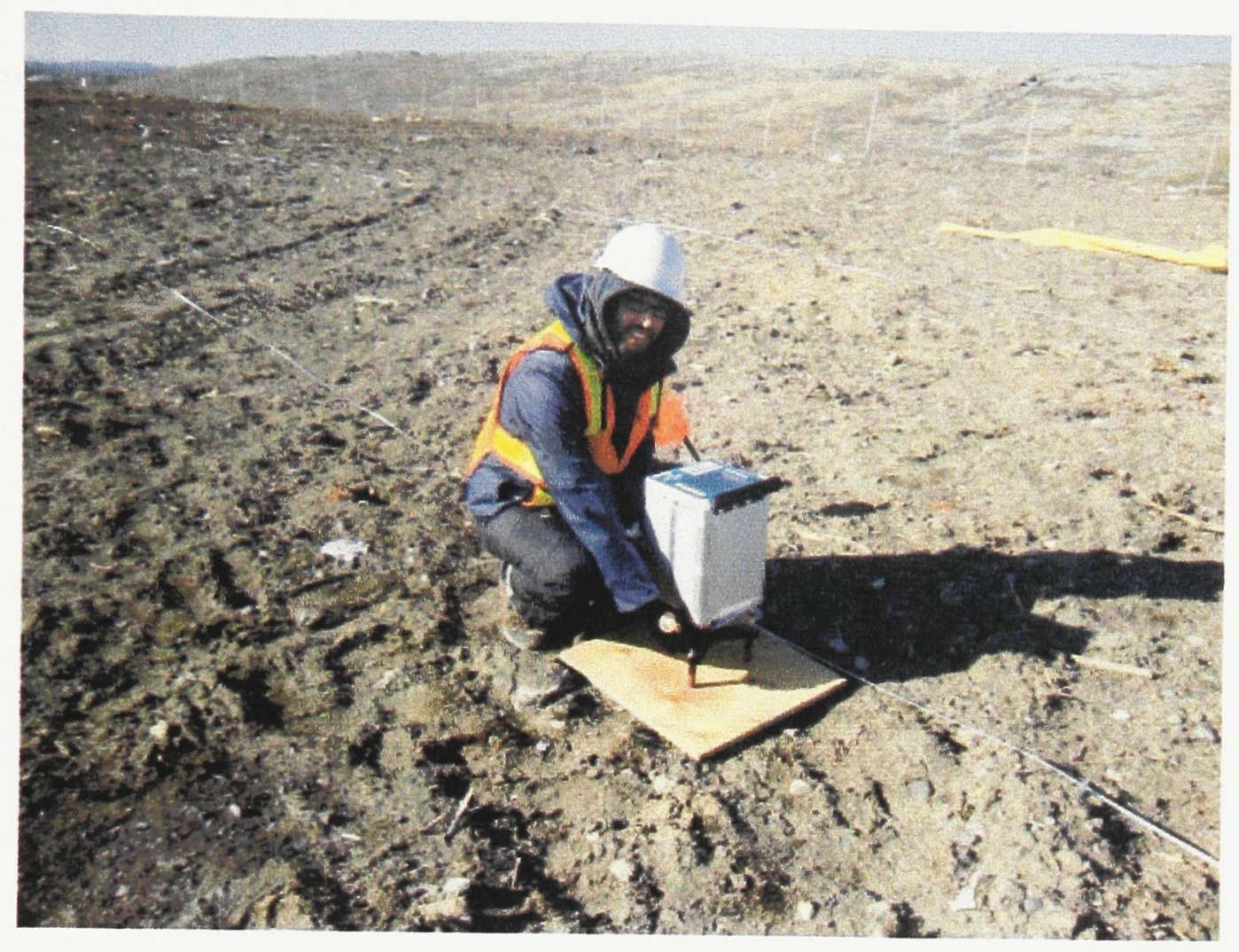

Figure 3-8: Cell During Survey 4

\subsection{Survey 5 (April 2012)}

Survey 5 was performed on April 14 and 15, 2012. The survey was done over most of the surface area of Phase 3 , in zone 4 of the facility, and comprised of the red squares illustrated in Figure 3-9. Station spacing was $10 \mathrm{~m}$ by $10 \mathrm{~m}$. As seen in Figure 3-7 and Figure 3-9, several stations from survey 4 could not be reoccupied during survey 5 due to blockage by heavy machinery or soil mounds. Most notably, two lines at the far northeast of the cell and stations along the easternmost edge were lost, as well as several stations along the edge in the southwest of the cell. Base station B was used again in order to allow comparison between data from surveys 4 and 5 .

On average, the height of the waste during survey 5 was a few centimeters less than the height during survey 4. No waste was deposited between the two surveys, and the slight drop in elevation is likely due to a small amount of settlement. The reason for performing survey 5 at this time was to obtain an understanding of settlement and density of waste over time when no 
further waste is added. During survey 5, the waste and soil were at their driest and flattest; however, the survey was again impeded by mounds of cover soil and heavy machinery. Also, the wind was strong, which greatly affected the measurement error of the gravimeter as the instrument swayed back and forth slightly during each reading, and heavy machinery was in operation in the adjacent phase (Phase 2), resulting in seismic disturbances. In fact, the average standard deviation during this survey was $0.18 \mathrm{mGal}$, which is more than four times the minimum expected measurement error computed in section 2.4.2. Due to this effect, many stations had to be repeatedly measured until the standard deviation and rejected counts of the measurements was comparable to other stations in the survey.

Figure 3-10 shows the areas covered by each survey overlain to put into perspective their relative sizes and positions. 


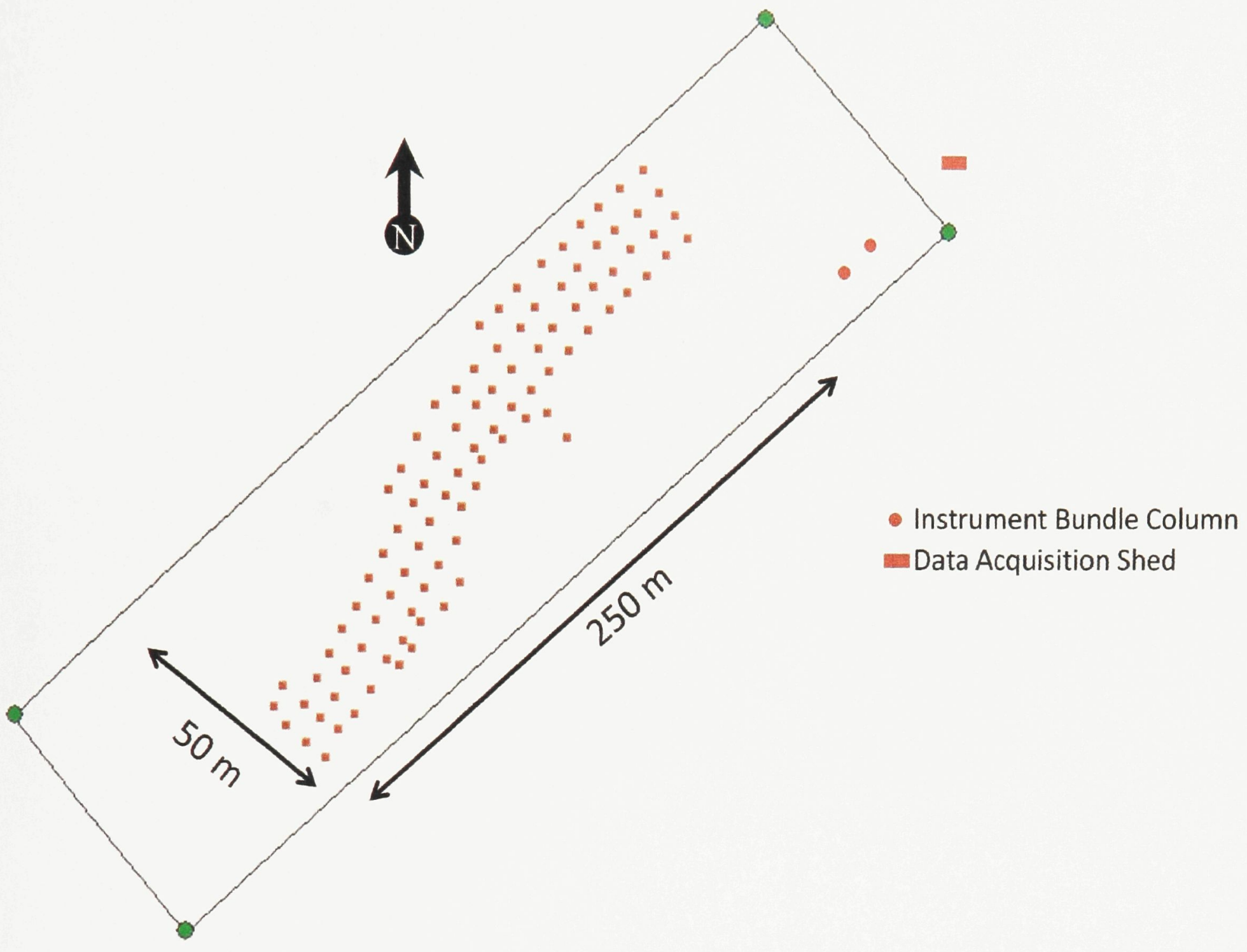

Figure 3-9: Survey 5 Stations 


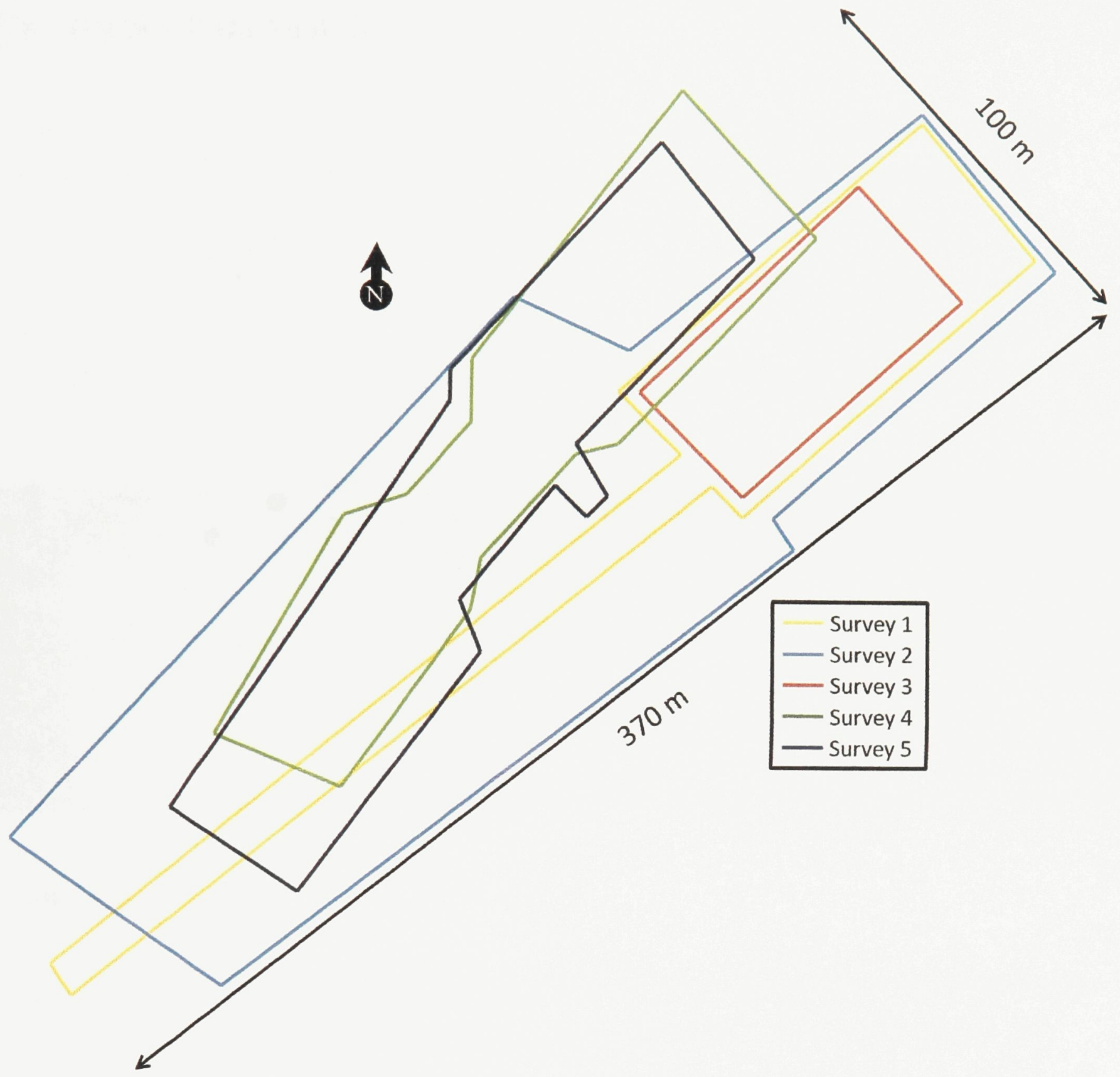

Figure 3-10: Overlay of All Survey Areas 


\section{Gravity Data Analysis}

The results of each gravity survey are presented in the following sections and are summarized below in Table 4-1. The minimum and maximum values simply show how much the gravity varies across the cell during a particular survey. The average values are not necessarily redatumed to any other survey, and are presented only for comparison with maximum and minimum values. The gravity and elevation maps in this section were produced with ArcGIS software, which extrapolated between survey stations to produce continuous plots.

Table 4-1: Summary of Gravity Survey Data

\begin{tabular}{|c|ccccc|cccccc|}
\hline Survey & \multicolumn{9}{c|}{ Corrected Gravity [mGal] } & \multicolumn{5}{c|}{ Elevation [m] } \\
\cline { 2 - 13 } & Min & Max & Difference & Average & St.Dev. & Min & Max & Difference & Average & St.Dev. \\
$\mathbf{1}$ & 4814.82 & 4815.67 & 0.85 & 4815.20 & 0.23 & 69.39 & 75.05 & 5.66 & 71.82 & 1.52 \\
$\mathbf{2}$ & 5259.29 & 5259.92 & 0.63 & 5259.55 & 0.15 & 76.09 & 80.28 & 4.19 & 78.06 & 1.19 \\
$\mathbf{3}$ & 5259.39 & 5260.70 & 1.31 & 5260.17 & 0.15 & 84.24 & 86.51 & 2.27 & 85.49 & 0.54 \\
$\mathbf{4}$ & 5259.77 & 5260.88 & 1.11 & 5260.35 & 0.15 & 88.81 & 91.81 & 3.00 & 90.52 & 0.96 \\
$\mathbf{5}$ & 5846.88 & 5847.85 & 0.97 & 5847.24 & 0.15 & 88.17 & 91.61 & 3.44 & 90.11 & 0.85 \\
\hline
\end{tabular}

\subsection{Survey 1}

Survey 1 was conducted over the empty cell. Figure 4-1 shows the elevation data obtained from the entire survey 1 , including a line of stations that traverses the complete length of the cell, and one cross-line further towards the southwest end of the cell. The northeast end of the cell was surveyed the most extensively with a station spacing of $5 \mathrm{~m}$. The elevation of this section of the cell is fairly uniform, with an average elevation of $72.1 \mathrm{~m}$ and a standard deviation of $0.4 \mathrm{~m}$, excluding the gravel berm located along its northwest edge which has an average elevation of $75.0 \mathrm{~m}$ and a standard deviation of $0.05 \mathrm{~m}$. The northeast end is the highest part of the cell and slopes slightly downward to the southwest. If the waste is filled to a uniform elevation, it should be noted that there would be approximately $3 \mathrm{~m}$ more waste in the southwest end of the cell than the northeast due to this slope in the empty cell. 


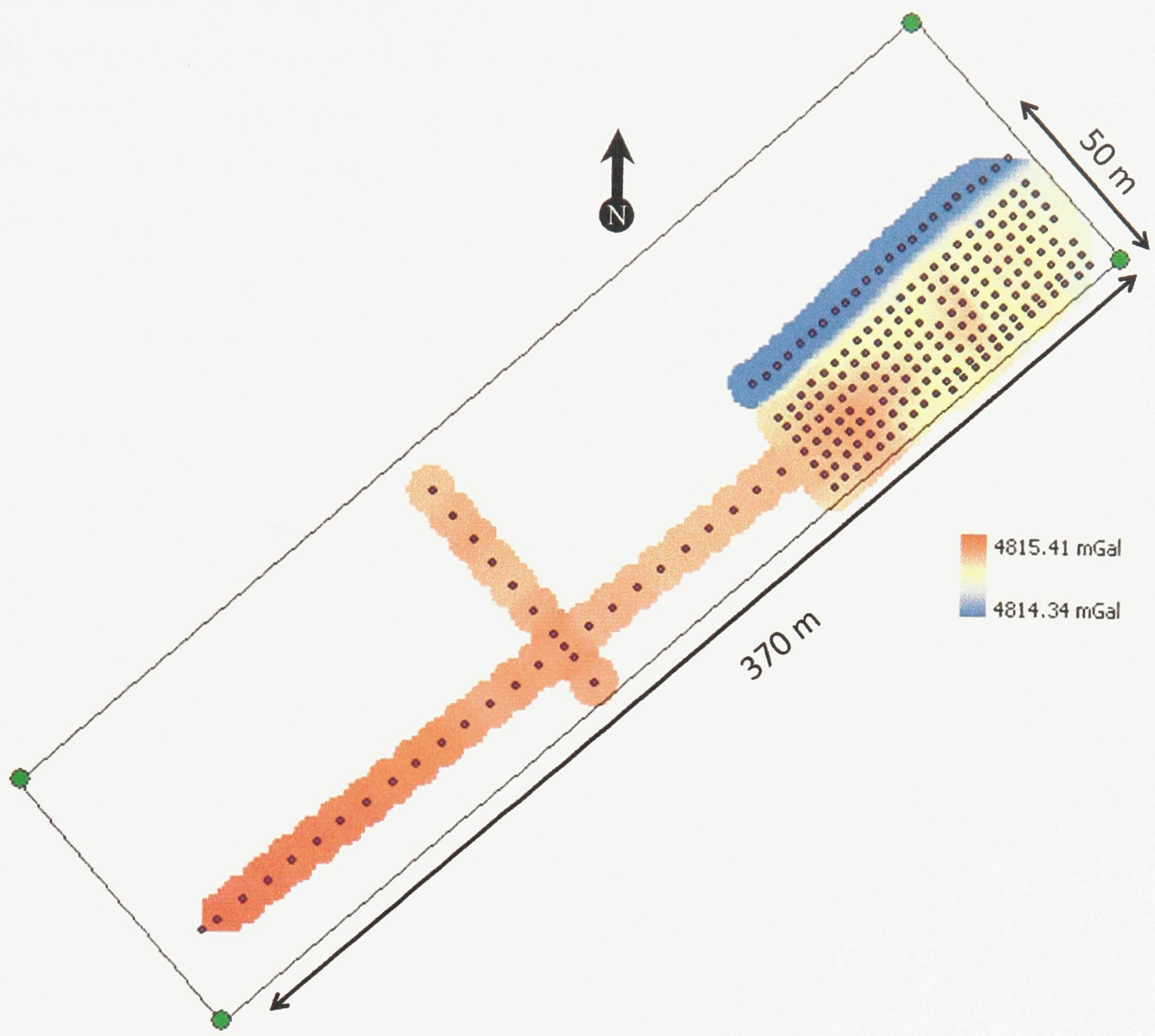

Figure 4-2: Gravity Map of the Entire Cell of Survey 1 (Before Elevation Corrections)

Figure 4-3 shows the gravity data after corrections for elevation (as well as for tides and drift) were applied. This was done to identify any gravity trends that span the entirety of the cell. The gravity in this figure is corrected for elevation, and should therefore reflect only density variations of the underlying material. For example, as seen in Figure 4-3, the gravel berm which is denser than the surrounding material has higher values of gravity. Aside from the gravel berm, the gravitational field of the empty cell is quite uniform. The standard deviation of the gravity data excluding the berm is $0.12 \mathrm{mGal}$, which is three times greater than the 
measurement error of this survey, $0.04 \mathrm{mGal}$. This indicates that the gravity trends observed are due to geological variations and/or to the presence of infrastructure below the cell floor. It should be noted that since density computations depend on the differences in gravity between surveys, the density trends from the subsurface will not have consequences on the results presented in the next chapters.

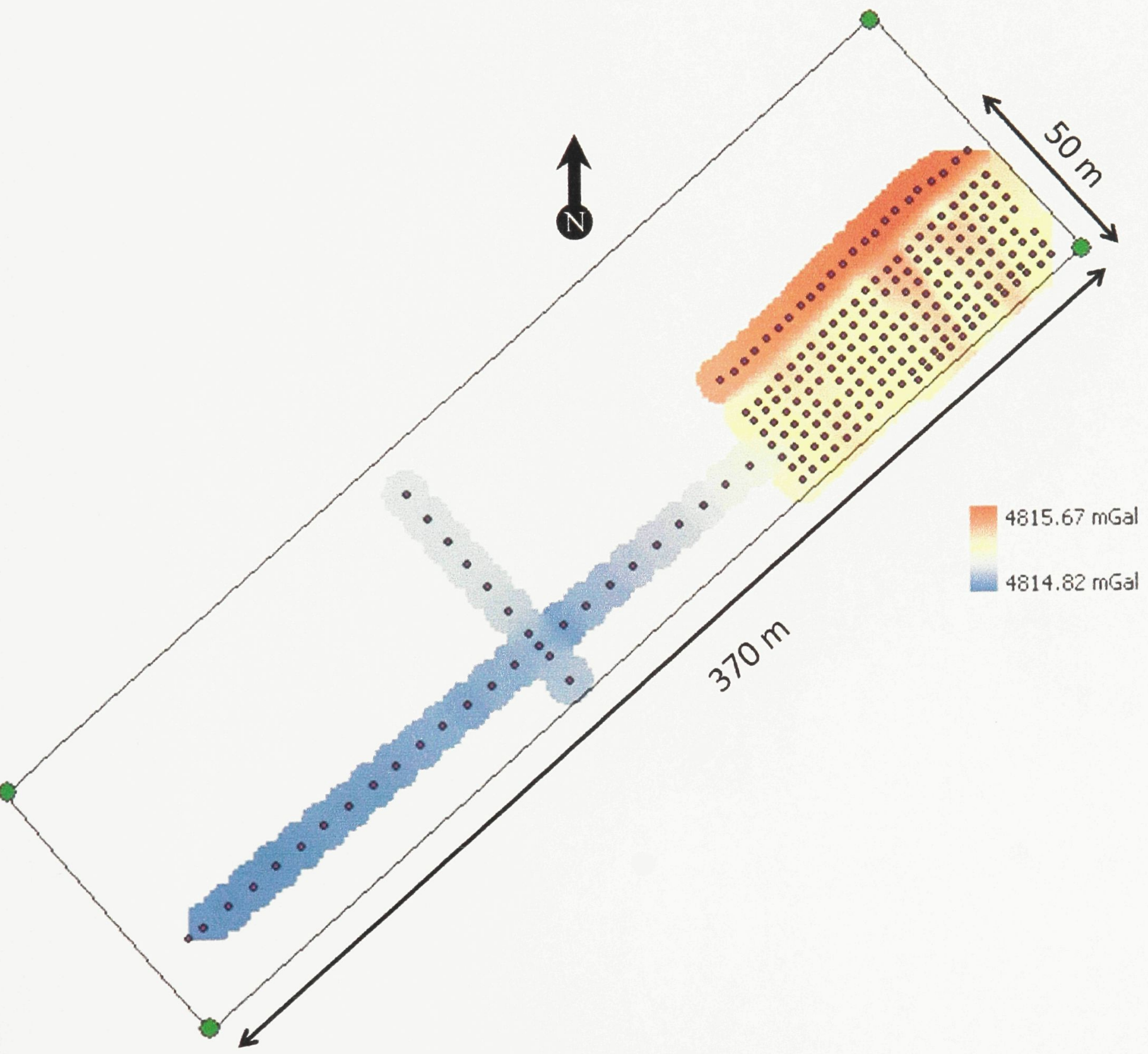

Figure 4-3: Corrected Gravity Map of the Entire Cell in Survey 1 


\subsection{Survey 2}

Figure 4-4 shows the elevation of the top of the waste during survey 2 . It is clear that there is a $3 \mathrm{~m}$ drop partway through the map as the northeast side of the cell was filled earlier than the southwest side. Figure 4-5 shows the elevation difference between surveys 2 and 1 . There is up to $9 \mathrm{~m}$ of waste immediately northeast of the drop off, approximately 4-6 $\mathrm{m}$ of waste in both the far northeast and far southwest areas of the cell, and only $3.5 \mathrm{~m}$ of waste above the berm.

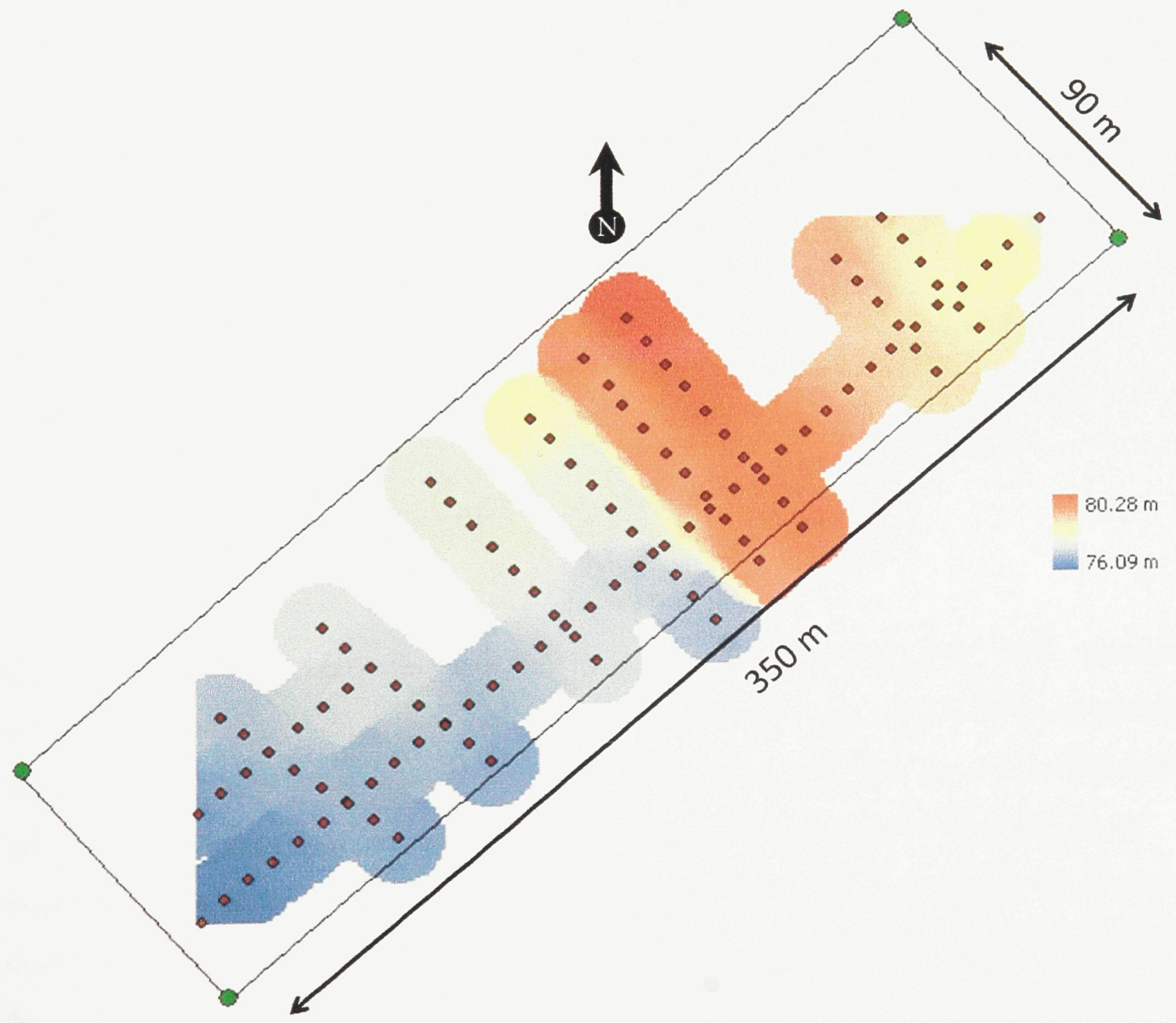

Figure 4-4: Elevation Map of Survey 2 


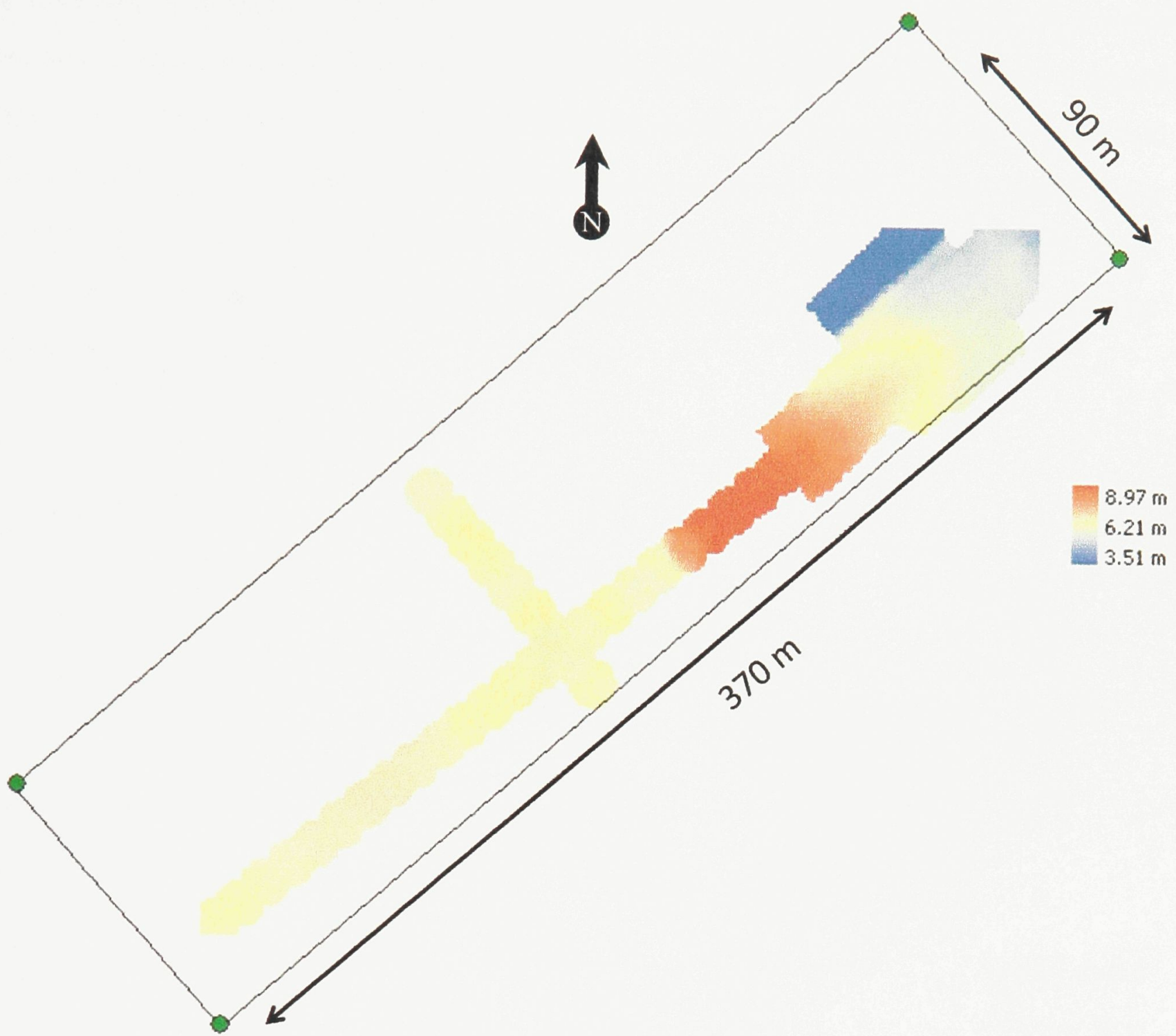

Figure 4-5: Elevation Difference Between Surveys 2 and 1

Figure 4-6 shows the gravity data recorded during survey 2, corrected for elevation, tides and drift. The gravitational field is strongest in the northeast end of the cell above the location of the gravel berm, which is to be expected since the berm is denser than the surrounding waste. When Figure 4-5 is analyzed along with Figure 4-6 it may also be observed that the gravity decreases more gradually across the cell than the elevation does. In fact, the gravity measured over the last line before the drop is only $0.1 \mathrm{mGal}$ higher on average than the first line after the drop, while the maximum contrast across the entire cell is more than six times that amount. The gravity in Figure 4-6 is corrected for elevation, therefore it is likely that the waste is only 
slightly more compacted on the northeast side of the elevation drop since the gravity does not decrease as abruptly as the elevation. It may also be observed that there are areas on opposite ends of the cell with the same thickness of overlying waste, but the gravity is still greater over the areas in the northwest end of the cell. Two explanations exist for this observation: (1) the waste is denser over the northeast end of the cell (possibly the waste has been slightly more compacted), or (2) the subsurface gravity trend identified in Figure 4-3 (gravity decreasing to the southwest) is still present.

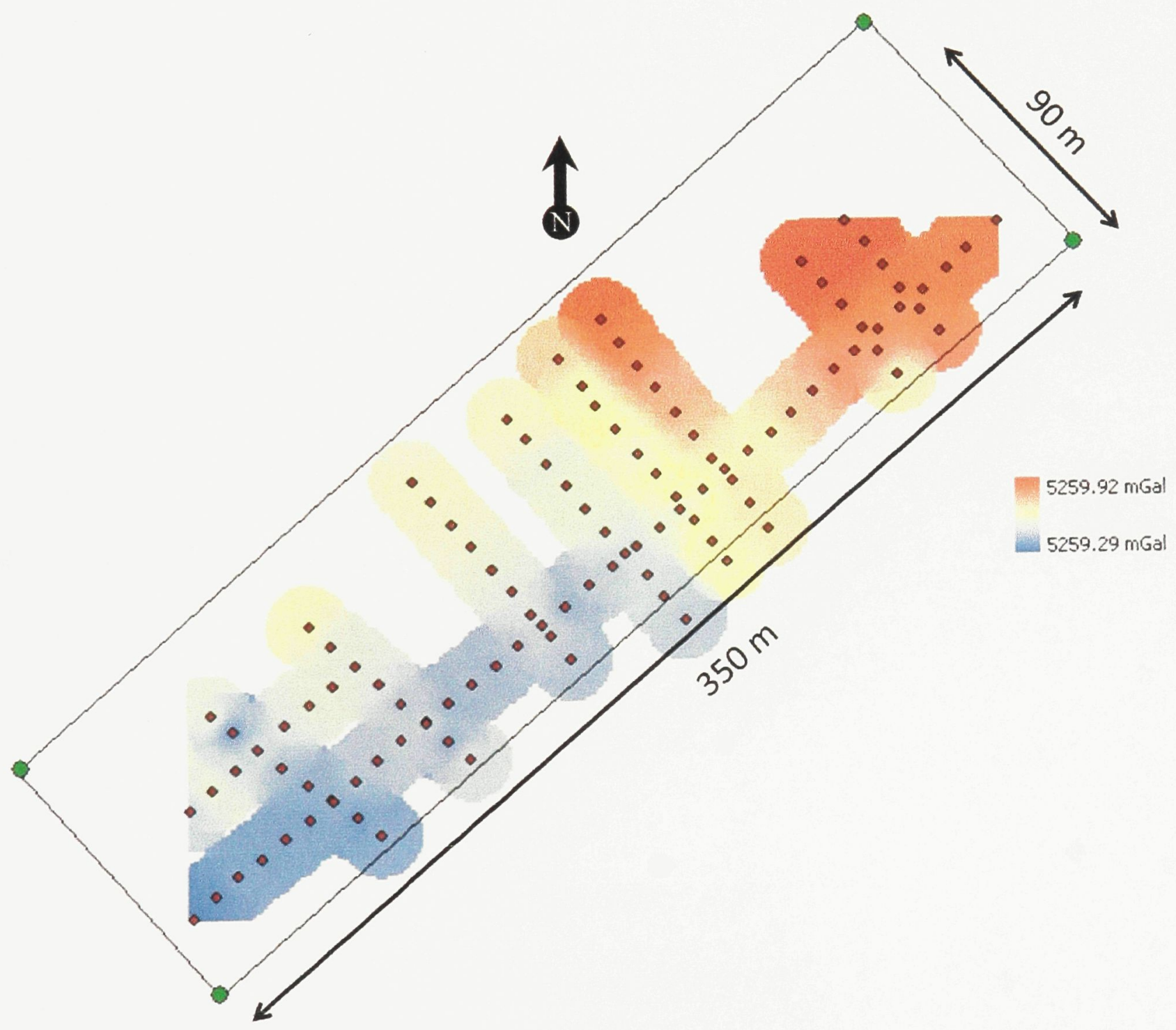

Figure 4-6: Corrected Gravity Map of Survey 2 


\subsection{Survey 3}

The area covered by survey 3 was approximately the same as the $5 \mathrm{~m}$ by $5 \mathrm{~m}$ area in the northeast end of survey 1 (Figure 3-10). Figure 4-7 shows the elevation of the survey 3 area. The survey area slopes slightly downward towards the northeast. In this Figure 4-7, the surrounding lines are at a different location as in previous figures, and so their bounding coordinates are marked. The berm is buried under approximately $10 \mathrm{~m}$ of waste along the northwest edge of the figure.

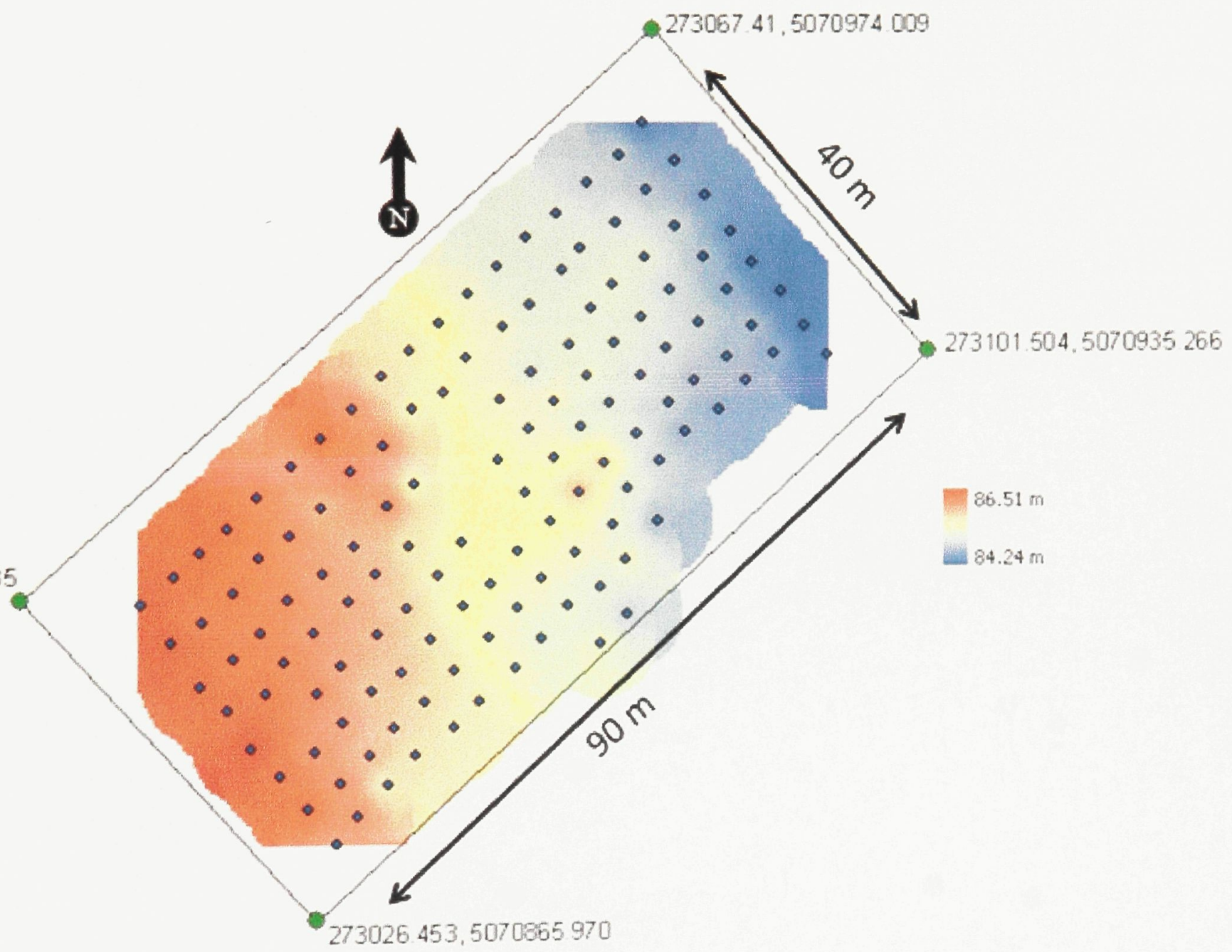

Figure 4-7: Elevation Map of Survey 3 
Figure 4-8 shows the gravity in this area of the cell, which generally increases towards to the northeast. The berm is no longer an obvious gravity anomaly as it was for survey 2 . The average strength of the gravitational field above the berm is only $0.1 \mathrm{mGal}$ higher than the average strength of the field over the remainder of the cell. In Figure 4-8, there are noticeable localized heterogeneities. It is unclear whether these are the results of poor survey conditions or if there actually exist localized heterogeneities in the underlying waste.

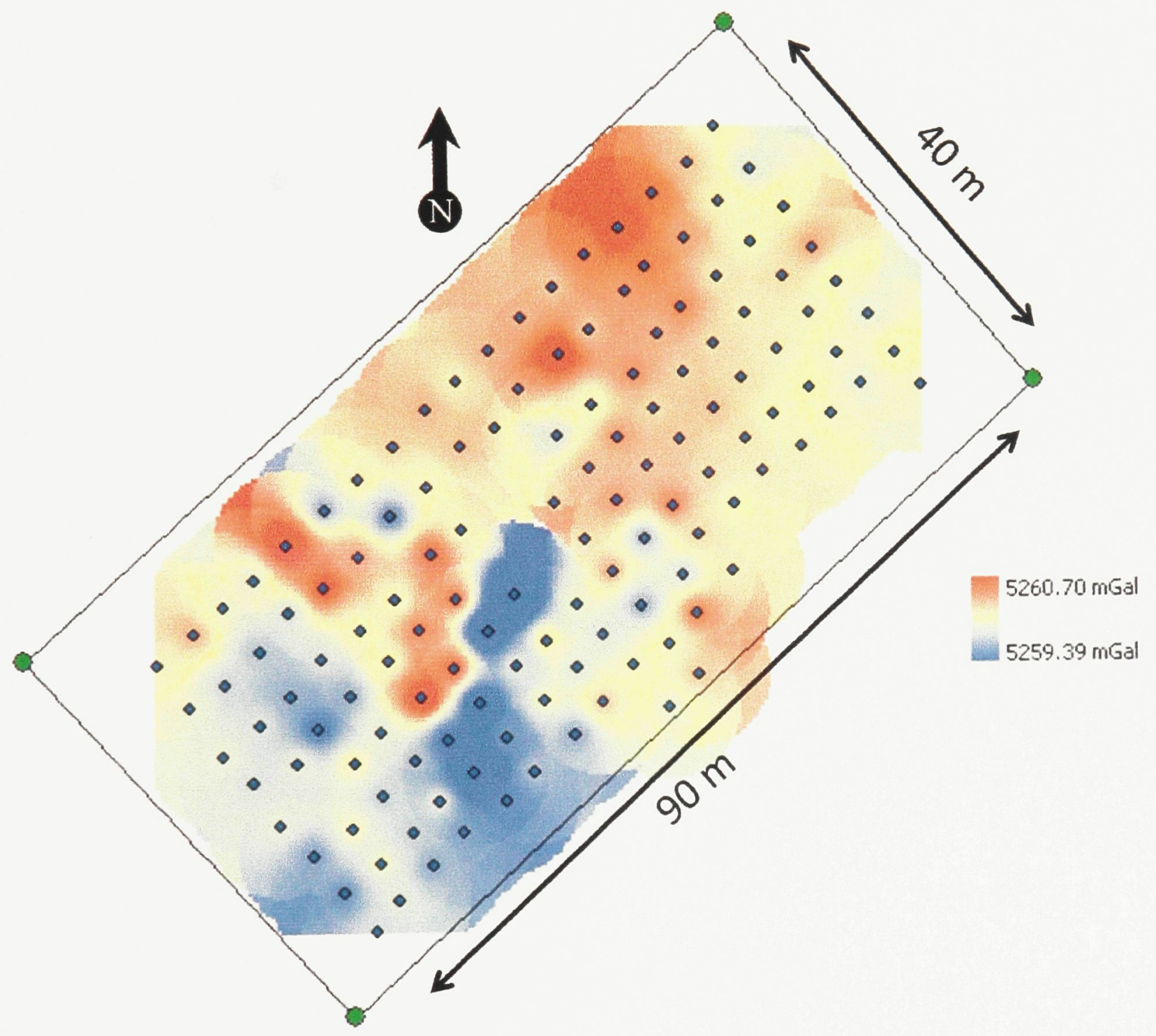

Figure 4-8: Corrected Gravity Map of Survey 3 


\subsection{Comparison Between Surveys 2 and 3}

Figure 4-9 shows the stations in survey 2 overlain with the survey 3 stations. Surveys 2 and 3 can only be compared in the northeast end of the cell, where the surveys overlap (Figure 3-10).

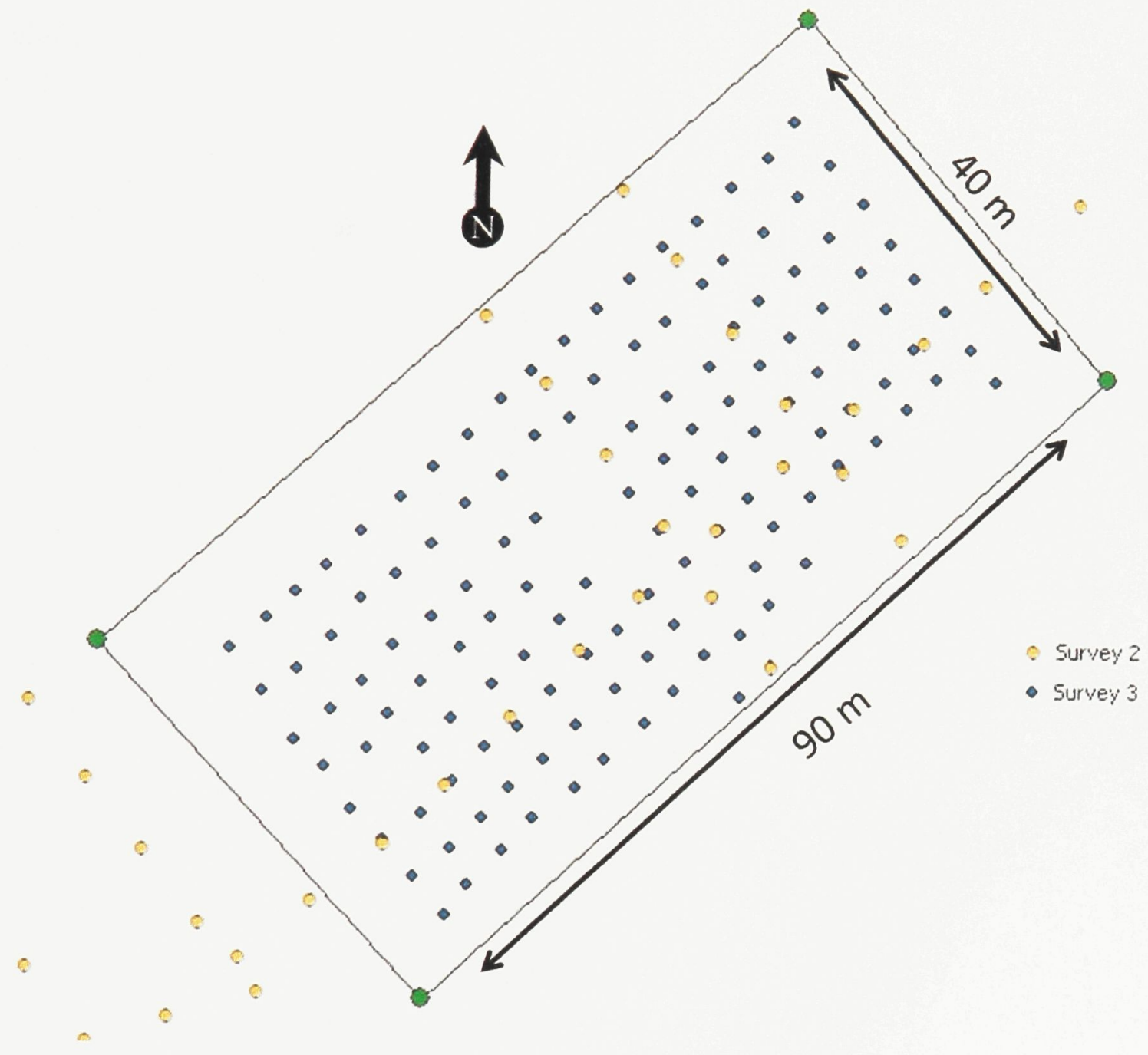

Figure 4-9: Overlay of Survey 2 and 3 Stations

In Figure 4-10, survey 3 is set to the same datum as survey 2, which is equal to the minimum elevation in survey 2. Gravity data from survey 2 is then subtracted from gravity data from survey 3 . The localized heterogeneities visible in this figure are mostly due to the 
heterogeneities from survey 3. The gravity trend observed in Figure 4-8 (decrease towards the southwest) is no longer visible, indicating it is likely due to material beneath the landfill.

Other than a few localized outliers, most of the waste yields a fairly uniform gravitational field, with an average field of $0.434 \mathrm{mGal}$ and a standard deviation of $0.101 \mathrm{mGal}$. This deviation would be acceptable if the survey area was much larger, but it is unlikely that the gravity deviates that much over such a small area. Possible mechanisms for this will be discussed in chapter 5 .

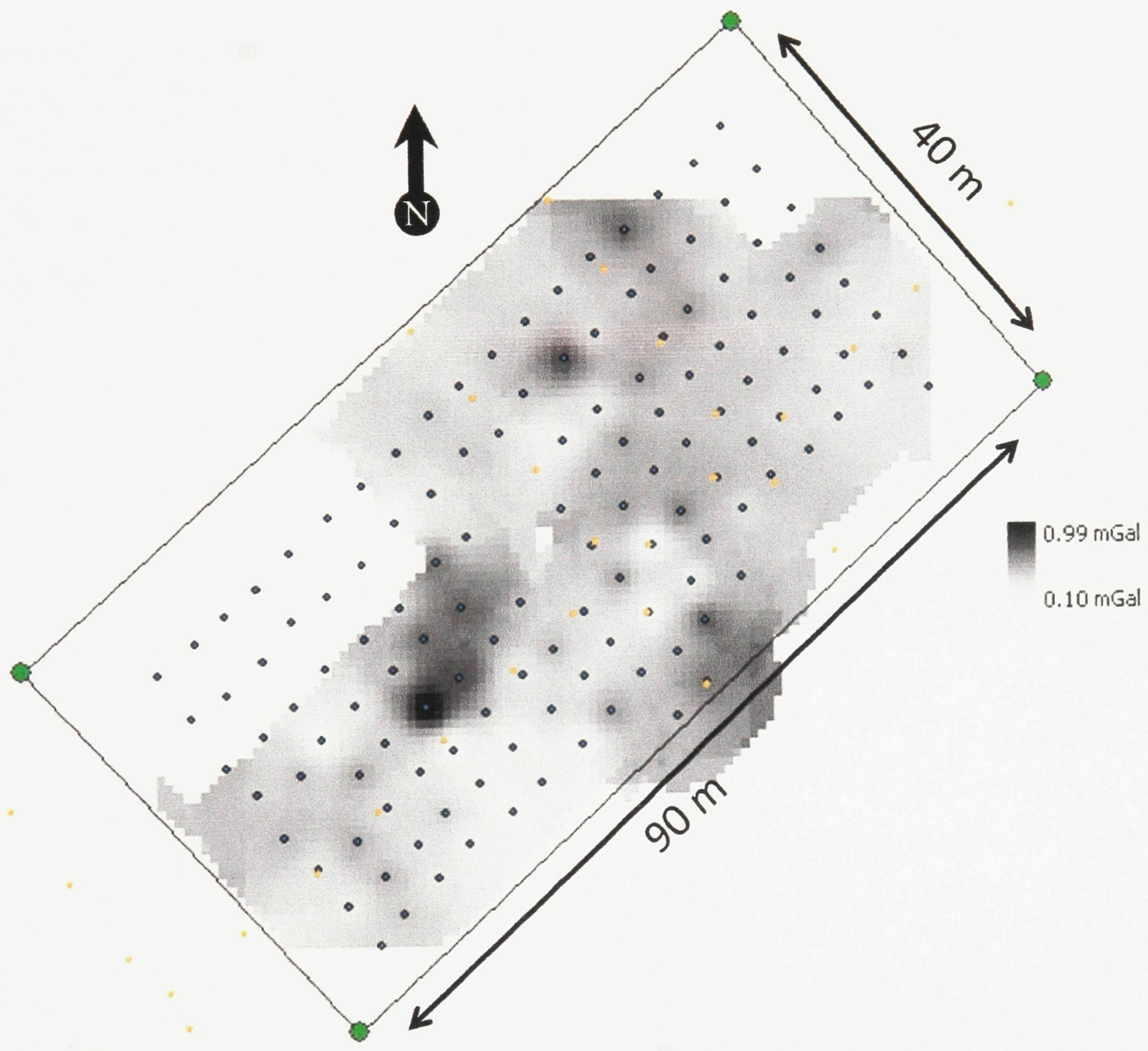

Figure 4-10: Gravity Contrast Between Surveys 3 and 2 (Outliers in Survey 3 Removed) 


\subsection{Survey 4}

Figure 4-11 shows the elevation map for survey 4, with the surrounding box marking out the same area as in Figure 4-1. Unlike survey 2, which also spanned most of the cell, survey 4 was done without any sudden elevation changes in the waste level. However, the surface slopes slightly downward towards the northeast, with a maximum change of $3 \mathrm{~m}$. This slope is in the opposite direction as the slope of the empty cell shown in Figure 4-1, which means that at the time of survey 4 there was a larger volume of waste, and likely mass, under the southwest end of the cell than there was under the northeast end.

Figure 4-12 depicts the corrected gravity data recorded during survey 4 . The gravity data recorded during survey 4 follows the same trend of steadily decreasing gravity toward the southwest end of the cell, with a maximum deviation of $1.11 \mathrm{mGal}$ and a standard deviation of $0.15 \mathrm{mGal}$. On average, the gravity of northeasternmost quarter of the cell is $0.2 \mathrm{mGal}$ higher than that of the southwesternmost quarter. 


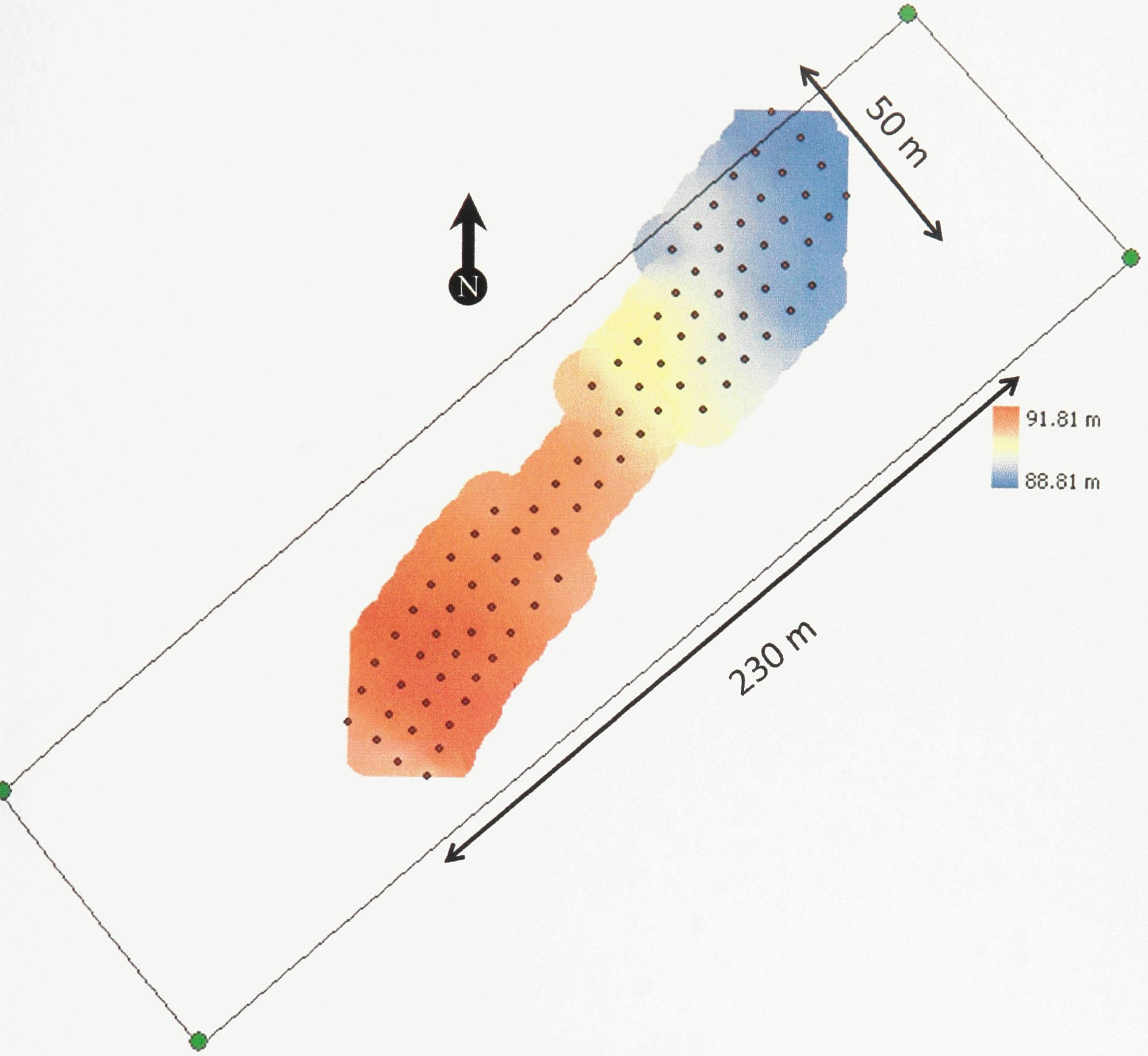

Figure 4-11: Elevation Map of Survey 4 


\subsection{Comparison Between Surveys 2 and 4}

Figure 4-13 shows the survey 4 stations overlain with the survey 2 stations. There is a lack of overlap in the northeast end of the cell due to the fact that, during survey 4 , that part of the cell was covered with mounds of cover soil and heavy machinery.

The gravity data from survey 2 and survey 4 was processed following the methodology described in section 4.4. Figure 4-14 shows the gravity contrast between survey 4 and survey 2 after survey 4 was datumed to the minimum elevation of survey 2 . The average gravity contrast is $0.737 \mathrm{mGal}$ and there is a standard deviation of $0.140 \mathrm{mGal}$. Since the effect of any material beneath survey 2 has been subtracted out, Figure 4-14 shows only the gravitational field caused by the waste between the two surveys. The contrast is highest at the southwest end of the cell, and is lowest at the far northeast end of the cell. This can likely be explained by the fact that there is more waste mass in the southwest end of the cell than there is in the northwest, as was explained in section 4.5 .

The small box in Figure 4-14 outlines the area of survey 3, which has minimal overlap of survey 4 , and thus illustrates why surveys 4 and 3 cannot be compared. 


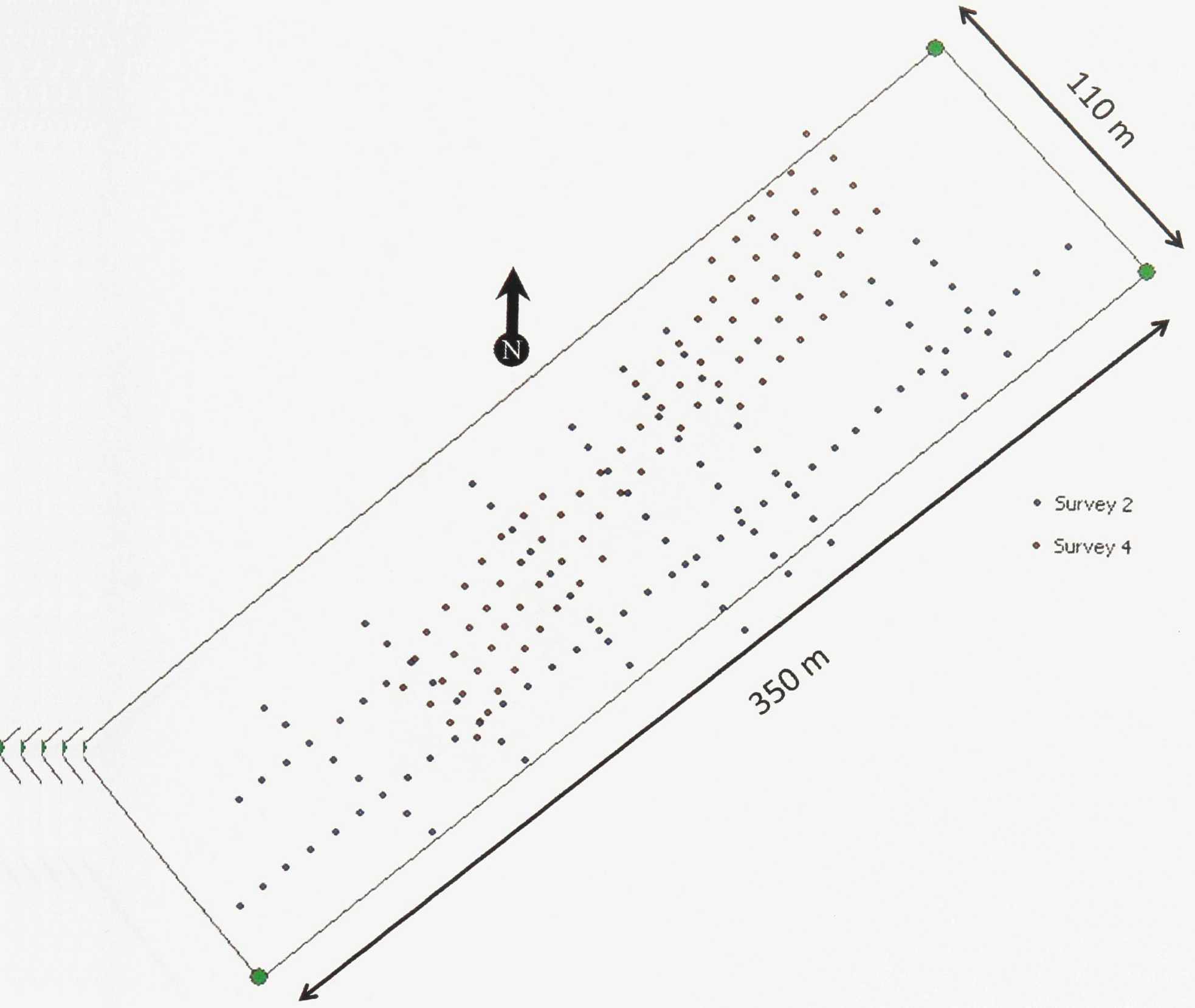

Figure 4-13: Overlay of Survey 2 and 4 Stations 


\subsection{Survey 5}

Figure 4-15 shows the elevation map during survey 5 . It is appears similar to Figure 4-11 because no additional waste placed after survey 4 . There was a small amount settlement between surveys 4 and 5; however, the slope downward towards the northeast remains the same.

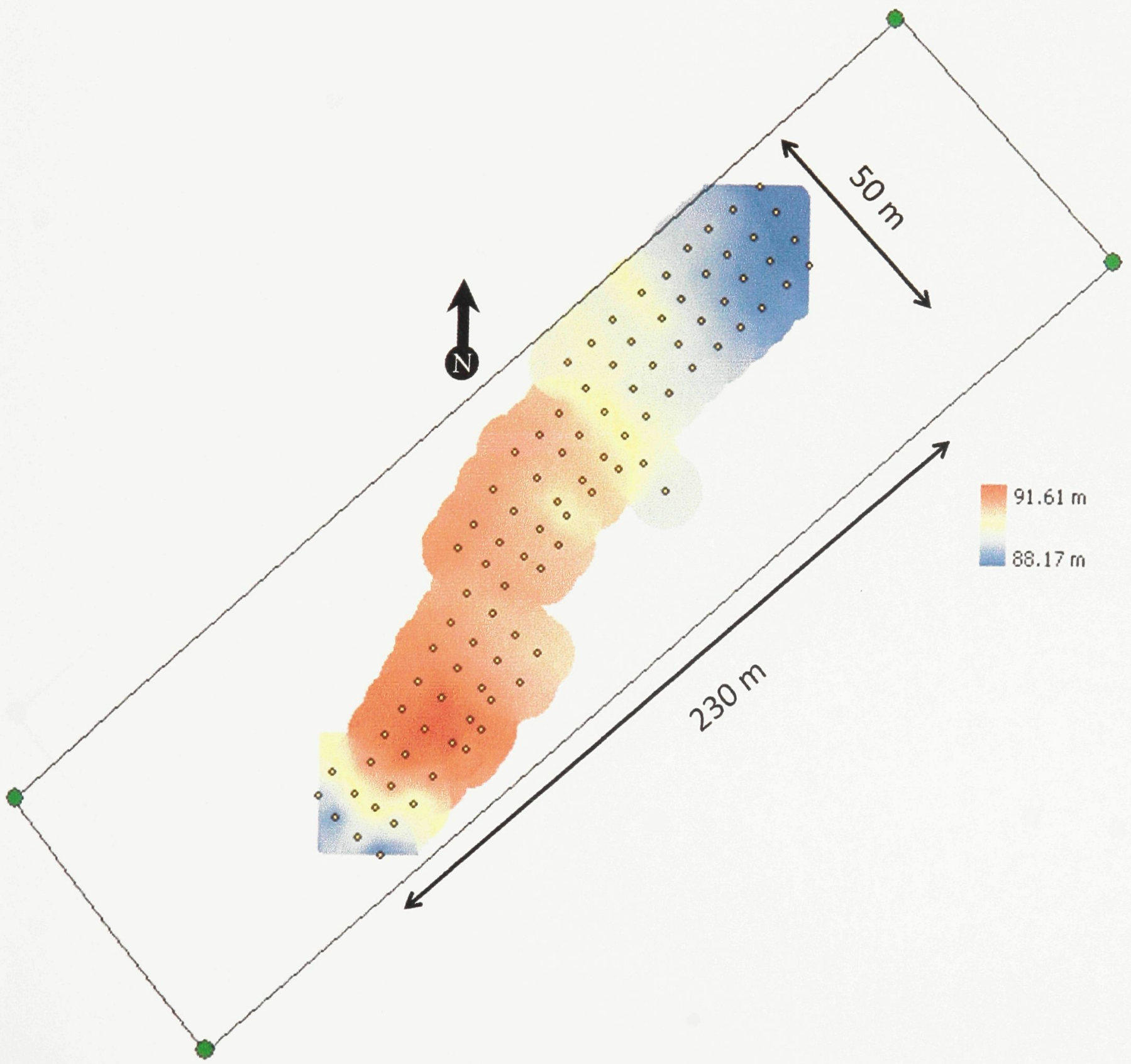

Figure 4-15: Elevation Map of Survey 5 
Figure 4-16 shows the gravity data recorded during survey 5 , and there is once again a trend of decreasing gravity towards the southwest. The maximum deviation of the gravity is $0.97 \mathrm{mGal}$ and the standard deviation is $0.149 \mathrm{mGal}$. And similar to in survey 4 , the average gravity in the northeasternmost end of the cell is $0.2 \mathrm{mGal}$ higher than the average gravity in the southwesternmost end.

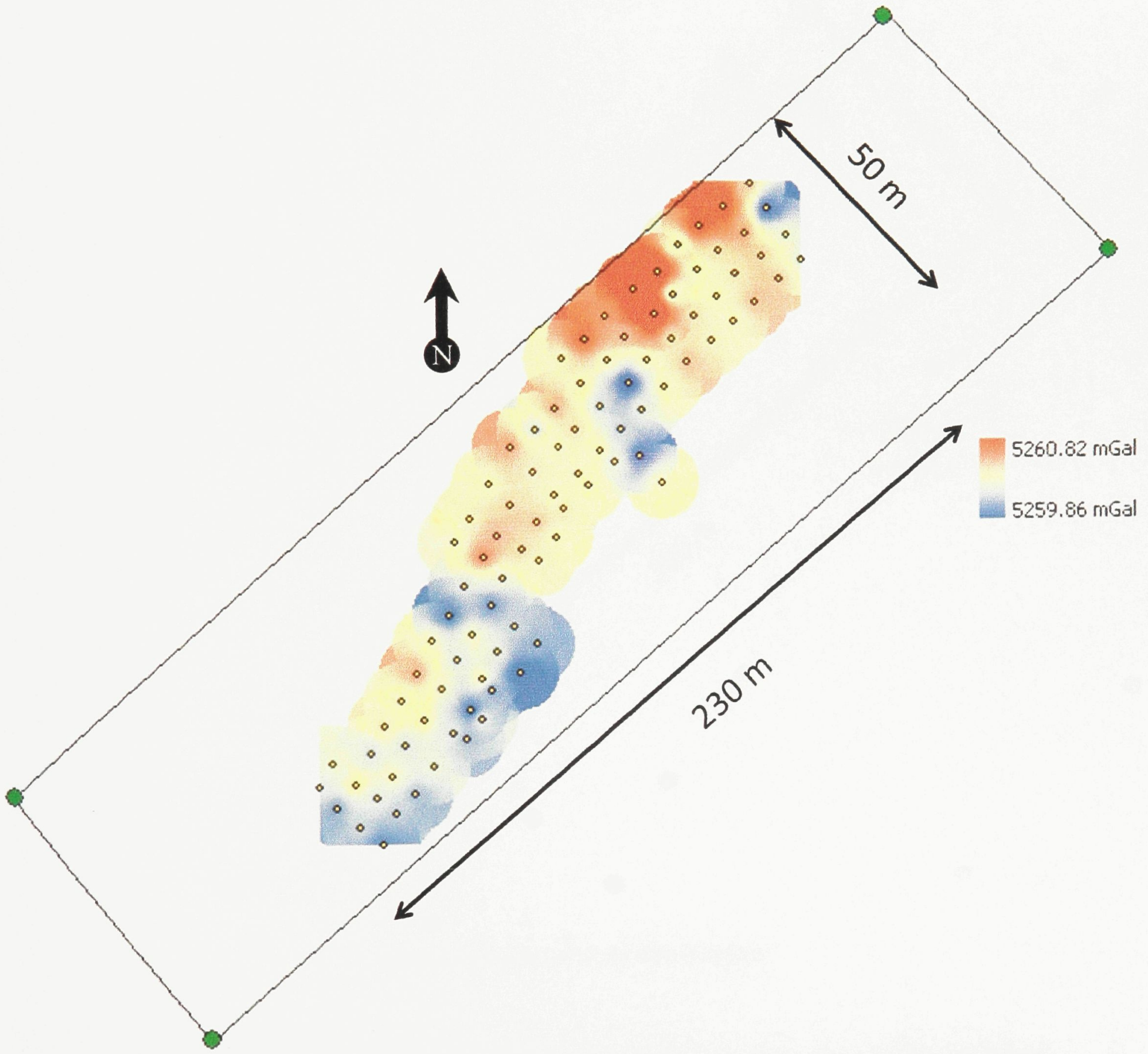

Figure 4-16: Gravity Map of Survey 5 


\subsection{Comparison between Surveys 4 and 5}

Figure 4-17 shows the survey 5 stations overlain with the survey 4 stations. The topography was very similar during the two surveys, so a greater amount of overlap was possible compared to previous surveys.

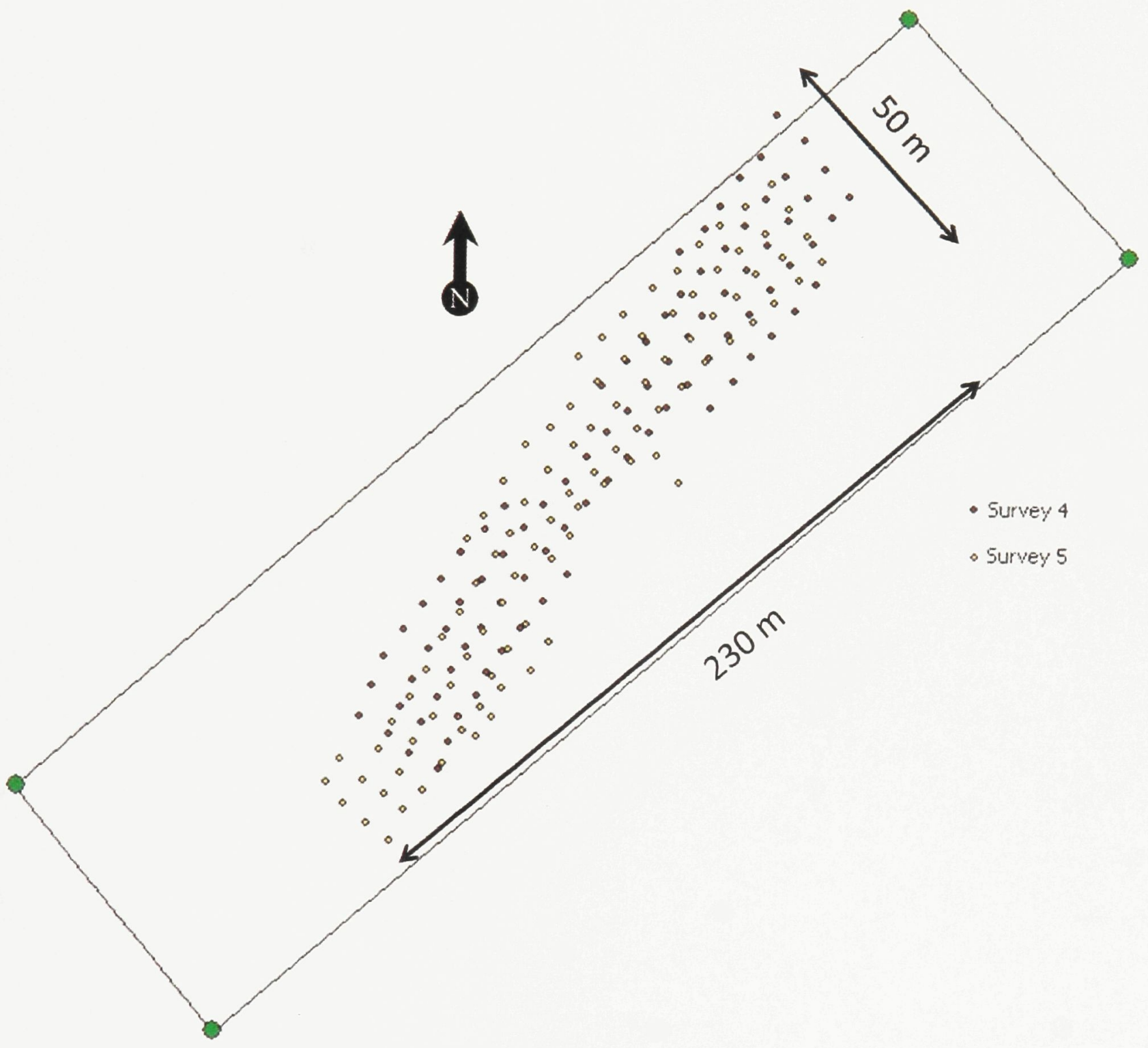

Figure 4-17: Overlay of Survey 4 and 5 Stations

Figure 4-18 shows the elevation difference between surveys 5 and 4 . The average settlement between surveys 4 and 5 was $0.60 \mathrm{~m}$ with a standard deviation of $0.20 \mathrm{~m}$. Locally, the waste has settled (negative difference) as much as $1.19 \mathrm{~m}$ and has apparently rebounded (positive 
difference) as much as $0.46 \mathrm{~m}$. However, these extremes likely represent individual points that have been taken over small elevation anomalies, such as small mounds of daily cover, or in holes that existed in one survey but not the in other.

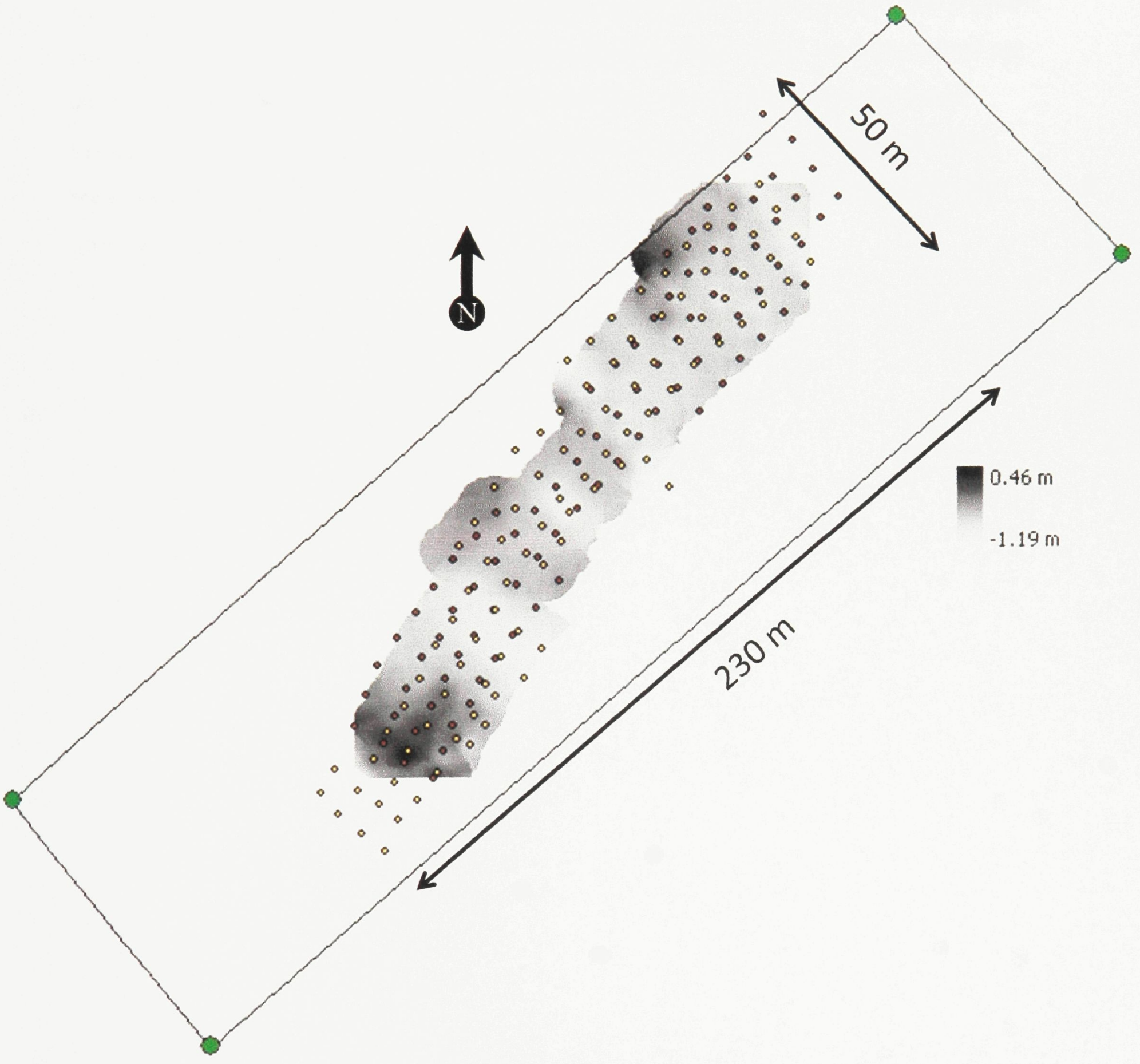

Figure 4-18: Elevation Difference Between Surveys 5 and 4 (Negative Values Correspond to Settlement) 
The gravity constrast between surveys 5 and 4, displayed in Figure 4-19 shows no clear trends, being fairly uniform from one end to the other, aside from localized heterogeneities. Gravity has increased only slightly in some areas and decreased only slightly in other areas; this is to be expected since no waste was deposited between surveys 4 and 5 . In section 2.4.1, it was shown that when the waste layers were approximated as Bouguer slabs, settlement alone should not increase or decrease the gravity over the cell. On average, the gravity actually decreased between surveys 4 and 5 by an amount of $0.076 \mathrm{mGal}$, which is significantly lower than the measurement error in these surveys and therefore negligible. In this case, the Bouguer slab approximation was accurate. 


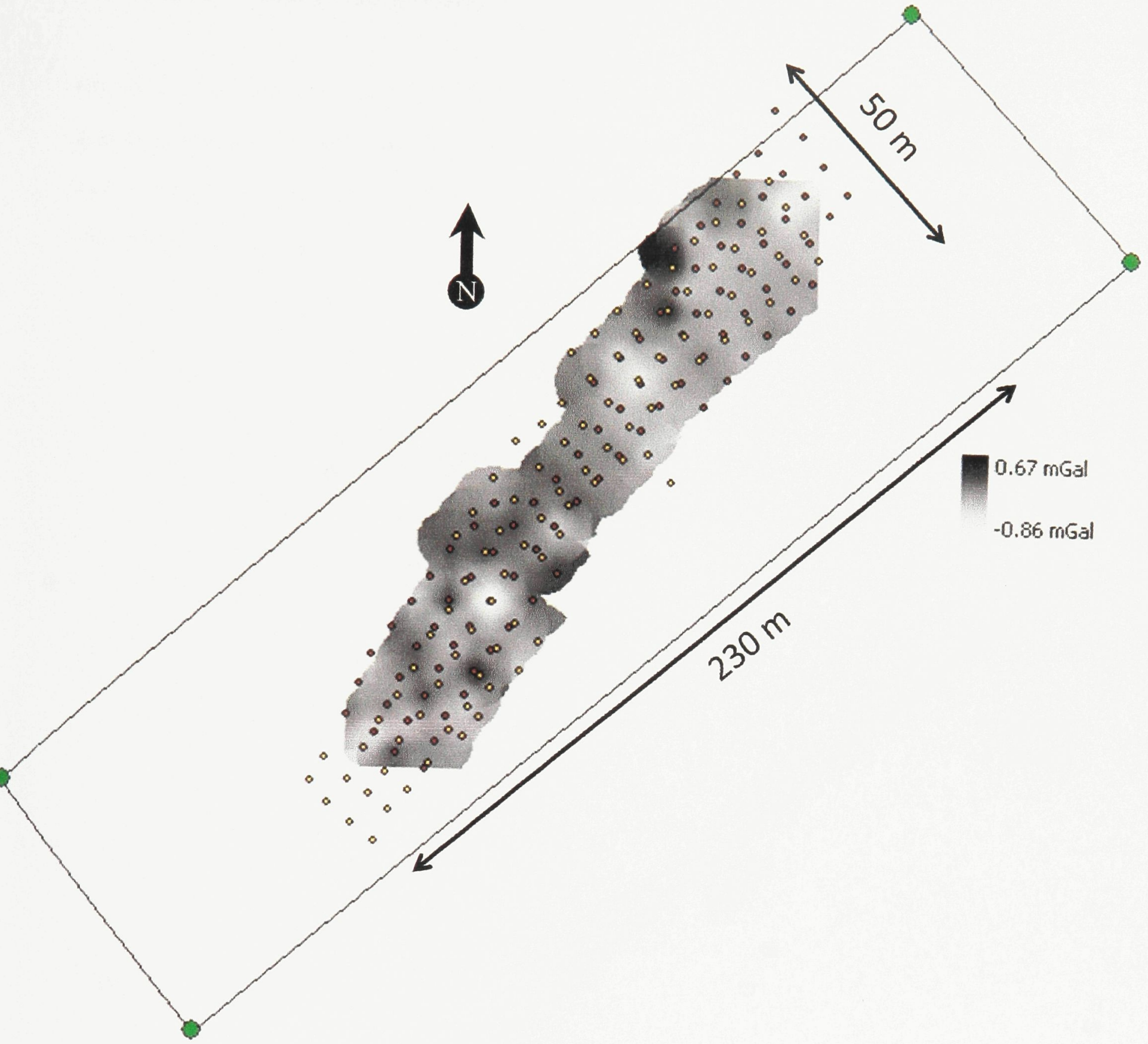

Figure 4-19: Gravity Contrast Between Surveys 5 and 4 


\subsection{Survey 2 and 5 Comparison}

Figure 4-20 shows the survey 5 stations overlain with the survey 2 stations. There is approximately the same amount of overlap as in the comparison between surveys 4 and 2 . Again, very little overlap in the northeast end of the cell due to that area being overlain by mounds of cover soil and heavy equipment.

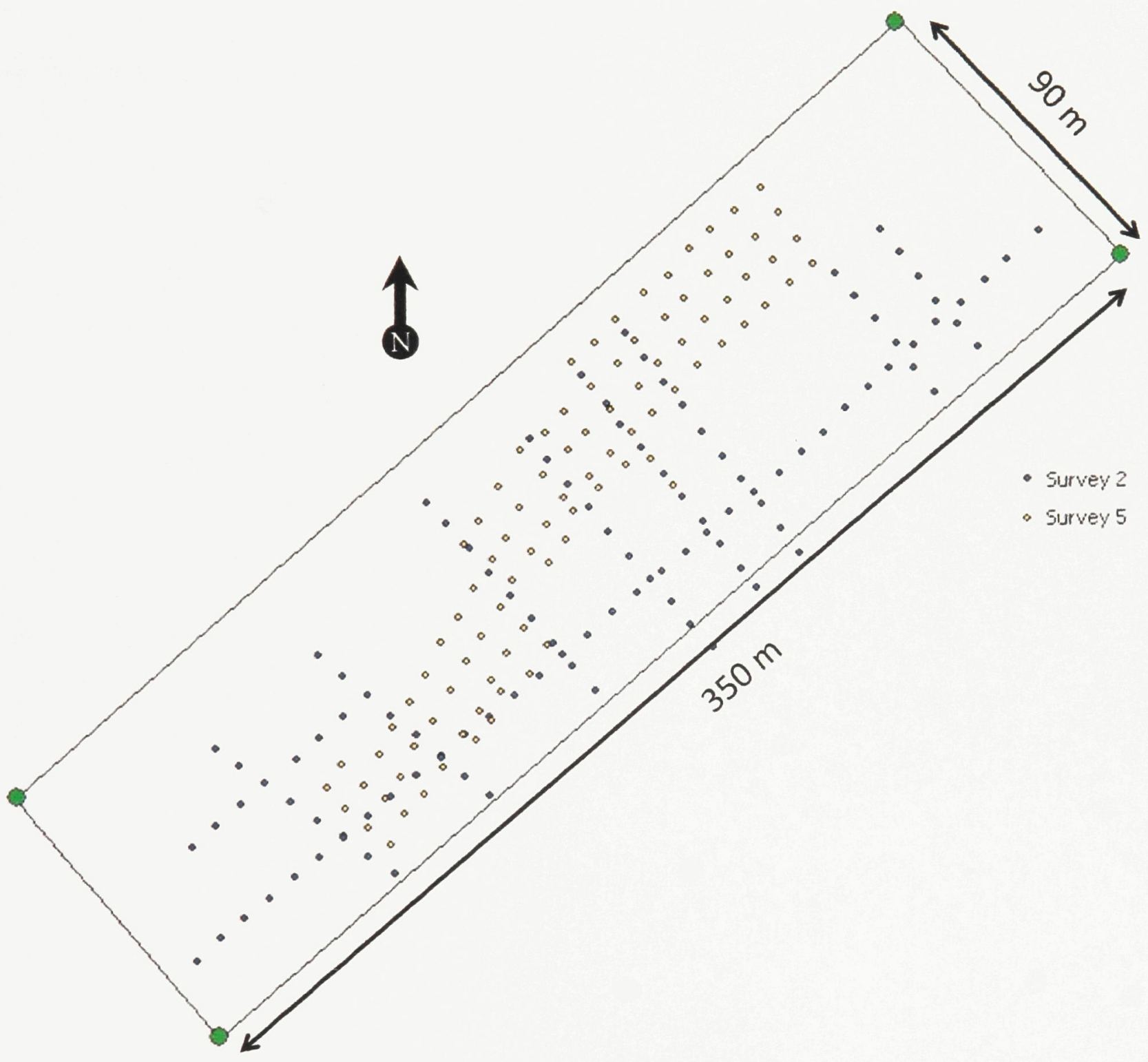

Figure 4-20: Overlay of Survey 2 and 5 Stations

Figure 4-21 shows the gravity contrast between surveys 5 and 2, which reflects density variations in the waste between the two surveys. As opposed to the gravity contrast map between surveys 4 and 2 (Figure 4-14), there does not seem to be any visible trend in this map 
when anomalies are overlooked; namely the low anomaly in the northeast end of the cell. The average gravity contrast is $0.644 \mathrm{mGal}$ and the standard deviation is $0.117 \mathrm{mGal}$. This deviation is less than in the contrast between surveys 4 and 2 , due to fewer gravitational anomalies in the survey 5 data. The average gravity contrast is lower than what was computed in the surveys 4 and 2 comparison, however, this does not necessarily imply a decrease in density. The slab of waste between surveys 2 and 5 is likely thinner than the slab between surveys 2 and 4 , therefore settlement data must be analyzed before any statements can be made about temporal density variations. 


\section{Settlement Analysis}

\subsection{Settlement Modeling for Surveys 2 and 3}

At the time of survey 3 , the surface over which survey 2 was performed had subsided due to settlement. This necessitates finding a method to quantify the degree of settlement in order to determine the thickness of the waste between the two surveys at the time of survey 3 . Instrument bundles 5 and 6 were placed in the cell at the same time that survey 2 was performed (Figure 2-5). Therefore, the data from the liquid settlement gauges in these instrument bundles will be analyzed to quantify this settlement. It should be noted though, that when instrument bundles are installed, they are buried approximately $1 \mathrm{~m}$ below the surface. This means that the instrument bundles are subjected to more overlying mass than the actual surveyed surface. This effect could result in a slight overestimation of settlement.

The assumption will be made that waste settles consistently throughout the entire cell, and that the settlement experienced by instrument bundles 5 and 6 is representative of the settlement of the overall waste. One method of quantifying the settlement is to simply take the difference in the elevations of the bundle at two different times. A drawback of this method is that the data fluctuates daily, and several different values can be obtained depending on the time of day that the elevation value is taken. Two possible solutions would be to (1) compute settlement averages and use those values to compute the elevation differences, or (2) model the settlement data to obtain a trend that is void of daily fluctuations. Both of these methods will be used to quantify the settlement in this section.

The liquid settlement gauges take four measurements per day, and the readings are plotted in Figure 5-1. Instrument bundle 5 is displayed in orange and bundle 6 is in green. By looking at the two days of data immediately preceding survey 2 , the average elevation of instrument bundle 5 is $77.79 \mathrm{~m}$ with a standard deviation of $0.01 \mathrm{~m}$ (over 8 readings), and the average elevation of instrument bundle 6 is $78.27 \mathrm{~m}$ with a standard deviation of $0.06 \mathrm{~m}$ (over 8 readings). Instrument bundle 5 did not record data on the days immediately before and after survey 3 was performed, so the values used to compute the average were taken from up to 6 
days prior to the survey. These values yielded an average of $76.82 \mathrm{~m}$ and a standard deviation of $0.01 \mathrm{~m}$ (over 4 readings). The final elevation of instrument bundle 6 was taken from two days of readings immediately preceding survey 3 and was found to be $77.07 \mathrm{~m}$ with a standard deviation of $0.06 \mathrm{~m}$ (over 8 readings). By simply taking the differences of these values, bundle 5 settled $(0.972 \pm 0.003) \mathrm{m}$ and bundle 6 settled $(1.20 \pm 0.01) \mathrm{m}$.

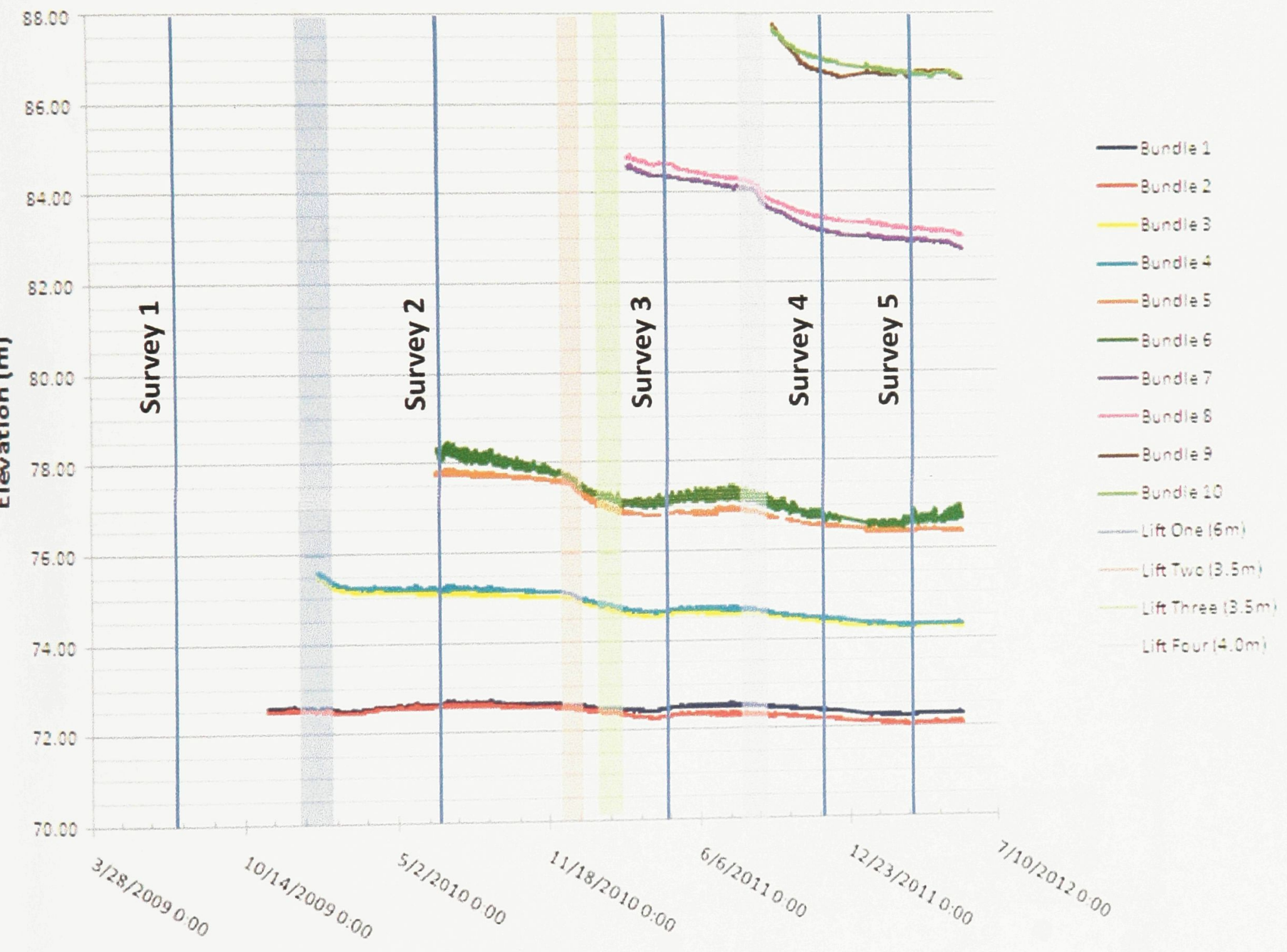

Time

Figure 5-1: Settlement Data For All Instrument Bundles 


\subsubsection{Primary and Secondary Settlement}

The settlement that occurs shortly after the installation of these instrument bundles and shortly after each lift is deposited is quite chaotic, and much difficulty is encountered in modeling it. To obtain robust settlement values, only trends around the desired date will be modeled in order to enhance precision. For each model, an "elevation zero" will be chosen at the time the last waste lift was deposited before the survey was done. The elevation zero is simply the elevation of the bundle at the time of the lift placement.

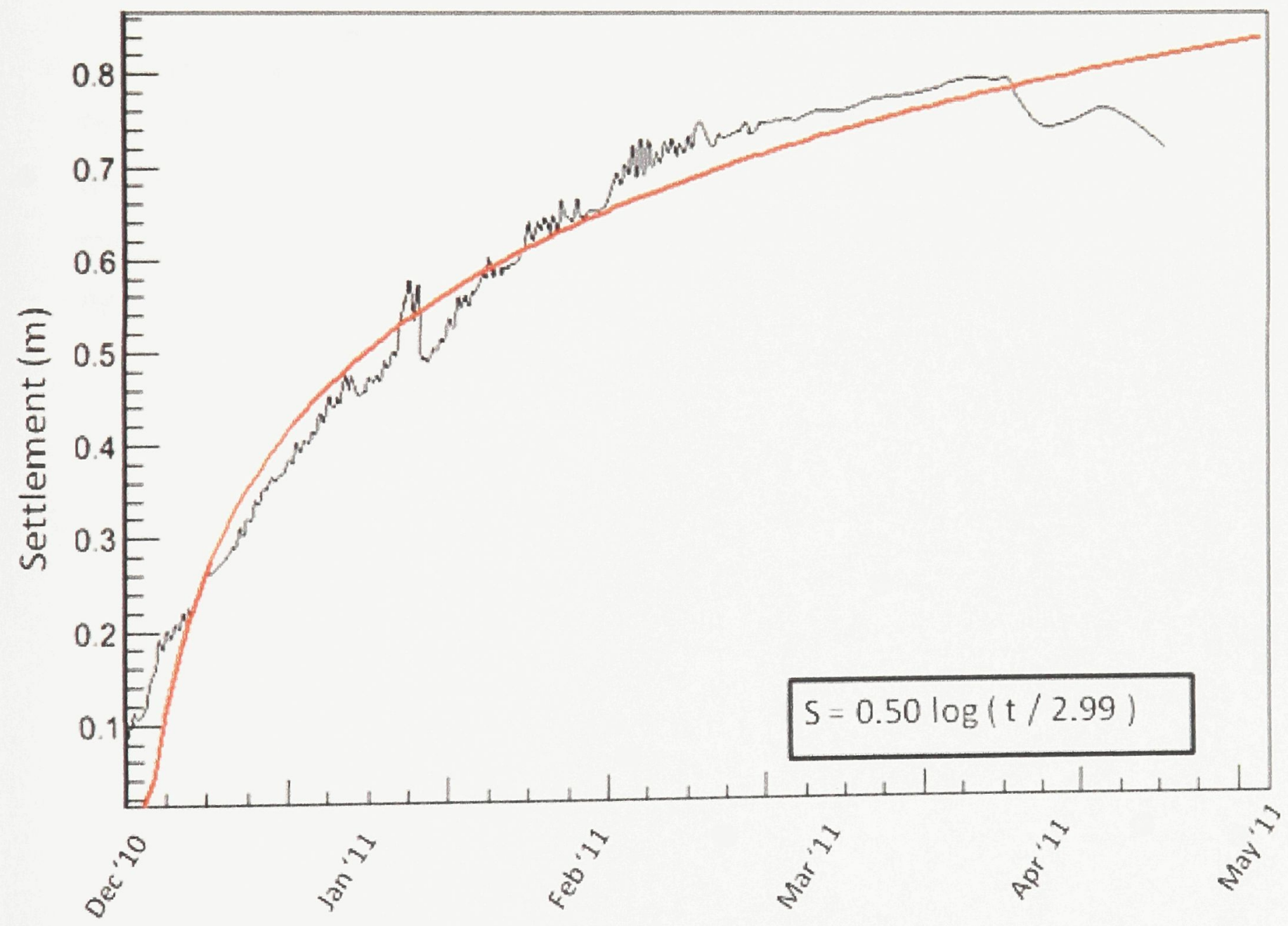

Figure 5-2: Primary and Secondary Settlement Model of Bundle 5

Figure 5-2 shows the settlement data of instrument bundle 5 modeled with a primary and secondary settlement equation (equations $2.12 \mathrm{a}$ and $\mathrm{b}$ ). The parameters of this equation are 
visible in the bottom right area of the figure. In the equation, $S$ represents total settlement, in metres, from the beginning of the plotted period, and $t$ represents the total number of days since the beginning of the plotted period.

Elevation zero for gauge 5 was $77.60 \mathrm{~m}$ above sea level, and the $y$-axis shows the total settlement from that point. Elevation zero was chosen to be in December 2010, when a lift of waste was deposited, and settlement accelerated. The settlement value predicted by the model is simply subtracted from the elevation zero to find the resulting elevation. On the first date of survey 3 (April 15, 2011), this model yields an elevation value of $76.77 \mathrm{~m}$, i.e. $1.02 \mathrm{~m}$ of settlement between surveys 2 and 3 .

This model depicts the settlement data to an extent that it is always within $10 \mathrm{~cm}$ of the data. This corresponds to approximately $0.03 \mathrm{~g} / \mathrm{cm}^{3}$ of error on the density. It should also be noted that near the end of Figure 5-2 ( April 2011), the settlement appears to decrease. However, much of the data from this time is missing, and so the plot is made from only a few points in April. 


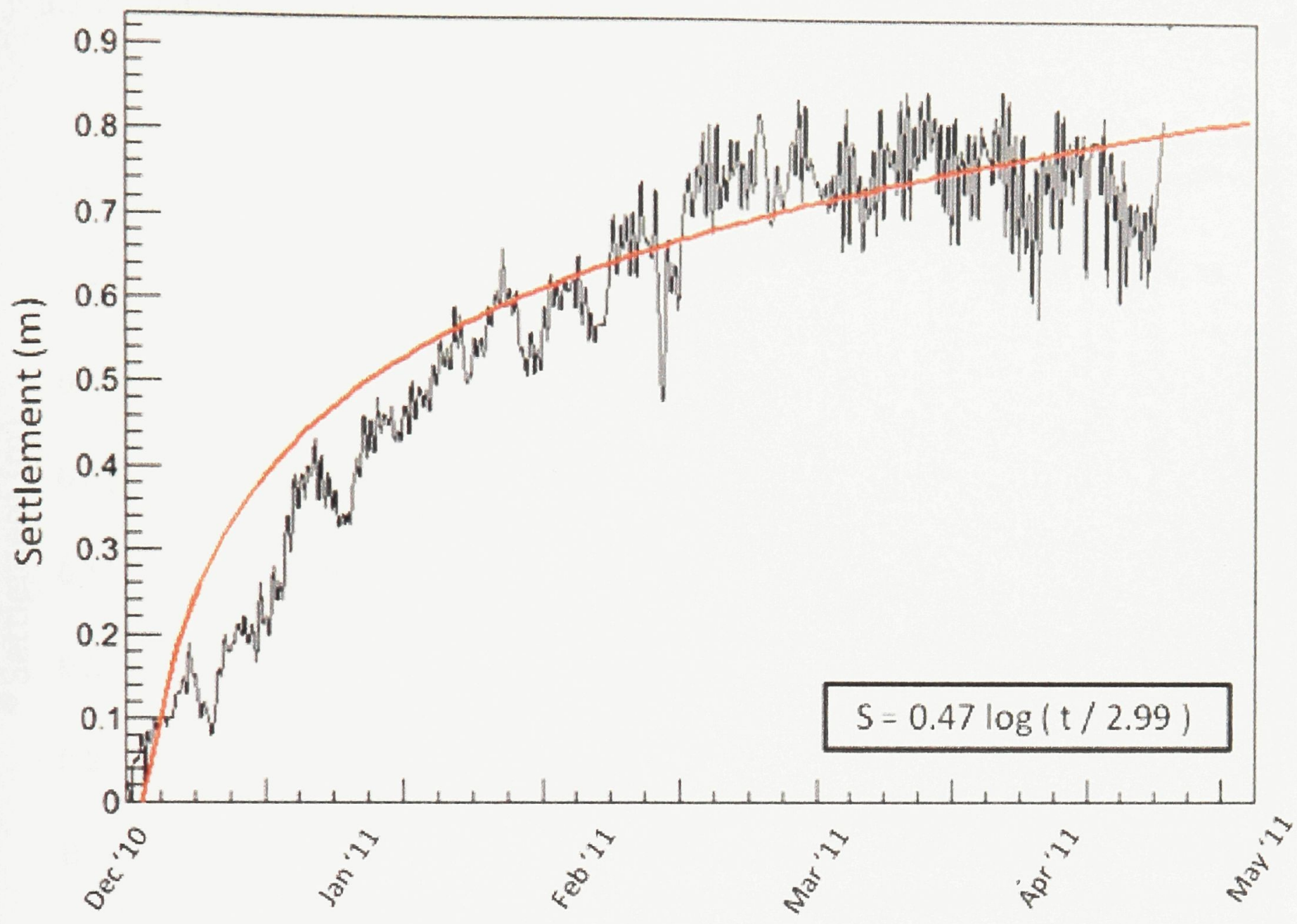

Figure 5-3: Primary and Secondary Settlement Model of Bundle 6

Figure 5-3 shows the settlement data of instrument bundle 6 modeled with a primary and secondary settlement equation (equations 2.12a and b), where elevation zero for gauge 6 was $77.84 \mathrm{~m}$ above sea level, and the $\mathrm{y}$-axis shows the total settlement from that point. At the time of survey 3 , this model predicts an elevation of $77.06 \mathrm{~m}$, or $1.21 \mathrm{~m}$ of settlement between surveys 2 and 3 . This model has the same accuracy as the one for bundle 5 , in that it deviates as much as $10 \mathrm{~cm}$ from the observed settlement data. 


\subsubsection{Settlement Due to Biodegradation}

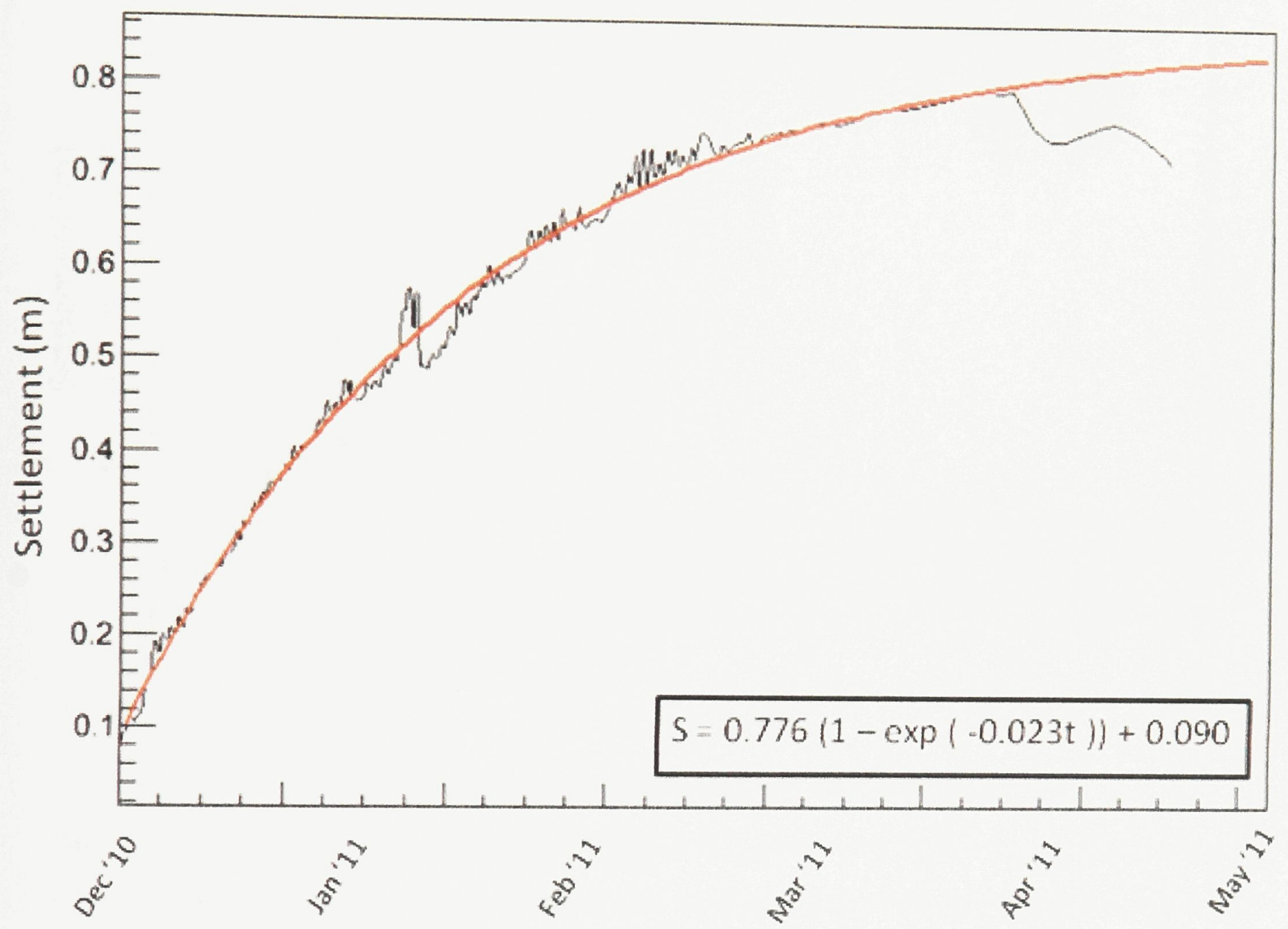

Figure 5-4: Biodegradation-Induced Settlement Model of Bundle 5

The same observed data from Figure 5-2 is shown in Figure 5-4. In Figure 5-4, however, the data is modeled by a settlement equation derived for biodegradation-induced settlement. This model deviates only at most $6 \mathrm{~cm}$ from the observed data until it reaches April, when data becomes sparse due to instrument failure. This model estimates the elevation at the time of survey 3 to be $76.77 \mathrm{~m}$ (same as previous model), and thus a total settlement of $1.02 \mathrm{~m}$ from the initial survey 2 elevation. 


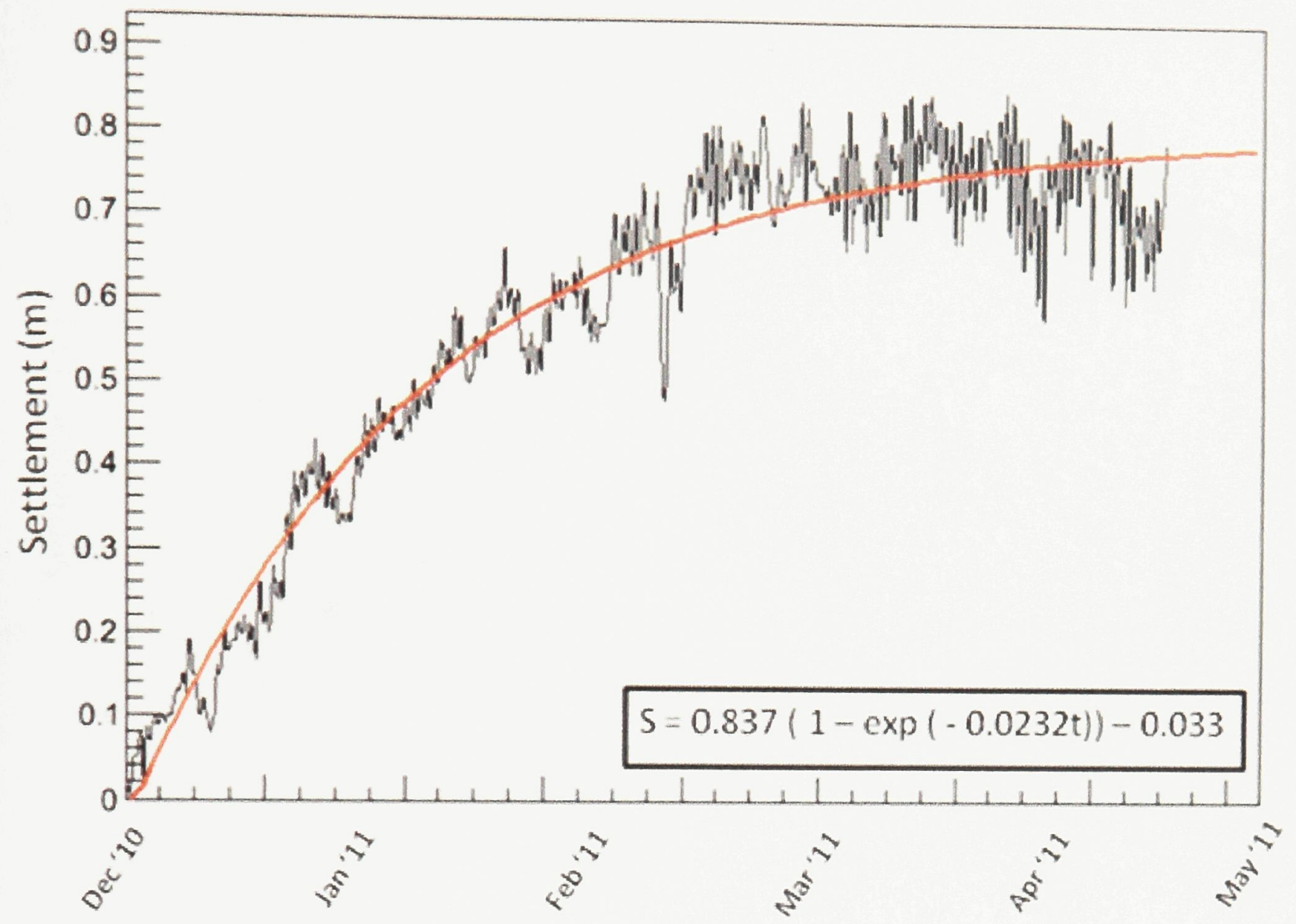

Figure 5-5: Biodegradation-Induced Settlement Model of Bundle 6

The same observed data from Figure 5-3 is shown in Figure 5-5. In Figure 5-5, however, the data is modeled by a settlement equation derived for biodegradation-induced settlement (equation 2.13). This model estimates the elevation at the time of survey 3 to be $77.07 \mathrm{~m}(1 \mathrm{~cm}$ higher than the previous model), or a total settlement of $1.20 \mathrm{~m}$ from the initial survey 2 elevation.

It is clear that there is an apparent rebound starting in March 2011 and continuing through April 2011. Although it is difficult to find an explanation for this as it does not seem to make physical sense, it is visible on both settlement gauges. To better model this, a linear term will be added to the biodegradation settlement model, as shown in Figure 5-6. The goal of this modeling is restricted to obtaining a settlement value, and therefore the physical explanation of this linear term will not be investigated further. This model estimates an elevation of 77.08 $\mathrm{m}$, or a total of $1.19 \mathrm{~m}$ of settlement. 


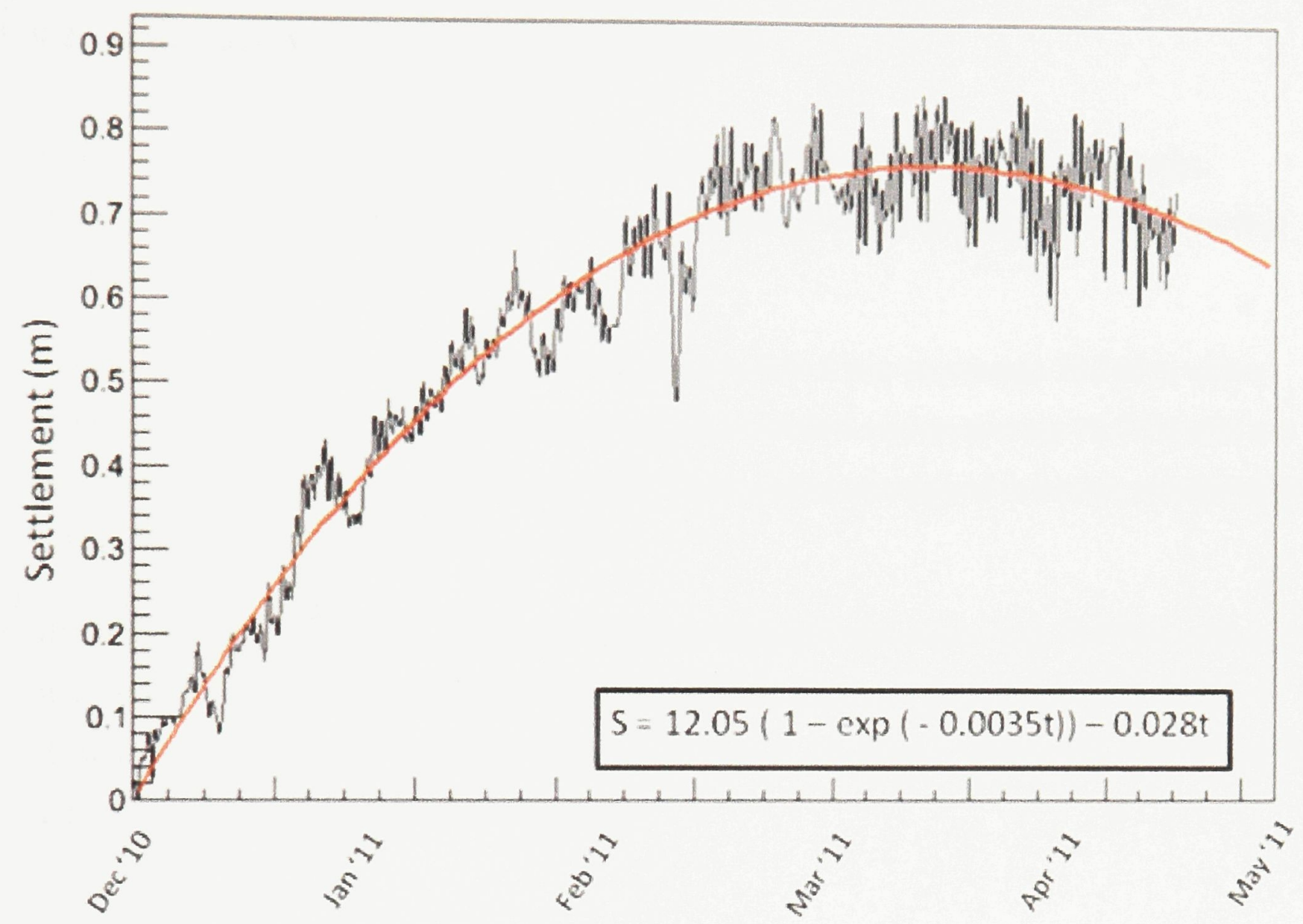

Figure 5-6: Biodegradation-Induced Settlement Model of Bundle 6 With Additional Linear Term

\subsubsection{Total Settlement Between Surveys}

The biodegradation models provided the most accurate representations of the settlement data, and therefore will be used for the settlement computation.

Instrument bundle 5 settled $1.02 \mathrm{~m}$, while bundle 6 settled $1.19 \mathrm{~m}$ at the time survey 3 was done. With only two values, extrapolation for the entire cell is not possible; therefore an average value will be used to quantify the settlement of the entire cell. The average settlement value is $1.11 \mathrm{~m}$. 


\subsection{Settlement Modeling for Surveys 2 and 4/5}

In Figure 5-1, the settlement data for bundles 5 and 6 is plotted until June 2012. Average elevation values as well as values obtained from modeling may be computed for the times that survey 4 and survey 5 were completed.

The elevation at the time of survey 4 of instrument bundle 5 was on average $76.568 \mathrm{~m}$ with a standard deviation of $0.003 \mathrm{~m}$ (over 8 readings), and bundle 6 was on average $76.77 \mathrm{~m}$ with a standard deviation of $0.03 \mathrm{~m}$ (over 8 readings). These values correspond to a total settlement of $1.23 \mathrm{~m}$ for bundle 5 and $1.50 \mathrm{~m}$ for bundle 6 .

The elevation at the time of survey 5 of instrument bundle 5 was on average $76.426 \mathrm{~m}$ with a standard deviation of $0.006 \mathrm{~m}$ (over 8 readings), and bundle 6 was on average $76.76 \mathrm{~m}$ with a standard deviation of $0.08 \mathrm{~m}$ (over 8 readings). These values correspond to a total settlement of $1.36 \mathrm{~m}$ for bundle 5 and $1.51 \mathrm{~m}$ for bundle 6 . 


\subsubsection{Primary and Secondary Settlement}

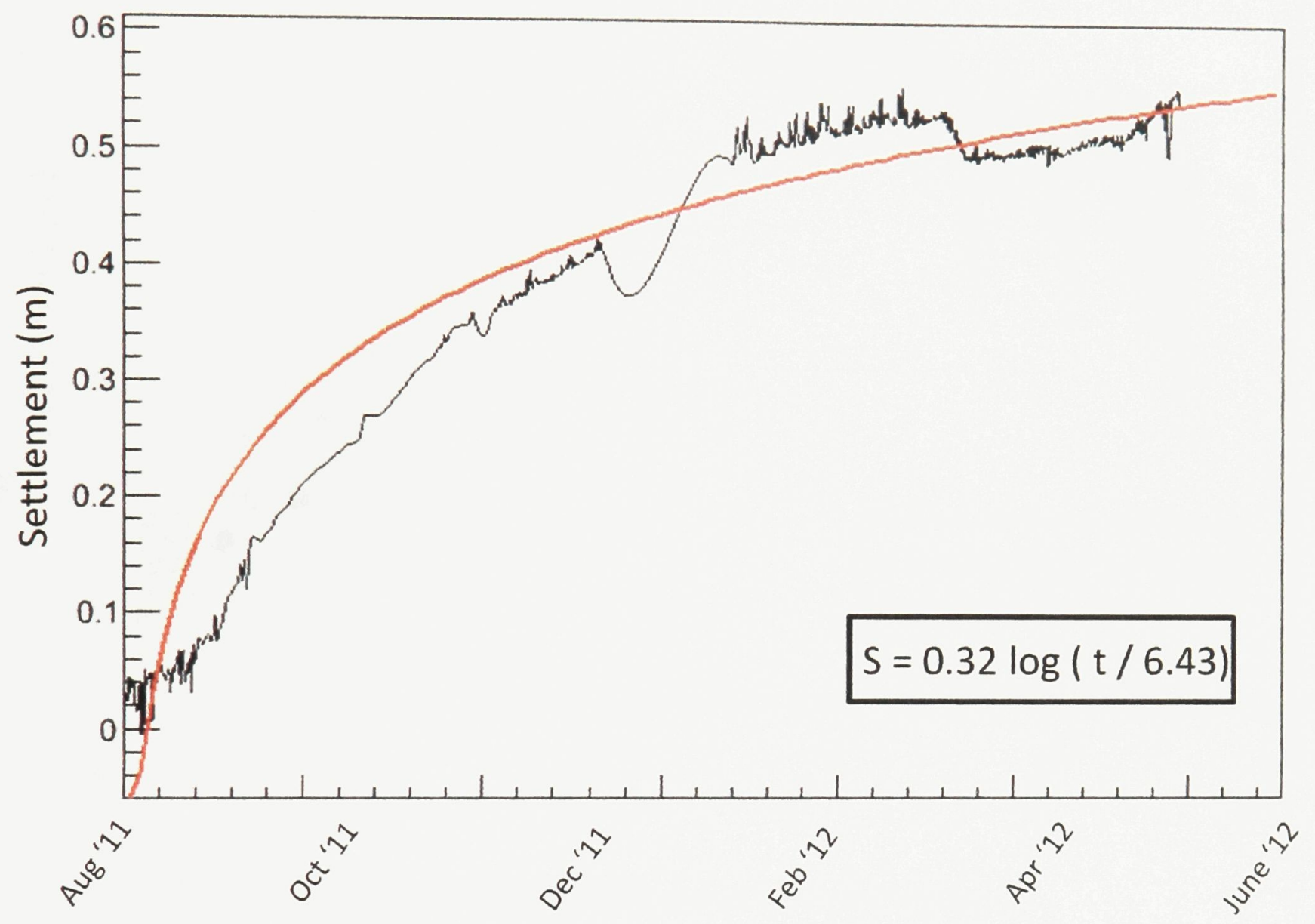

Figure 5-7: Primary and Secondary Settlement Model of Bundle 5

Figure 5-7 shows the settlement data from instrument bundle 5 taken from August 2011 through until June 2012. The elevation zero for gauge 5 was $76.93 \mathrm{~m}$ above sea level, and the $\mathrm{y}$ axis shows the total downward settlement from that point. This elevation zero was in August 2011, after a lift of waste was added, and settlement accelerated. Much of the data in January is absent due to equipment problems affecting both gauges 5 and 6 .

This model estimates the elevation of the survey 2 surface to be at $76.55 \mathrm{~m}$ at the time of survey 4 , and $76.42 \mathrm{~m}$ at the time of survey 5 . This corresponds to a total of $1.24 \mathrm{~m}$ of settlement at the time of survey 4 , and $1.37 \mathrm{~m}$ at the time of survey 5 . 


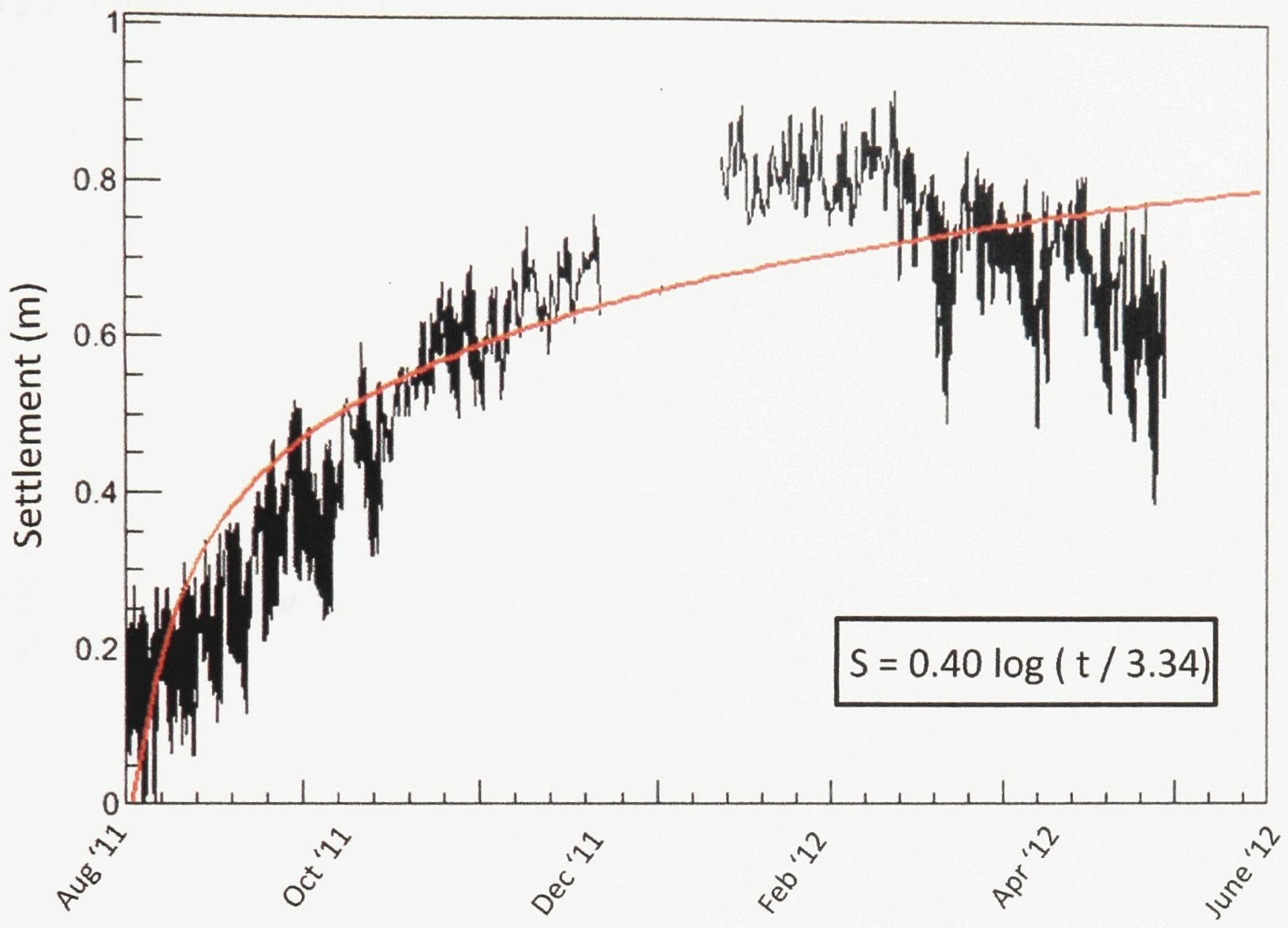

Figure 5-8: Primary and Secondary Settlement Model of Bundle 6

In Figure 5-8, the zero of gauge 6 was $77.39 \mathrm{~m}$ above sea level, and the $y$-axis shows the total downward settlement from that point. This model estimates the survey 2 surface to be at an elevation of $76.80 \mathrm{~m}$ at the time of survey 4 and $76.63 \mathrm{~m}$ at the time of survey 5 . This corresponds to a total settlement of $1.47 \mathrm{~m}$ at the time of survey 4 , and $1.64 \mathrm{~m}$ at the time of survey 5.

The models in Figure 5-7 and Figure $5-8$ both deviate from the observed data by up to $10 \mathrm{~cm}$. Therefore it is likely that primary and secondary settlement are not the only significant mechanisms for settlement of this waste. 


\subsubsection{Settlement Due to Biodegradation}

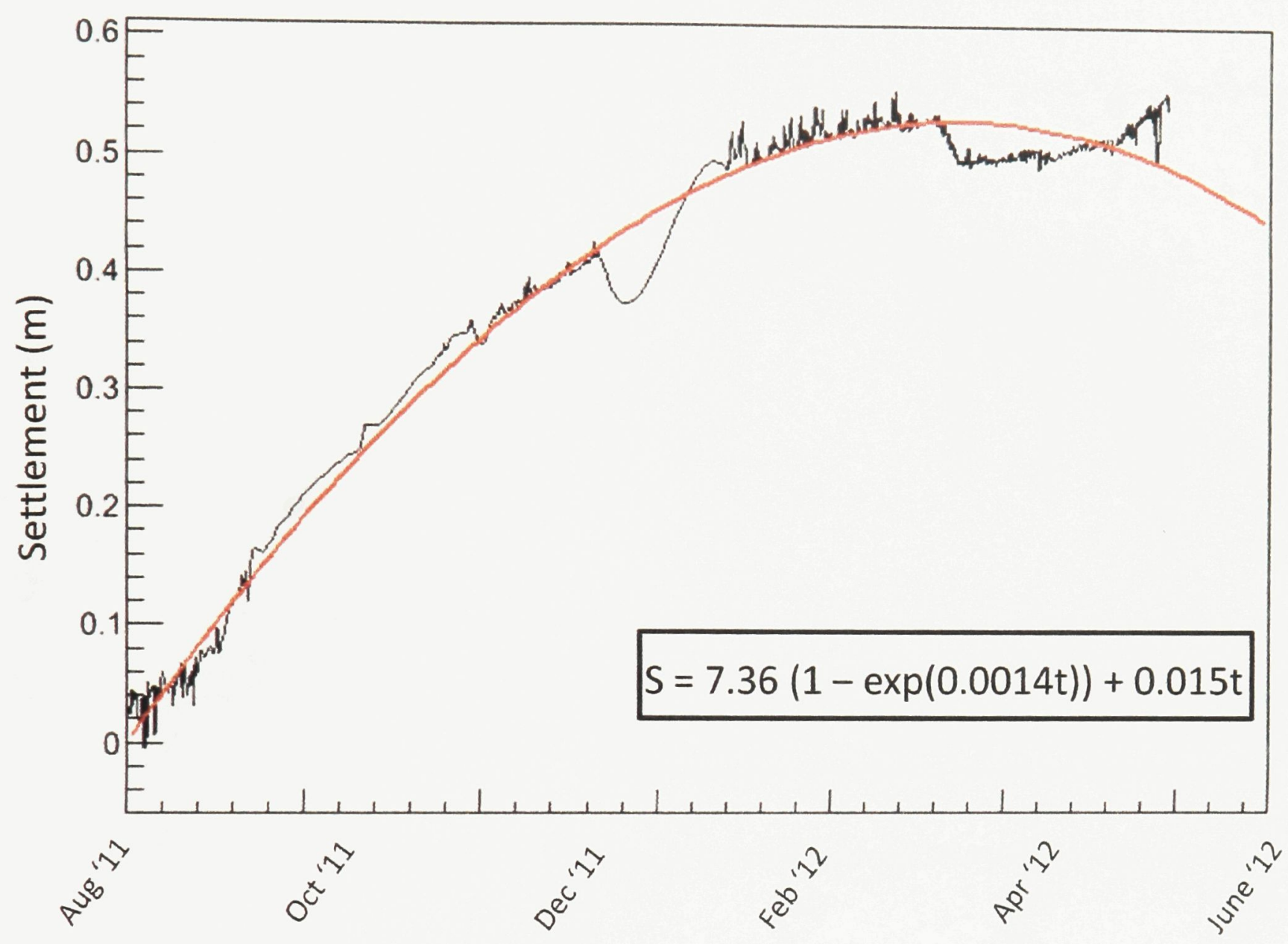

Figure 5-9: Biodegradation Model of Bundle 5 (with linear term)

Figure 5-9 shows the same settlement data as Figure 5-7, however, the data is modeled with the biodegradation-induced settlement equation with a linear term added to account for any rebound. This model is significantly more accurate than the primary and secondary settlement model, and deviates a maximum of $2 \mathrm{~cm}$ from the observed data.

At the time of survey 4 , this model estimates an elevation of $76.53 \mathrm{~m}$ and, at the time of survey 5 , an elevation of $76.26 \mathrm{~m}$. This corresponds to a total settlement of $1.26 \mathrm{~m}$ at the time of survey 4 , and $1.53 \mathrm{~m}$ at the time of survey 5 .

Figure 5-10 shows the same settlement data as Figure 5-8, however, the data is modeled with the biodegradation-induced settlement equation with the linear term for rebound. This model predicts an elevation of $76.72 \mathrm{~m}$ at the time of survey 4 , and $76.59 \mathrm{~m}$ at the time of survey 5 . 
This corresponds to a total settlement of $1.55 \mathrm{~m}$ at the time of survey 4 , and $1.68 \mathrm{~m}$ at the time of survey 5 .

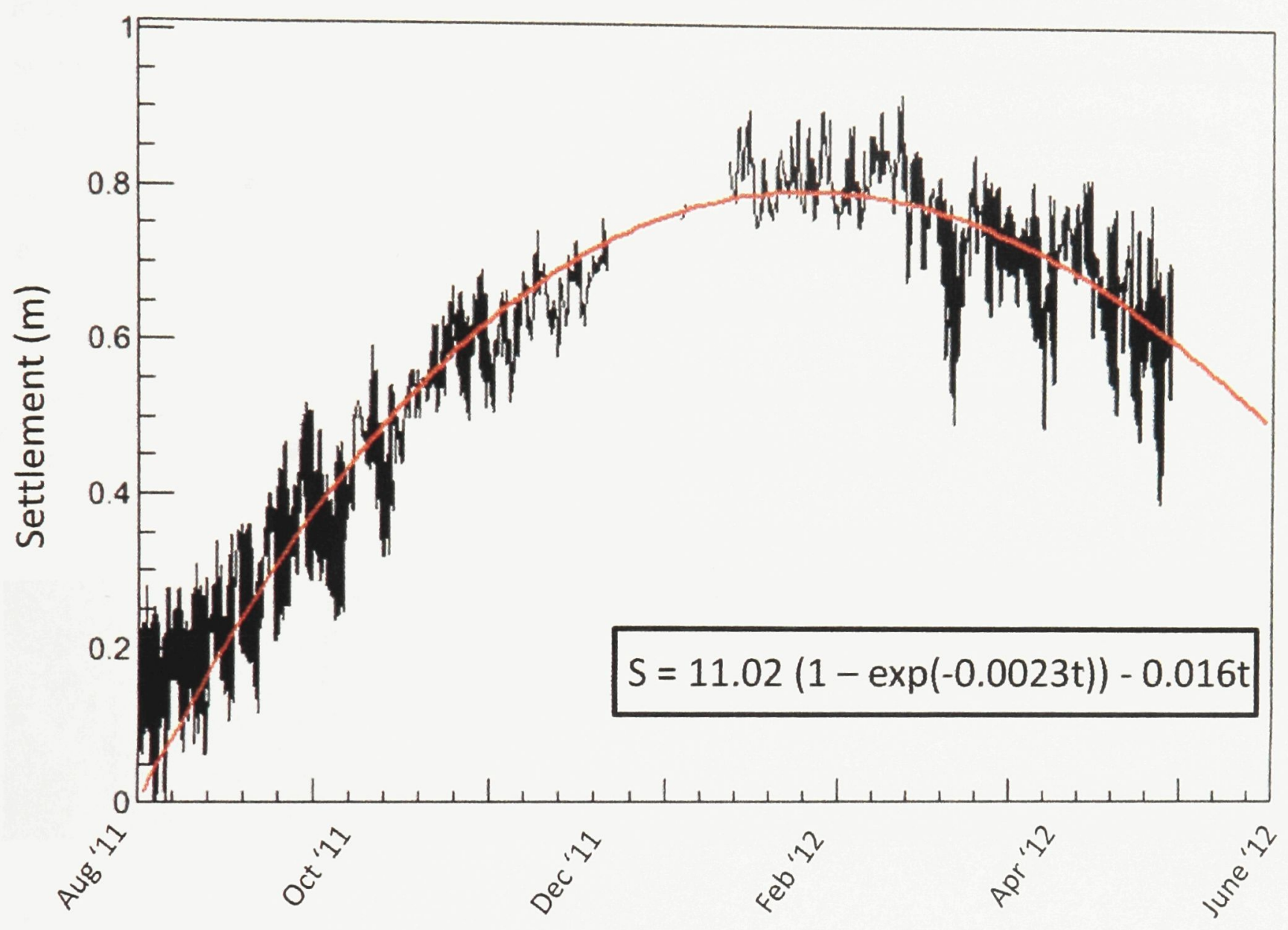

Figure 5-10: Biodegradation Model of Bundle 6 (with linear term)

\subsubsection{Total Settlement Between Surveys}

For instrument bundle 5, the method of computing average elevations at the time of surveys 2 and 4 and then subtracting them yields a settlement value of $1.23 \mathrm{~m}$, while the biodegradationinduced settlement model yields a value of $1.26 \mathrm{~m}$. Since the latter value is free of daily and periodic fluctuations, it will be used. At the time of survey 5 , the biodegradation-induced settlement model yields a settlement of $1.53 \mathrm{~m}$. However, this deviates greatly from the observed data, therefore the method of subtracting average elevations will be used, and thus a value of $1.36 \mathrm{~m}$. 
For instrument bundle 6, the method of computing average elevations at the time of surveys 2 and 4 and then subtracting them yields a settlement value of $1.51 \mathrm{~m}$, and the biodegradationinduced settlement model that includes the linear rebound term estimates a value of $1.55 \mathrm{~m}$. Since the value obtained from the modeling is free of daily and periodic fluctuations, it will be used. At the time of survey 5 , the biodegradation driven settlement model with the linear rebound term yields a settlement value of $1.68 \mathrm{~m}$, while the method of subtracting average elevations yielded $1.51 \mathrm{~m}$. Since the latter value was obtained during a period of rapid fluctuation, as is visible in Figure 5-10, the value obtained from modeling will be used.

The average settlement at the time of survey 4 is $1.41 \mathrm{~m}$, and the average at the time of survey 5 is $1.52 \mathrm{~m}$. Table 5-1 presents a summary of the settlement results.

Table 5-1: Settlement Summary of Instrument Bundles

\begin{tabular}{|cccc|}
\hline Settlement $(\mathbf{m})$ & Survey 3 & Survey 4 & Survey 5 \\
\hline Bundle 5 & 1.02 & 1.26 & 1.36 \\
\hline Bundle 6 & 1.19 & 1.55 & 1.68 \\
Average & 1.11 & 1.41 & 1.52 \\
\hline
\end{tabular}




\section{Waste Density Estimation}

From section 2.1.1 it was shown that the density of a waste slab can be approximated by equation 2.6:

$$
\rho=-\frac{g}{2 \pi G h}
$$

In this chapter, density variations over time will be estimated by computing density values for waste contained between surveys 2 and 3 , surveys 2 and 4 , and surveys 2 and 5 . The height (slab thickness) values will need to be calculated by adding the settlement values found in chapter 5 to the known elevation differences taken at the time of the surveys.

The density values computed via the microgravity method will be compared to density values computed from the AUF, which provide quarterly survey data of incoming mass, and volume into the landfill cell. These density values are computed by dividing the total mass by the total volume of incoming material deposited on the end of the cell of interest. The results of these computations are shown below in Figure 6-1.

From Figure 1-2, it is clear that waste deposited during a quarter is not always confined strictly to one half of the cell. However, mass and volume data is not available per month, only by quarter. So the greatest source of error in the AUF values in Table 6-1 comes from the uncertainty of how much of each quarter's waste actually lies in a certain half of the cell. To estimate the uncertainty associated with density values from the AUF, it will be assumed that the waste is homogeneous during each quarter. It will be estimated from visual inspection of Figure 1-2 how much of each quarter's waste (mass and volume) may not be within its assigned cell region. The propagation of error formula below will then be used to compute each error:

$$
\sigma_{\rho}=\sqrt{\left(\frac{\partial \rho}{\partial m} \sigma_{m}\right)^{2}+\left(\frac{\partial \rho}{\partial V} \sigma_{V}\right)^{2}}
$$




$$
\sigma_{\rho}=\sqrt{\left(\frac{\sigma_{m}}{V}\right)^{2}+\left(\frac{m \sigma_{V}}{V^{2}}\right)^{2}}
$$

For example, in the first quarter of 2011 , the AUF was found to be $1.31 \mathrm{~g} / \mathrm{cm}^{3}$, but about half of the July 2010 waste appears to be in the northeast end of the cell, and all of the October 2010 waste appears to be in the southwest end of the cell. From Appendix A, this corresponds to a volume uncertainty of $33469 \mathrm{~m}^{3}$, and a mass uncertainty of 42172 tonnes, which propagates to an uncertainty of $0.22 \mathrm{~g} / \mathrm{cm}^{3}$. 


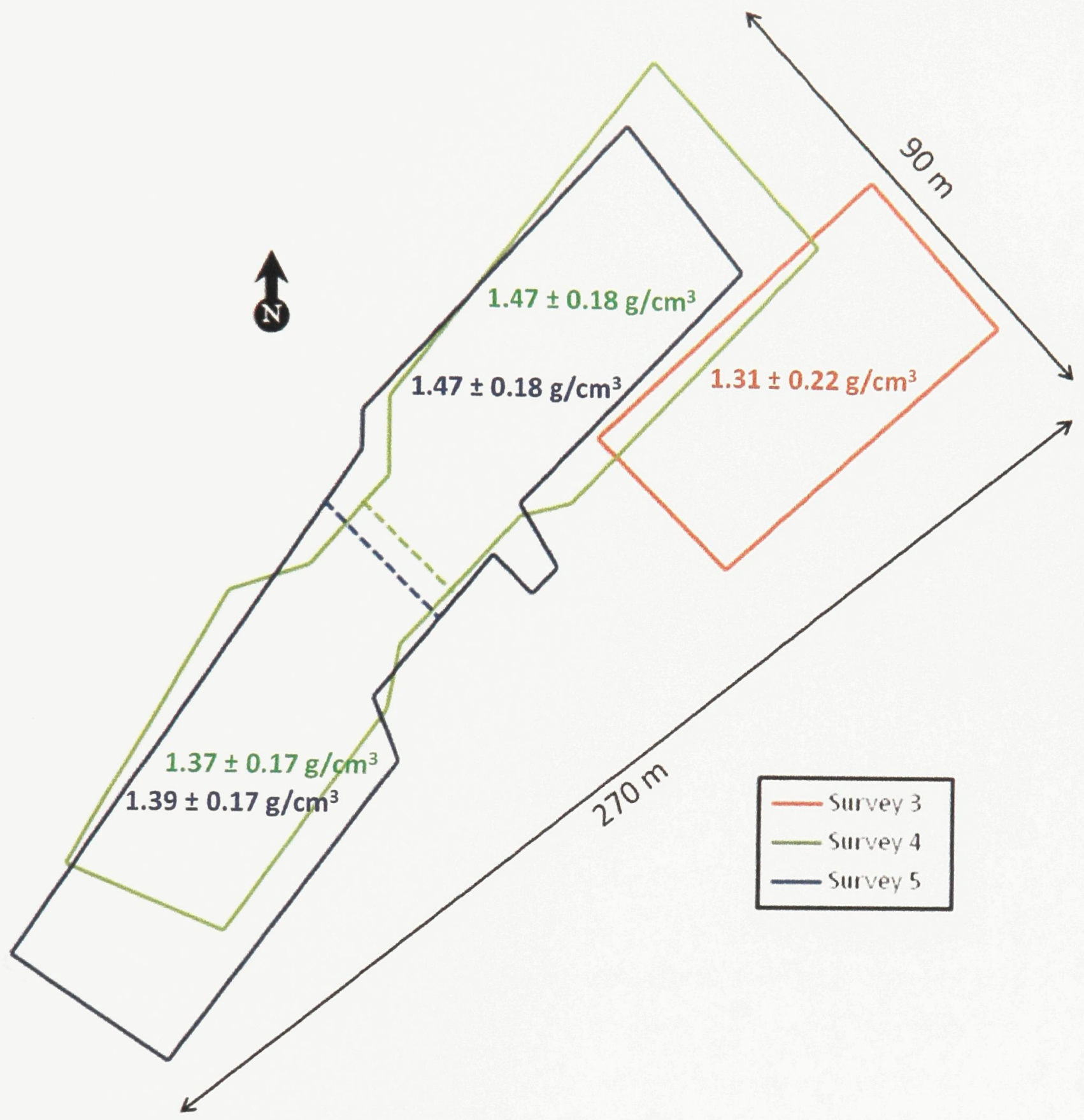

Figure 6-1: Summary of AUF Density Computations in NE and SW Ends of the Cell

The results computed via the microgravity method are summarized in Figure 6-2. Each box shows the area of its respective survey, with the density value written within it. Surveys 4 and 5 are bisected by a dashed line to show where the northeast end southwest ends are defined. 


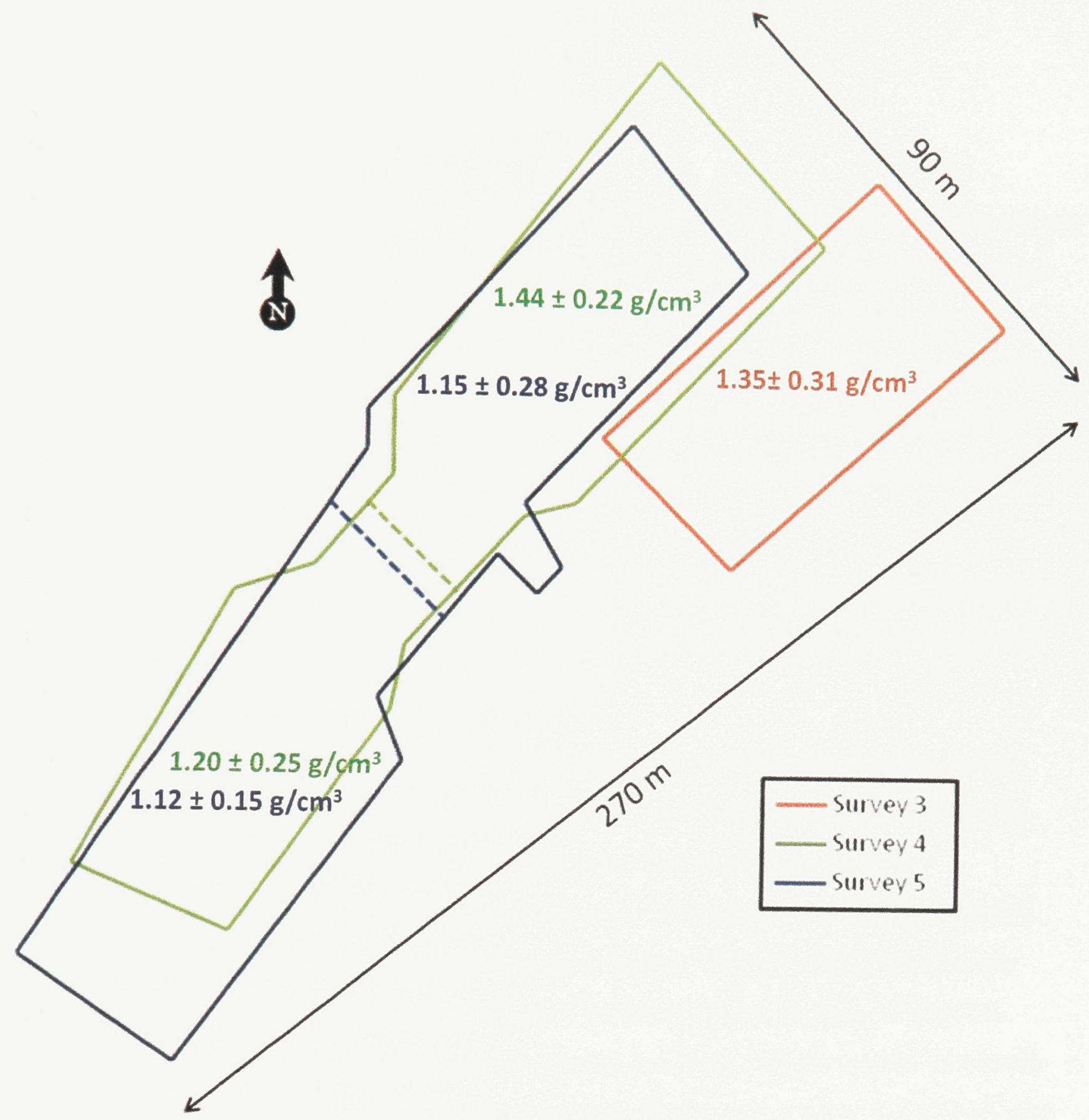

Figure 6-2: Summary of Density Values Computed Via Microgravity Surveys

For each slab of waste, a density map will also be presented from the microgravity surveys. The values in these maps cannot be compared to AUF values due to the fact that the AUF values cannot represent localized homogeneities. The maps will show the density distributions within the waste, which is the main advantage of the microgravity method. 


\subsection{Estimation of Density From Surveys 2 and 3}

The area of overlap between surveys 2 and 3 was relatively small (Figure 4-9), and there did not seem to be any gravitational trend when the outliers were removed from the data. For these reasons, the average gravity of the waste between surveys 2 and 3 is assumed to be representative of all of the waste between the two surveys. This average value is $0.434 \mathrm{mGal}$. The average settlement that occurred between these surveys was $1.11 \mathrm{~m}$, and when this is added to the differences in elevation at the time of each survey, the slab of waste is $7.69 \mathrm{~m}$ thick.

Using equation 2.6 , these values yield a density value of $1.35 \mathrm{~g} / \mathrm{cm}^{3}$. The standard deviation for the settlement value is $0.09 \mathrm{~m}, 0.19 \mathrm{~m}$ for the initial elevation differences, and $0.10 \mathrm{mGal}$ for the gravity; which yields a density error of $0.31 \mathrm{~g} / \mathrm{cm}^{3}$.

Figure 6-3 shows the density distribution of the surveyed area. The survey stations are not shown in order to better view the homogeneities. There are clearly areas that show density values of more than twice the average, as well as some that shows values that are unrealistically low. The high values may be due to actual homogeneities in the slab, possibly areas of highly compacted soil, or large groupings of metals. The AUF shows waste density values as low as $0.6 \mathrm{~g} / \mathrm{cm}^{3}$, compared to $0.3 \mathrm{~g} / \mathrm{cm}^{3}$ visible in the density map. Though it is possible that the waste may actually be at this density, it is likely that the extreme values are due to errors in measurement. Most of the map shows density values between $1.0 \mathrm{~g} / \mathrm{cm}^{3}$ and $1.6 \mathrm{~g} / \mathrm{cm}^{3}$, and on average $1.35 \mathrm{~g} / \mathrm{cm}^{3}$. 


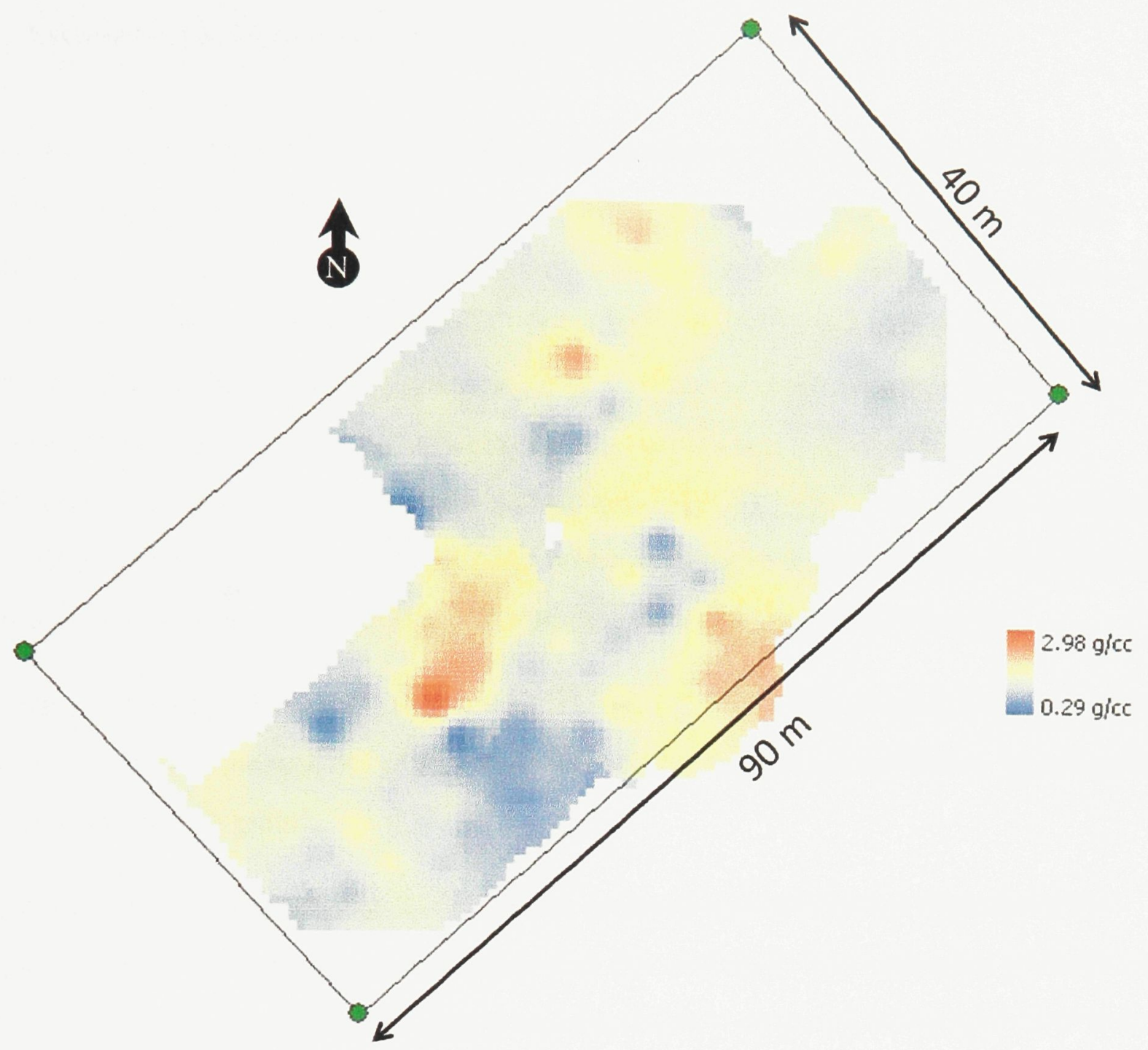

Figure 6-3: Density Distribution Between Surveys 2 and 3

\subsubsection{Comparison With Quarterly Survey Results (AUF)}

From the quarterly surveys, 207803 tonnes of waste and soil were placed between the surfaces of survey 2 and survey 3 , over a volume of $158200 \mathrm{~m}^{3}$. The density computed from these values is $1.31 \mathrm{~g} / \mathrm{cm}^{3}$, which is $3 \%$ lower than what was computed through the microgravity method. 


\subsection{Estimation of Density From Surveys 2 and 4}

As survey 4 was taken over a much larger area than survey 3 , there was considerably more overlap with survey 2 (Figure 4-13). Since there was an abrupt elevation change in the cell during survey 2 , the slab of waste between the surveys will have two different thicknesses. The northeast end has an average thickness of $9.95 \mathrm{~m}$ and a standard deviation of $0.06 \mathrm{~m}$, and the southwest end has an average thickness of $13.90 \mathrm{~m}$ and a standard deviation of $0.44 \mathrm{~m}$. The average settlement that occurred between the two surveys was $1.41 \mathrm{~m}$ with a standard deviation of $0.21 \mathrm{~m}$. The gravity contrast on average was $0.737 \mathrm{mGal}$. However, the northeast end of the cell had an average of $0.679 \mathrm{mGal}$ with a standard deviation of $0.101 \mathrm{mGal}$, and the southwest had an average of $0.773 \mathrm{mGal}$ with a standard deviation of $0.153 \mathrm{mGal}$.

The average density for the northeast end of the cell is found to be $1.43 \mathrm{~g} / \mathrm{cm}^{3}$ with an error of $0.22 \mathrm{~g} / \mathrm{cm}^{3}$, and the average density for the southwest end of the cell is found to be $1.20 \mathrm{~g} / \mathrm{cm}^{3}$ with an error of $0.25 \mathrm{~g} / \mathrm{cm}^{3}$.

Figure 6-4 shows the density distribution of the surveyed area. With some exceptions, the southwest end of the cell appears less dense than the northeast. There are again localized high and low anomalies. One particularly high anomaly, visible in deep red, in the southwest end of cell will be compared with the density in the survey 5 (Figure 6-5) density map to determine its origin. 


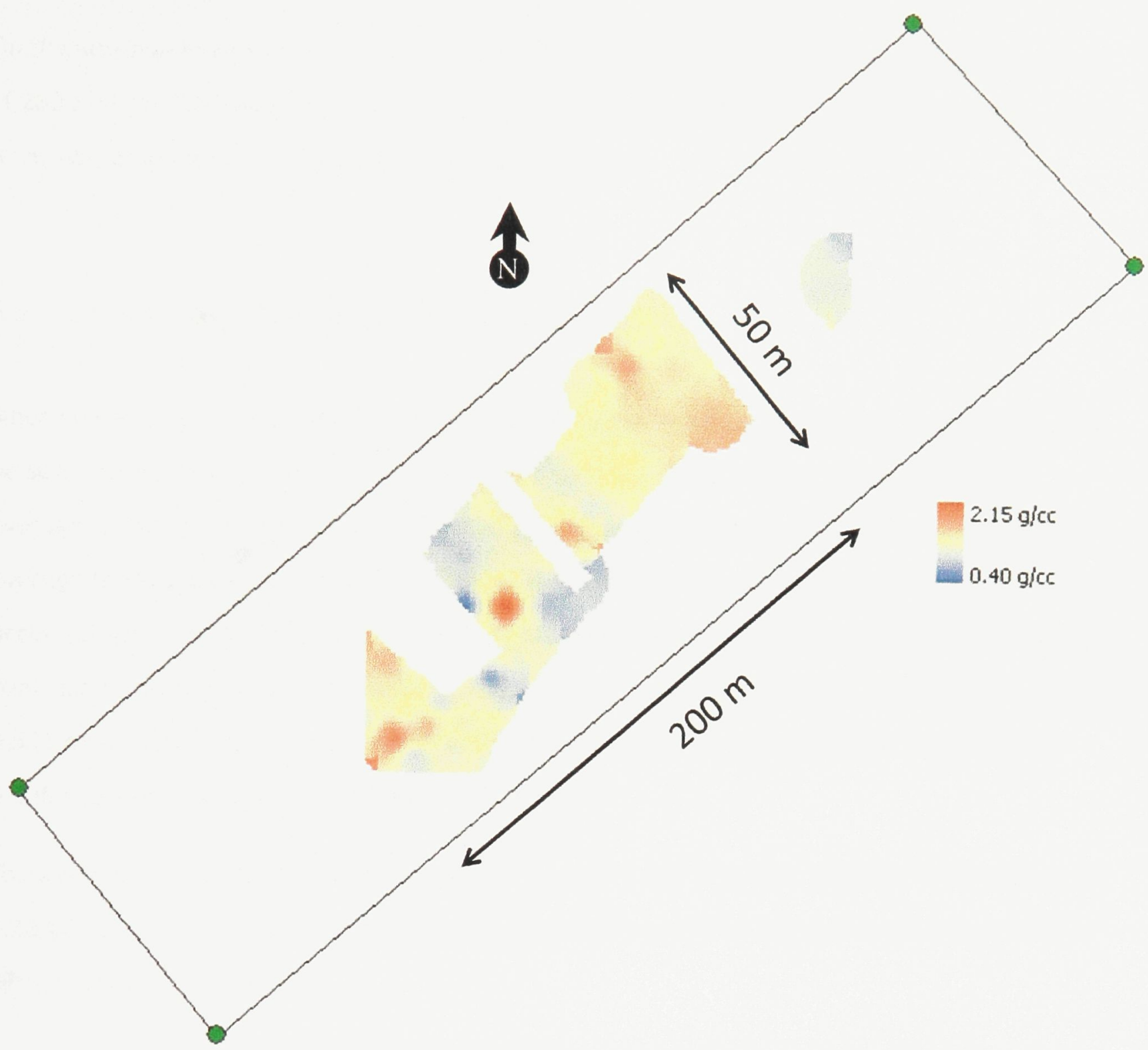

Figure 6-4: Density Distribution Between Surveys 2 and 4

\subsubsection{Comparison With Quarterly Survey Results (AUF)}

From the quarterly surveys, 332360 tonnes of waste and soil were placed on the northeast end of the cell between the surfaces of survey 2 and survey 4 , over a volume of $226741 \mathrm{~m}^{3}$. The density computed from these values is $1.47 \mathrm{~g} / \mathrm{cm}^{3}$, which is $3 \%$ higher than what was computed through the microgravity method. 
On the southwest end of the cell, 365786 tonnes of waste and soil were placed over a volume of $262576 \mathrm{~m}^{3}$. The density computed from these values is $1.39 \mathrm{~g} / \mathrm{cm}^{3}$, which is $12 \%$ higher than what was computed through the microgravity method.

\subsection{Estimation of Density From Surveys 2 and 5}

Since survey 5 covered approximately the same area as survey 4 , the density analysis will again be separated into two different sections of the cell. The northeast end of the cell has an average thickness of $9.67 \mathrm{~m}$ and a standard deviation of $0.47 \mathrm{~m}$, and the southwest end has an average thickness of $12.94 \mathrm{~m}$ and a standard deviation of $0.74 \mathrm{~m}$. The average settlement that occurred between the two surveys was $1.52 \mathrm{~m}$, with a standard deviation of $0.23 \mathrm{~m}$. The gravity contrast on average was $0.644 \mathrm{mGal}$. However, the northeast end of the cell had an average of $0.541 \mathrm{mGal}$ with a standard deviation of $0.123 \mathrm{mGal}$, and the southwest had an average of $0.686 \mathrm{mGal}$ with a standard deviation of $0.080 \mathrm{mGal}$.

The average density for the northeast end of the cell is found to be $1.15 \mathrm{~g} / \mathrm{cm}^{3}$ with an error of $0.28 \mathrm{~g} / \mathrm{cm}^{3}$, and the average density for the southwest end of the cell is found to be $1.12 \mathrm{~g} / \mathrm{cm}^{3}$ with an error of $0.15 \mathrm{~g} / \mathrm{cm}^{3}$.

Figure 6-5 shows the density distribution of the surveyed area. Again, the southwest end of the cell is generally less dense as the northeast with some exceptions. The high anomaly in Figure 6-4 is no longer visible in Figure 6-5, which suggests that it was simply due to a measurement error, or possibly was due to a large amount of water that was trapped in that area and drained before survey 5 was done. In Figure 6-5, a rather low anomaly is visible in the northeast end of the cell as deep blue. This was not present in Figure 6-4, where it was in fact an area of relatively high density. Again this is either due to a measurement error in survey 5 , or an evacuation of trapped water after survey 4. 


\subsubsection{Comparison With Expected Values}

As no waste or soil was placed on the surveyed surface between survey 4 and survey 5 , the survey 5 densities can only be compared to the same values as in survey 4 . In this case, the quarterly survey values are significantly higher than the microgravity method values. The northeast end of the cell is $22 \%$ less dense with the microgravity method, and the southwest end is $19 \%$ less dense.

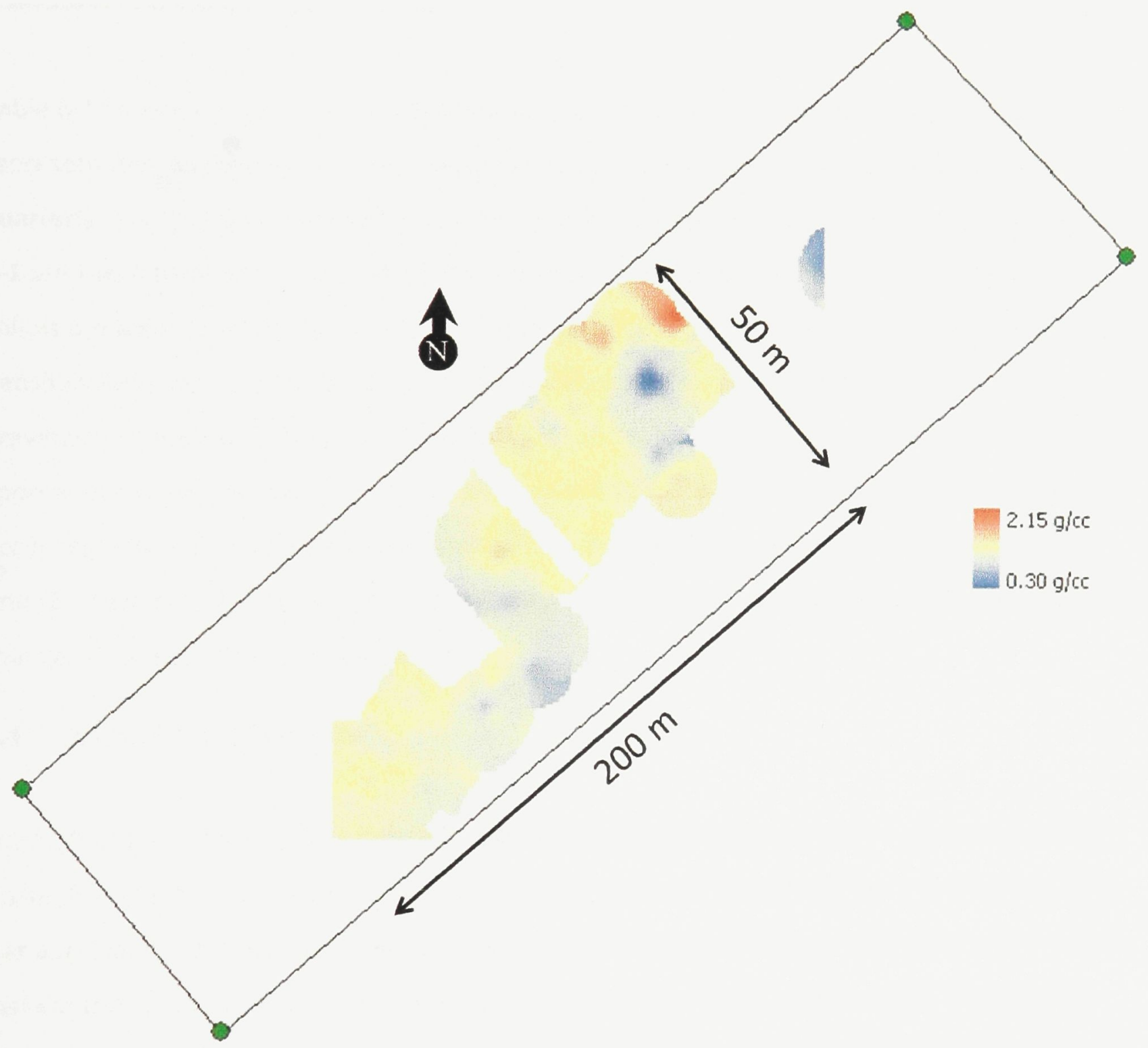

Figure 6-5: Density Distribution Between Surveys 2 and 5 
Table 6-1: Summary of AUF and Microgravity Results

Date
2011

Q2
Q3

4

2012

Q1

\begin{tabular}{|l|l|l|l|l|}
\hline 79407 & 72074 & 68541 & 66035 & 0 \\
\hline
\end{tabular}

\begin{tabular}{|c|c|c|c|c|c|c}
199 & 106604 & 116699 & 124557 & 97209 & 0 \\
\hline 28 & 1.31 & 1.31 & 1.47 & 1.47 & 1.47 \\
\hline
\end{tabular}

Waste density $\left[\mathrm{g} / \mathrm{cm}^{3}\right]$

1.22

1.37

1.35

\begin{tabular}{|c|c|}
\multirow{2}{*}{$\begin{array}{c}\text { quarterly } \\
\text { surveys }\end{array}$} & $\mathrm{NE}$ \\
\cline { 3 - 3 } microgravity & $\mathrm{SW}$ \\
& $\mathrm{N}$ \\
& $\mathrm{SW}$ \\
\hline
\end{tabular}

\begin{tabular}{|c|c|c|}
\hline 1.37 & 1.39 & 1.39 \\
\hline 1.44 & - & 1.15 \\
\hline 1.20 & - & 1.12 \\
\hline
\end{tabular}

Table 6-1 shows a summary of the AUF and microgravity results. The volume and tonnage represent only waste that has been deposited since survey 2 . Appendix $A$ is the summarized quarterly survey report of zone 4 , and is not specific to phase 3 . The volume values from Table 6-1 are taken from the column titled "Net volume used over the period" and the tonnage values are taken from the column titled "Tonnage of W and RGS landfilled over the period". The density values are then computed by simply dividing the tonnage by the volume. The main drawbacks of the AUF values are (1) the location of the waste placement can only be vaguely approximated by referencing the dates of deposition to where on the cell the deposition was occurring. These don't always correspond well to the NE/SW boundaries defined in this study. And (2) these density values represent the waste at the time of deposition, and any subsequent change in density cannot be computed.

\subsection{Discussion of Results}

The high degree of agreement between the microgravity and the quarterly survey results in the waste during survey 3 can be credited to the fact that the settlement of the instrument bundles was adequately representative of the settlement of the waste in the surveyed area. Two factors that contribute to this degree of representation are, (1) the instrument bundles are located in the same area of the cell as the survey location; every point in the survey is no more than $90 \mathrm{~m}$ away from an instrument bundle, and (2) the survey was done less than eight months after the installation of the instrument bundles, thus the degree of differential settlement is likely 
minimal compared to that of later surveys. Differential settlement refers to different rates of settlement at various locations. The longer the duration, the greater the degree of differential settlement is likely to be. In the waste at time of survey 4 , the degree of agreement of the results in the northeast was likely again due to the fact that the settlement of the instrument bundles represented that of the entire northeast end of the cell. But the density computed for the southwest end of the cell disagreed significantly from the value calculated from the quarterly surveys. It is possible that the settlement measured by the instrument bundles poorly represented the settlement of waste in this area. Not only were the bundles further away, but the southwest end of the cell was filled approximately four months later than the northeast, thus the settlement data from the northeast end is at best a rough approximation for the southwest end. And for the waste during survey 5 , it is probable that at the time of this survey the degree of differential settlement was too large to be represented by two instrument bundles at one end of the cell; thus contributing to a higher degree of deviation between the results of the two methods.

Considering the density values computed from survey 3 , and the northeast end of survey 4 , the average density of the waste increased from $1.35 \mathrm{~g} / \mathrm{cm}^{3}$ to $1.44 \mathrm{~g} / \mathrm{cm}^{3}$, an increase of $7 \%$ over seven months. This increase can be explained by a two effects: at the time of survey 3 , the waste above survey 2 was relatively uncompacted compared to that same waste at the time of survey 4 . At the time of survey 4 , fresh, uncompacted waste existed near the top of the cell, and was underlain by densely compacted waste. The average waste density was therefore higher than after survey 3 . The other contributing effect was that the incoming waste between surveys 3 and 4 was actually denser to begin with than the waste between surveys 2 and 3 . This can be seen by comparing the "Operational AUF" values in Appendix A. Another possible effect could be the additional mass of ice within the waste in the northeast end of the cell. Analysis of the waste at surveys 4 and 5 both yield density values higher in the northeast end of the cell. The northeast end of the cell contains waste placed almost exclusively during winter months (Figure 1-2), and had remained below $0{ }^{\circ} \mathrm{C}$ until the time of surveying (Figure 6-6). Where trapped water could flow through the waste in the southwest end of the cell, it would become trapped and frozen in the northeast. However, the density of water is $1.00 \mathrm{~g} / \mathrm{cm}^{3}$, which is less 
dense than the waste itself. For this effect to increase waste density, ice would have to fill the void spaces in the waste without significantly reducing the ability of the waste to compact. The temperature data from the instrument bundles is presented in Figure 6-6, and though it is uncertain how representative this data are of the entire cell, or even the northeast end of the cell, it is clear that bundle 6 is below $0{ }^{\circ} \mathrm{C}$ at the time of survey 4 , and reaches $0{ }^{\circ} \mathrm{C}$ before the time of survey 5 . However, bundle 6 is the only bundle that displays this trend. 


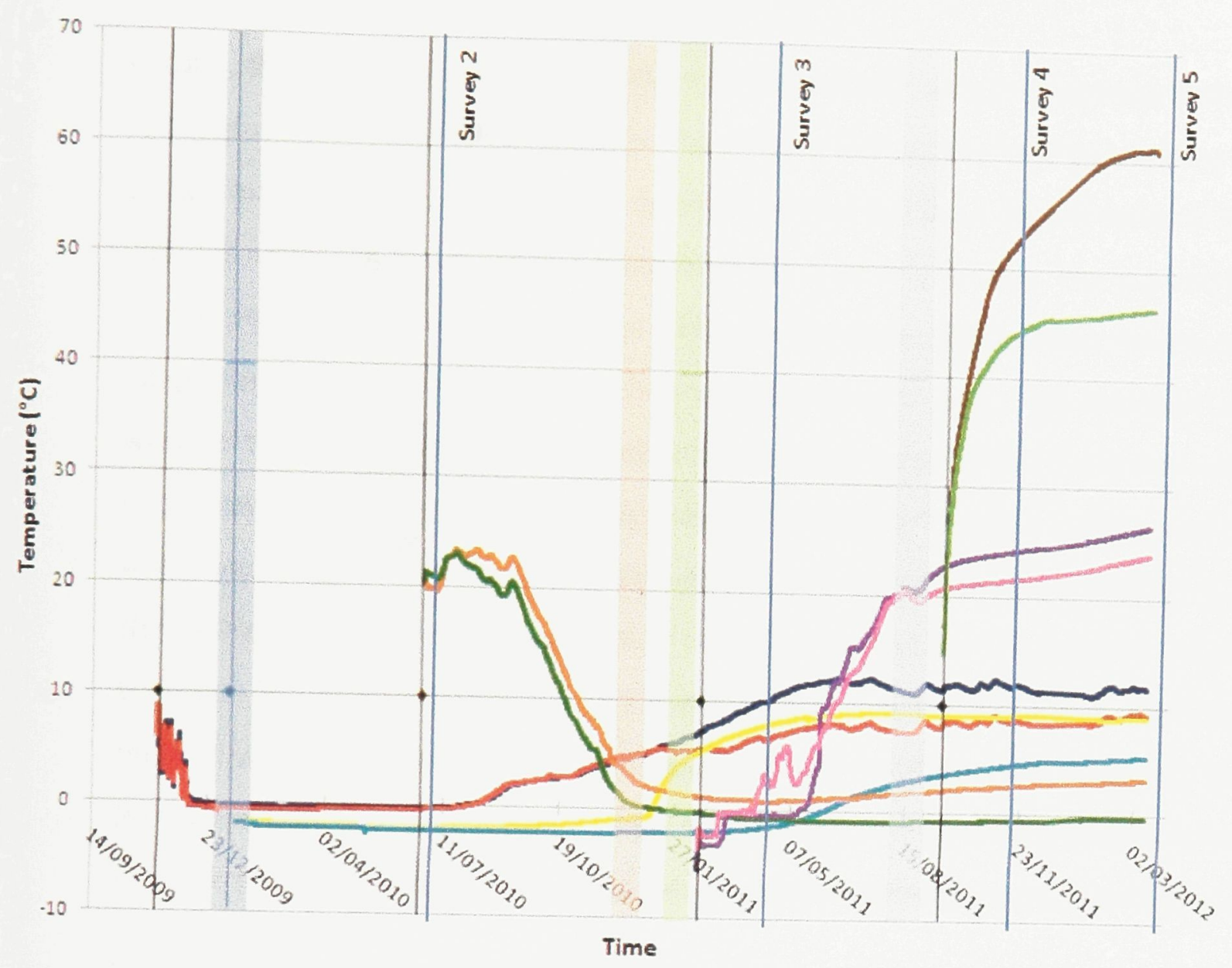

- Bundle

- Bunde:

Buncle 3

- Bundie 4

Buncles

- Bundie 6

-Bundle?

- Bundies

- Eundle 9

- Bundle 10

$\rightarrow$ nstallation of Eundles $1 \& 2$

- nstallation of Bundles $3 \& 4$

$\rightarrow$-nstallation of Bundes $5 \& 6$

$\rightarrow$ - nstallation of Bundles 788

$\rightarrow$ nstaliation of Bundles. $9 \& 10$

Cuftone $(6.0 \mathrm{~m})$

Lift T: $13.5 \mathrm{~m})$

bift Three $(3.5 \mathrm{~m})$

ift $=\operatorname{cour}(4.0 \mathrm{~m})$

Figure 6-6: Temperature Data From Instrument Bundles 


\section{Conclusions and Recommendations}

In total, three slabs of waste were defined and analyzed using microgravity and settlement data to compute their respective densities. The bottom slab was defined by the June 2010 and April 2011 waste elevations, and the microgravity method yielded a density value of $1.35 \mathrm{~g} / \mathrm{cm}^{3}$, which is within $3 \%$ of the value derived from the quarterly surveys. The top and bottom of the second slab were defined by the June 2010 and November 2011 waste elevation. Given the longer time period there was more time for settlement to occur. The area was larger and the waste in the southwest end of the cell was up to $250 \mathrm{~m}$ away from the instrument bundles. The microgravity method yielded a density value of $1.44 \mathrm{~g} / \mathrm{cm}^{3}$ in the northeast end of the cell, which was within $3 \%$ of the result obtained from the quarterly survey data, and $1.20 \mathrm{~g} / \mathrm{cm}^{3}$ in the southwest, which was within $13 \%$ of the value derived from the quarterly survey data. The third slab was defined by the June 2010 and April 2012 waste elevations. The microgravity method yielded a density value of $1.15 \mathrm{~g} / \mathrm{cm}^{3}$ for the northeast end of the cell, which is $22 \%$ less dense than the result obtained from the quarterly survey data. The density computed for the southwest end of the cell, $1.12 \mathrm{~g} / \mathrm{cm}^{3}$, is $19 \%$ less dense than the quarterly survey value.

Quantifying the amount of settlement across the cell over time was the greatest challenge in this study due to the degree of approximation required. In this study, the instrument bundles were not installed with the intent of using them to estimate settlement across the entire cell, and were therefore placed in locations that were not optimal for this objective. The density values in the northeast end of the cell agreed fairly well with the quarterly survey results even after 17 months of settlement, and the survey stations were up to $90 \mathrm{~m}$ away from the settlement gauges for those computations. Vingerhoeds (2011) explains that in phase 3, the settlement observed from the gauges is due to the load of the overlying waste, since it has not reached a temperature adequate for biodegradation-induced settlement. However, in the southwest end of the cell, where no settlement or temperature data is available, the waste was placed in warmer months, and different settlement mechanisms may be active. To better account for differential settlement across the surveyed area, settlement gauges should be placed at several locations in both the northeast and southwest ends of the cell. Fortunately, in 
this study, settlement gauges were placed at the time of survey 2, and thus better captured the elevation of that survey over time. In future studies, this would maximize the accuracy of the settlement estimates.

In the future, if microgravity is used to determine the density of waste in an operational bioreactor landfill, there are some measures that could be taken to improve on the efficiency of surveying and accuracy of the results. Factors such as soft surface conditions and strong winds increased the error on each gravity measurement. Surveys should be planned for dry conditions, and thus spring months should be avoided. Snow is not an optimal surface to survey on, since over the course of a reading the gravimeter tends to settle unevenly as the snow compacts and melts under the pressure of the instrument. On top of the landfill, there is little vegetation to protect from winds, however avoiding heavy winds is crucial to minimize measurement error. Even light winds had a noticeable impact on the measurements.

A team of three is best for conducting microgravity surveys: One person to operate and carry the gravimeter from station to station, one person to carry and place the flat wooden surface to keep the instrument leveled, and one person to carry and operate the GPS unit. To maximize efficiency, each team member should maintain the same role for the duration of the survey.

In the future, GPS receivers could be placed on the compactors to relate compaction effort to waste density. A colour contour map could be constructed depicting areas of higher and lower compaction effort, then compared to a density map. From this comparison, it would be possible to determine the effectiveness of the compactors.

It would also be useful to continue to pursue an accurate model for the settlement of waste. Though the biodegradation induced settlement model was used in this study to quantify the settlement, it was clear that very little biodegradation was actually occurring in the vicinity of the instrument bundles. Finding a better model would allow for the extraction of parameters that would provide useful details about the waste; however, the settlement of waste is still not a well understood process. Lab experiments have provided accurate models for waste settlement in controlled environments, such as those in Hettiarachchi (2007), but under 
continuously varying temperatures and overlying loads these models serve as approximations at best.

In summary, this study has demonstrated that it is possible to characterize the density of waste at a bioreactor landfill temporally and spatially via microgravity and settlement analysis. This method may be employed to monitor the density for the use of optimization of biogas production. The advantage of this method is that there is no requirement to estimate the volume of the waste, which can become quite difficult to do when waste settles to a smaller volume. Also, the analysis of settlement contributes a more detailed quantitative understanding of density trends than simply computing the density of waste during deposition. Though more laborious than the current method of computing the AUF, this method provides greater detail on waste density variations that are useful when optimizing conditions for anaerobic biodegradation. Settlement analysis also contributed to a higher accuracy, as current AUF values tend to overestimate density due to the fact that they do not account for the volume change in the waste slab over time. 


\section{References}

Catley, A.J. (2006) Seismic Velocity Analysis to Determine Moisture Distribution in a Bioreactor Landfill. M.A.Sc. Thesis, The Ottawa-Carleton Institute for Environmental Engineering.

CERN. (1995-2012). A Data Analysis Framework. In ROOT. Retrieved August 4, 2011, from http://root.cern.ch/drupal/.

El-Fadel, M. \& Al-Rashed, H. (1998a) Settlement in Municipal Solid Waste Landfills I. Field Scale Experiments. Journal of Solid Waste Technology and Management, 25 (2), pp 89-98.

Genivar (2008) Figure 4, Configuration du Réseau de Captage du Biogas Zone IV. L.E.S. de Sainte-Sophie. Project Number Q110532. Prepared for: Waste Management.

Qian X., Koerner R.M., Gray D.H. (2002) Geotechnical Aspects of Landfill Design and Construction. Prentice Hall, New Jersey.

Rees, J.F. (1980) Optimization of Methane Production and Refuse Decomposition in Landfills by Temperature Control. Journal of Chemical Technology \& Biotechnology, 30, pp 458-465.

Reinhart, D.R. \& Townsend, T.G. (1998) Landfill Bioreactor Design and Operation. Lewis Publishers, Boca Raton, FL.

Scintrex (2006) CG-5 Scintrex Autograv System Operation Manual. Revision 2.

Stegmann, R. (1983) New Aspects on Encancing Biological Processes in Sanitary Landfills. Waste Management \& Research, 1, pp 201-211.

Timmons, J., Cho, Y.M., Townsend, T., Berge, N. \& Reinhart, D. (2011) Total Earth Pressure Cells for Measuring Loads in a Municipal Solid Waste Landfill. Geotechnical \& Geological Engineering, 30, pp 95-105.

Verruijt, A. (2006) Soil Mechanics. Delft University of Technology.

Vingerhoeds, E. (2011) Instrument Installation and Preliminary Data in a Full-Scale Anaerobic Bioreactor Landfill, Sainte-Sophie, Quebec, Canada. M.A.Sc. Thesis, The Ottawa-Carleton Institute for Environmental Engineering.

Warith, M (2002) Bioreactor Landfills: Experimental and Field Results. Waste Management, 22, pp 7-17.

Warith, M., Li, X. \& Jin, H. (2005) Bioreactor Landfills: State-of-the-Art Review. Emirates Journal for Engineering Research, 10(1), pp 1-14. 
Yuen, S.T.S., Styles, J.R. \& McMahon, T.A. (1994) Process-Based Landfills Achieved by Leachate Recirculation - A Critical Review and Summary. Centre for Environmental Applied Hydrology Report. University of Melbourne.

Zekkos, D., Bray, J.D., Kavazanjian, E., Matasovic, N., Rathje, E.M., Riemer, M.F. \& Stokoe, K.H II (2006) Unit Weight of Municipal Solid Waste. Journal of Geotechnical \& Geoenvironmental Engineering 132(10), pp 1250-1261.

Zornberg, J.G., Jernigan, B.L., Sanglerate, T.R., Cooley, B.H. (1999) Retention of Free Liquids in Landfills Undergoing Vertical Expansion. Journal of Geotechnical \& Geoenvironmental Engineering 125(7), pp 583-594. 


\section{Appendices}

\section{Appendix A: Tableaux AUF Ste-Sophie Mars 2012}

\begin{tabular}{|c|c|c|c|}
\hline Date of Survey & $\begin{array}{l}\text { Tonnage of Lanfilled } \\
\text { Material over Period } \\
\text { (t) }\end{array}$ & $\begin{array}{l}\text { Net Volume Used } \\
\text { over Period }\left(\mathrm{m}^{3}\right)\end{array}$ & $\begin{array}{c}\text { Operational AUF } \\
\left(\mathrm{g} / \mathrm{cm}^{3}\right)\end{array}$ \\
\hline June 23,2010 & 106575 & 59559 & 1.789 \\
\hline Sept 15,2010 & 151860 & 124467 & 1.220 \\
\hline $\operatorname{Dec} 17,2010$ & 101199 & 78793 & 1.284 \\
\hline March 25, 2011 & 106604 & 79407 & 1.343 \\
\hline June 23,2011 & 116699 & 72074 & 1.619 \\
\hline Sept 27, 2011 & 124557 & 68541 & 1.817 \\
\hline $\operatorname{Dec} 13,2011$ & 97209 & 66035 & 1.472 \\
\hline
\end{tabular}

